INSTITUTO DE PESQUISAS ENERGÉTICAS E NUCLEARES

Autarquia associada à Universidade de São Paulo

\title{
ESTUDO SOBRE OS CONSTITUINTES INORGÂNICOS PRESENTES EM DIFERENTES ESPÉCIES DA PLANTA MEDICINAL DO GÊNERO Casearia COLETADAS EM REGIÕES DISTINTAS DA MATA ATLÂNTICA, SP
}

\author{
CELINA IZUMI YAMASHITA
}

Dissertação apresentada como parte dos requisitos para obtenção do Grau de Mestre em Ciências na Área de Tecnologia Nuclear - Aplicações

Orientadora:

Dra. Mitiko Saiki 


\section{AGRADECIMENTOS}

Em primeiro lugar à Dra. Mitiko Saiki pela orientação atenciosa e paciente, pelo exemplo de dedicação e pelos anos de convivência agradável e de grande aprendizagem.

Ao Dr. Jayme A. Sertié do Departamento de Farmacologia do Instituto de Ciências Biomédicas da USP pelas amostras concedidas para a realização deste trabalho.

Ao Instituto de Pesquisas Energéticas e Nucleares pela oportunidade concedida para a realização deste trabalho.

Aos meus pais e avós pelo permanente incentivo aos estudos, aos meus irmãos pela torcida, ao Fernando, Noboru e Nair pelo apoio em todos os momentos.

Aos amigos Andreza, Alessandra, Luciana, Cassio, Regina, Marilia, Eufemia, Ricardo, Edson Moreira, Edson Alves, Claudia, Selma, Claudio, Rogério, Marcelo Takata, e a todos os amigos da Iniciação Científica pela amizade e incentivo durante este período.

Ao amigo Osmãn pelo auxílio na parte estatística do trabalho.

Aos Doutores do Laboratório de Análise por Ativação com Nêutrons, Marina, Maria José, Vera, Deborah, Ana Maria, Rose e Casimiro pelo estímulo para a conquista deste título.

Ao CNPq e à FAPESP pelo auxílio financeiro. 


\section{ESTUDO SOBRE OS CONSTITUINTES INORGÂNICOS PRESENTES EM DIFERENTES ESPÉCIES DA PLANTA MEDICINAL DO GÊNERO CASEARIA COLETADAS EM REGIÕES DISTINTAS DA MATA ATLÂNTICA, SP.}

\section{CELINA IZUMI YAMASHITA}

\section{RESUMO}

O uso de plantas medicinais no tratamento de doenças tem aumentado de forma significativa nos últimos anos, bem como as pesquisas sobre a caracterização química destas plantas. Neste estudo, foram determinados os constituintes inorgânicos presentes nas folhas e nos extratos de três espécies da planta do gênero Casearia (C. sylvestris, $C$. decandra e C. obliqua) coletadas em regiões distintas da Mata Atlântica, SP. As composições elementares dos solos em que estas plantas foram cultivadas também foram determinadas. Tradicionalmente, estas plantas são utilizadas devido às suas propriedades antiinflamatórias, antiácidas, anti-sépticas e cicatrizantes. Além disso, as atividades antiulcerogênicas e antitumorais do gênero Casearia, e sua capacidade de neutralizar venenos de serpentes e abelhas, também tem sido comprovadas cientificamente. A metodologia analítica empregada foi a análise por ativação com nêutrons. Irradiações longas e curtas das amostras e dos padrões foram realizadas utilizando fluxos de nêutrons do reator de pesquisas IEA-R1 do IPEN/CNEN-SP. Nas folhas, o elemento K foi encontrado em níveis de porcentagens, os elementos $\mathrm{Ca}, \mathrm{Cl}, \mathrm{Mg}$ e $\mathrm{Na}$ na ordem de $\mathrm{mg} \mathrm{g}^{-1}$, Br, Fe, Mn, Rb e Zn em $\mu g g^{-1}$ e os elementos As, Co, Cr, Cs, La, Sb, Sc e Se em teores mais baixos, da ordem de $\mathrm{ng} \mathrm{g}^{-1}$. Os resultados obtidos nas análises dos extratos indicaram que os mesmos elementos determinados nas folhas de Casearia foram também encontrados em seus respectivos extratos. A comparação das composições elementares das folhas de Casearia sylvestris coletadas em três regiões diferentes da Mata Atlântica mostrou que as concentrações dos elementos encontrados nas plantas dependem da 
composição dos solos em que elas foram cultivadas. Por outro lado, espécies diferentes do gênero Casearia cultivadas em uma mesma região apresentaram composições elementares similares. Estes resultados mostram a importância da realização de estudos que avaliem as atividades farmacológicas de Casearias cultivadas em diferentes tipos de solos. A qualidade analítica dos resultados foi avaliada pela análise dos materiais de referência certificados NIST 1573a Tomato Leaves, NIST 1515 Apple Leaves, INCT-TL-1 Tea Leaves, IAEA-Soil-7 e USGS W1. Os desvios padrão relativos e os erros relativos obtidos nestas análises indicaram boa precisão e exatidão dos resultados. 


\title{
[STUDY OF THE INORGANIC CONSTITUENTS IN DIFFERENT SPECIES OF CASEARIA MEDICINAL PLANT COLLECTED IN DISTINCT REGIONS OF THE ATLANTIC FOREST, SP.
}

\section{CELINA IZUMI YAMASHITA}

\begin{abstract}
The use of medicinal plants in the treatment of diseases has increased significantly in the last years, as has research concerning chemical characterization of these plants. In this study, inorganic constituents were determined in leaves and in extracts from three medicinal plant species of the Casearia genus (C. sylvestris, C. decandra and $C$. obliqua) collected in distinct regions of the Atlantic Forest, SP. The elemental compositions of the soils in which these plants were grown were also determined. Traditionally, these plants are used due to their antiinflamatory, antiacid, antiseptic and cicatrizing properties. The antiulcer and the antitumor activities of the Casearia genus and its capacity to neutralize snake and bee venoms, have also been scientifically confirmed. The analytical methodology used was neutron activation analysis. Long and short irradiation periods of the samples and the standards were carried out at IPEN's IEA-R1 nuclear research reactor. In the leaf $\mathrm{K}$ was found at the percentage levels, $\mathrm{Ca}, \mathrm{Cl}, \mathrm{Mg}$ and $\mathrm{Na}$ at $\mathrm{mg} \mathrm{g}^{-1}$ levels and the elements $\mathrm{Br}, \mathrm{Fe}, \mathrm{Mn}, \mathrm{Rb}$ and $\mathrm{Zn}$ at the $\mu \mathrm{g} \mathrm{g}^{-1}$ levels. As, Co, Cr, Cs, La, Sb, Sc and Se at the ng $\mathrm{g}^{-1}$ levels. Results obtained in the extracts indicated that the same elements present in the leaves are also found in their extracts. The comparison between the inorganic composition of Casearia sylvestris leaves collected from three different regions of the Atlantic Forest showed that the elemental concentrations in the plants leaves varied depending on the place where they were grown. Different Casearia species cultivated in a same region presented similar elemental compositions. Based on these findings it can be concluded that the studies about the pharmacological effect of Casearia genus plants grown in different types of soil are of great importance. The quality
\end{abstract}


of the obtained results was assured by the analyses of the certified reference materials NIST 1573a Tomato Leaves, NIST 1515 Apple Leaves, INCT-TL-1 Tea Leaves, IAEASoil-7 and USGS W1. The relative standard deviations and the relative errors obtained in these analyses indicated good precision and accuracy of the results. 


\section{SUMÁRIO}

Página

1. INTRODUÇÃ

1.1 Considerações gerais sobre plantas medicinais ..................................................... 9

1.1.1 Locais de origem das amostras analisadas no trabalho...................................11

1.1.2 Espécies de plantas analisadas no trabalho ...................................................13

1.1.3 Composição elementar de plantas medicinais ................................................20

1.1.4 Estudos sobre análise elementar de plantas medicinais...................................21

1.2 Função biológica dos elementos no organismo humano .........................................2

1.3 Relação entre elementos presentes nos solos e nas plantas ....................................32

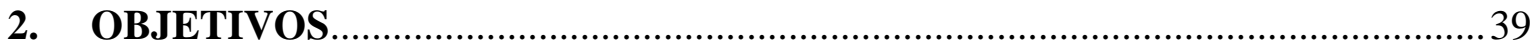

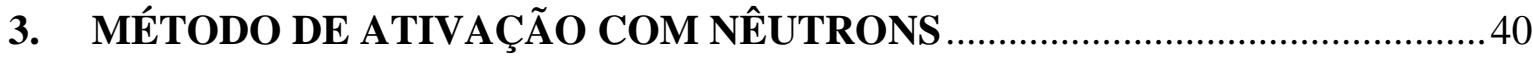

3.1 Considerações gerais sobre análise por ativação ................................................... 40

3.2 Princípio do método de ativação com nêutrons .................................................... 43

3.3 Equação fundamental da análise por ativação com nêutrons .................................. 44

3.3.1 Método comparativo de determinação de concentração elementar ....................47

3.4 Vantagens e desvantagens do método de ativação com nêutrons .............................48

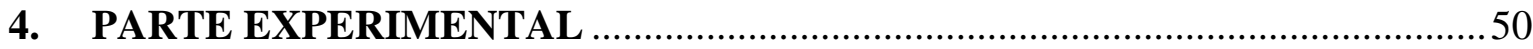

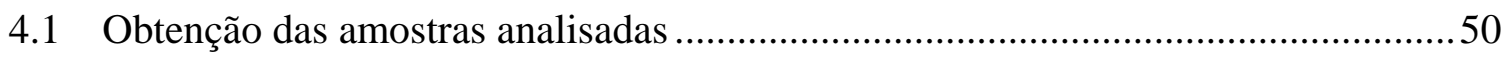

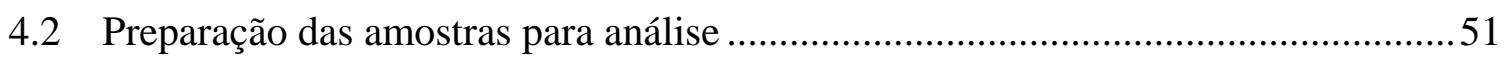

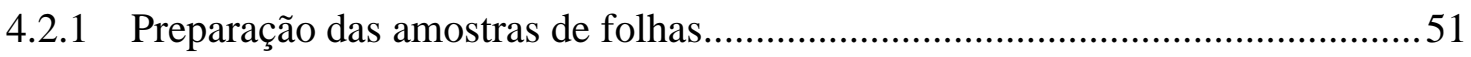

4.2.2 Preparação das amostras de extrato ................................................................52

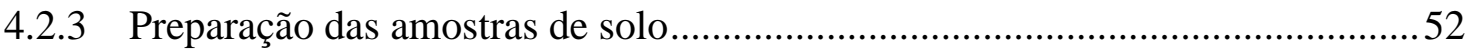

4.3 Preparação dos padrões sintéticos para análise.........................................................53

4.4 Procedimento para irradiação dos materiais ........................................................... 56

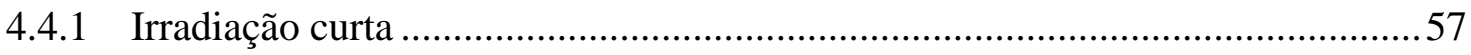

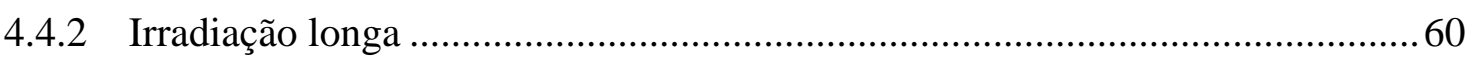

4.5 Procedimento para medida de $\mathrm{pH}$ das amostras de solo .......................................61 
4.6 Análise dos materiais de referência certificados...................................................61

4.7 Cálculos dos limites de detecção e determinação..................................................62

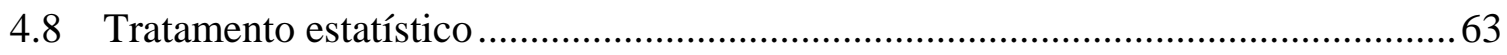

4.8.1 Análise hierárquica de agrupamentos (clusters) ............................................63

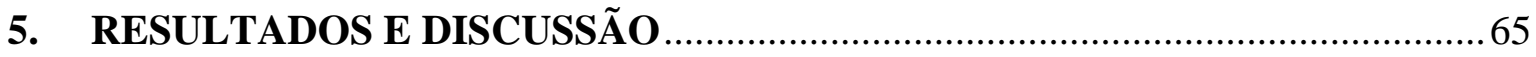

5.1 Resultado das análises dos materiais de referência certificados..............................65

5.2 Resultados das análises das folhas das plantas medicinais ...................................76

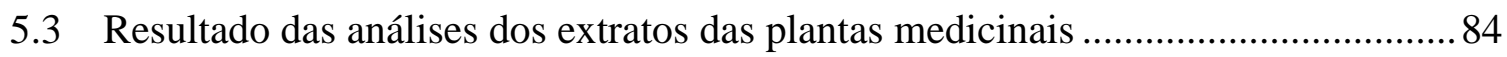

5.3.1 Comparação entre os resultados obtidos nas folhas e nos extratos....................88

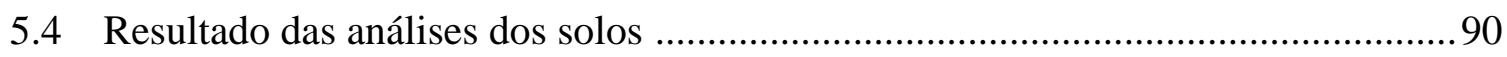

5.4.1 Coeficiente de Absorção Biológica ................................................................. 93

5.5 Limites de deteç̧ão e determinação dos elementos analisados................................96

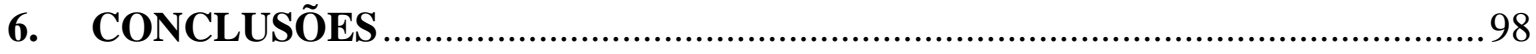

APÊNDICE 1 - Resultados individuais das análises de materiais de referência ..............100

APÊNDICE 2 - Resultados individuais das análises de planta........................................ 105

APÊNDICE 3 - Resultados individuais das análises de extratos de planta ...................... 112

APÊNDICE 4 - Resultados individuais das análises de solo......................................... 115

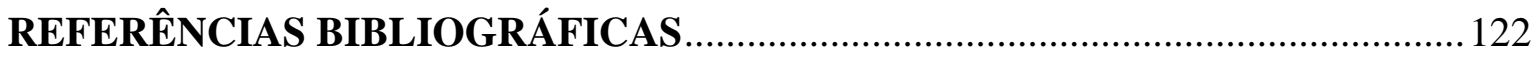




\section{INTRODUÇÃO}

\subsection{Considerações gerais sobre plantas medicinais}

As plantas medicinais têm sido utilizadas pelo homem na prevenção e no tratamento de diversas doenças desde a antigüidade aos tempos modernos. Principalmente nas duas últimas décadas, a necessidade de desenvolvimento de novos medicamentos tem provocado o aumento do uso de produtos medicinais à base de plantas em diversos países. Conseqüentemente, estudos sobre a caracterização química de plantas medicinais e a possível correlação de seus constituintes inorgânicos com suas propriedades farmacológicas têm despertado um interesse cada vez maior da comunidade científica.

Segundo a Organização Mundial de Saúde (WHO), uma grande parte da população mundial faz uso de plantas medicinais no cuidado à saúde. Um terço da população mundial, concentrada nos países subdesenvolvidos, não possui acesso aos serviços básicos de saúde e as plantas medicinais têm representado uma forma economicamente viável para os governos destes países ampliarem o alcance dos serviços de saúde à grande parte dessa população. Na África, mais de 70\% da população de países como Etiópia e Ruanda fazem uso da medicina tradicional no tratamento à saúde. Na Ásia, Malásia e Índia são alguns dos países que também utilizam amplamente a medicina tradicional, assim como Brasil, Chile e Colômbia, na América Latina (WHO, 2002).

O uso e a popularidade de plantas medicinais têm aumentado, porém, não apenas nos países em desenvolvimento, mas também nas nações industrializadas. Um 
número cada vez maior de consumidores tem demonstrado preocupação em relação aos efeitos colaterais provocados pelo uso das drogas convencionais, aumentando assim, a procura por alternativas à medicina alopática. A porcentagem da população que já fez uso da medicina tradicional pelo menos uma vez é de 38\% na Bélgica, 42\% nos Estados Unidos, 48\% na Austrália, 70\% no Canadá, 75\% na França e 90\% na Alemanha. (WHO, 2002). Atualmente o mercado mundial de medicamentos a base de plantas medicinais movimenta U\$60 bilhões/ano, valor este que tem aumentado a cada ano (WHO, 2003).

O aumento do consumo de plantas medicinais em vários países do mundo tem instigado consumidores, governos, profissionais da área de saúde a buscarem informações sobre eficácia, qualidade e a segurança do uso destas plantas. Este fato tem incentivado pesquisas científicas em diversas áreas do conhecimento com o objetivo de avaliar a toxicidade, efeitos colaterais, contra-indicações, mutagenicidade, etc. de plantas medicinais, bem como realizar ensaios farmacológicos e clínicos que comprovam sua eficácia.

O Brasil é um país com grande potencial para desenvolvimento de medicamentos a base de plantas devido à imensa diversidade de sua flora nativa. A Mata Atlântica é um dos ecossistemas brasileiros de maior importância por abrigar uma grande parcela da diversidade biológica do país. Ela cobre aproximadamente 15\% da extensão territorial do país, abriga mais de 20.000 espécies de plantas vasculares, e, no entanto, menos de 1\% destas plantas foram estudadas para fins medicinais (CONTE, 1996).

DI STASI et al. (2002) comprovaram que nas comunidades que vivem na região da Mata Atlântica o uso popular de plantas medicinas é bastante difundido. Em 200 entrevistas realizadas com os habitantes locais foram citados 290 medicamentos à base de plantas preparados a partir de 114 plantas medicinais diferentes utilizadas em 628 diferentes aplicações medicinais. Em um trabalho semelhante, BEGOSSI et al. (2002), por meio de 449 entrevistas, comprovaram que os habitantes da região costeira da Mata 
Atlântica (Caiçaras) também detêm grande conhecimento a respeito dos usos de plantas medicinais. Foram citadas 249 plantas medicinais, pertencentes a 77 famílias, utilizadas principalmente para combater febres, problemas respiratórios e gastrointestinais. Ambos os trabalhos mostram a diversidade de plantas medicinais presentes na Mata Atlântica, bem como o seu grande potencial para comercialização e desenvolvimento de estudos farmacológicos, toxicológicos e químicos de novas drogas.

\subsubsection{Locais de origem das amostras analisadas no trabalho}

As amostras de plantas medicinais e de solos analisados neste trabalho foram coletadas na Reserva Florestal do Morro Grande e no Instituto de Química da Universidade de São Paulo (IQUSP). Estes locais de coleta estão indicados nos mapas da FIG. 1.1. O IQUSP localiza-se no município de São Paulo e a Reserva Florestal do Morro Grande no município de Cotia, na região metropolitana de São Paulo. A Reserva Florestal do Morro Grande ocupa uma área de aproximadamente 10.600 hectares e é recoberta por uma rica variedade de espécies vegetais, sendo grande parte dela nativa, pertencentes ao domínio da Mata Atlântica (VELOSO et al., 1991). 


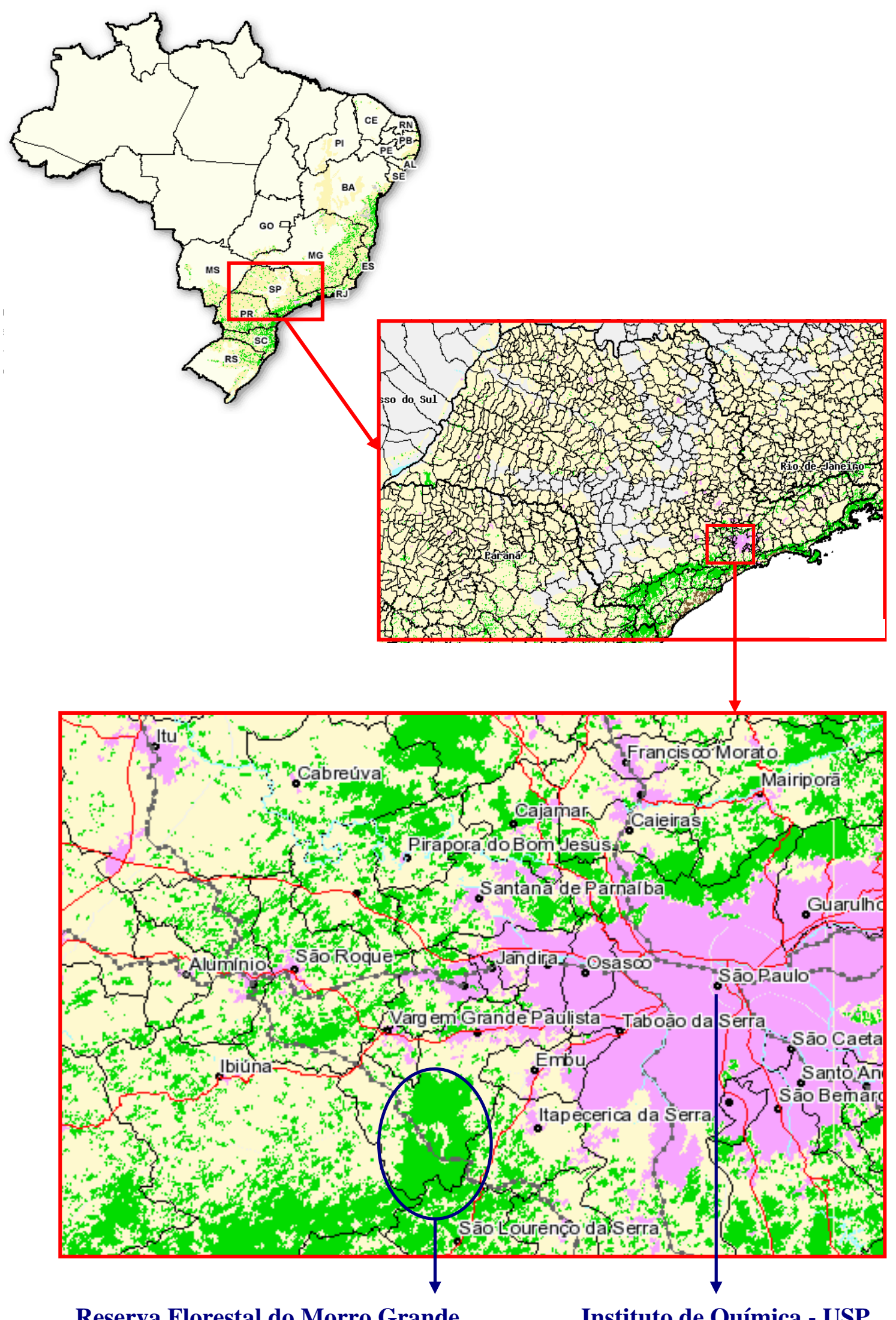

Reserva Florestal do Morro Grande

Instituto de Química - USP

FIGURA 1.1 - Mapa de localização da Reserva Florestal do Morro Grande (SOS MATA ATLANTICA, 2000). 


\subsubsection{Espécies de plantas analisadas no trabalho}

As plantas analisadas neste trabalho foram do gênero Casearia, pertencente à família Flacourtiaceae. As plantas do gênero Casearia, representadas por mais de 180 espécies (ALLABY, 1998), são típicas do continente americano e ocorrem desde o México e Antilhas até a América do Sul. No Brasil, são encontradas desde a Bahia até o Rio Grande do Sul (ESALQ, 2003). Dentre as várias espécies de Casearia, foram estudadas neste trabalho, três, a saber: Casearia sylvestris, Casearia decandra e Casearia obliqua.

\section{Casearia sylvestris}

A C. sylvestris, também conhecida pelos nomes populares de guaçatunga, cafezeiro-do-mato, pau-de-lagarto, chá-de-bugre, é uma espécie encontrada em todo território brasileiro, em quase todas as formações florestais do país (LORENZI, 1949). São arbustos ou árvores medindo até 10 metros de altura, atingindo 20 metros excepcionalmente, com casca rugosa e ramos alongados. As folhas de C. sylvestris são persistentes, inequiláteras, elípticas, agudas no ápice e arredondadas na base, e medem até $14 \mathrm{~cm}$ de comprimento e $3 \mathrm{~cm}$ de largura (CORRÊA, 1978).

Nas FIG. 1.2 e 1.3 estão apresentados, respectivamente, a foto e o esquema das principais partes da C. sylvestris.

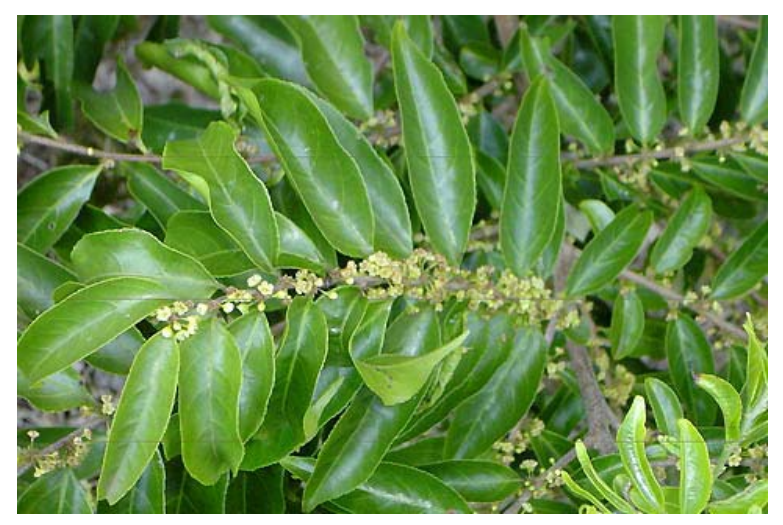

FIGURA 1.2 - Foto das folhas de Casearia sylvestris 


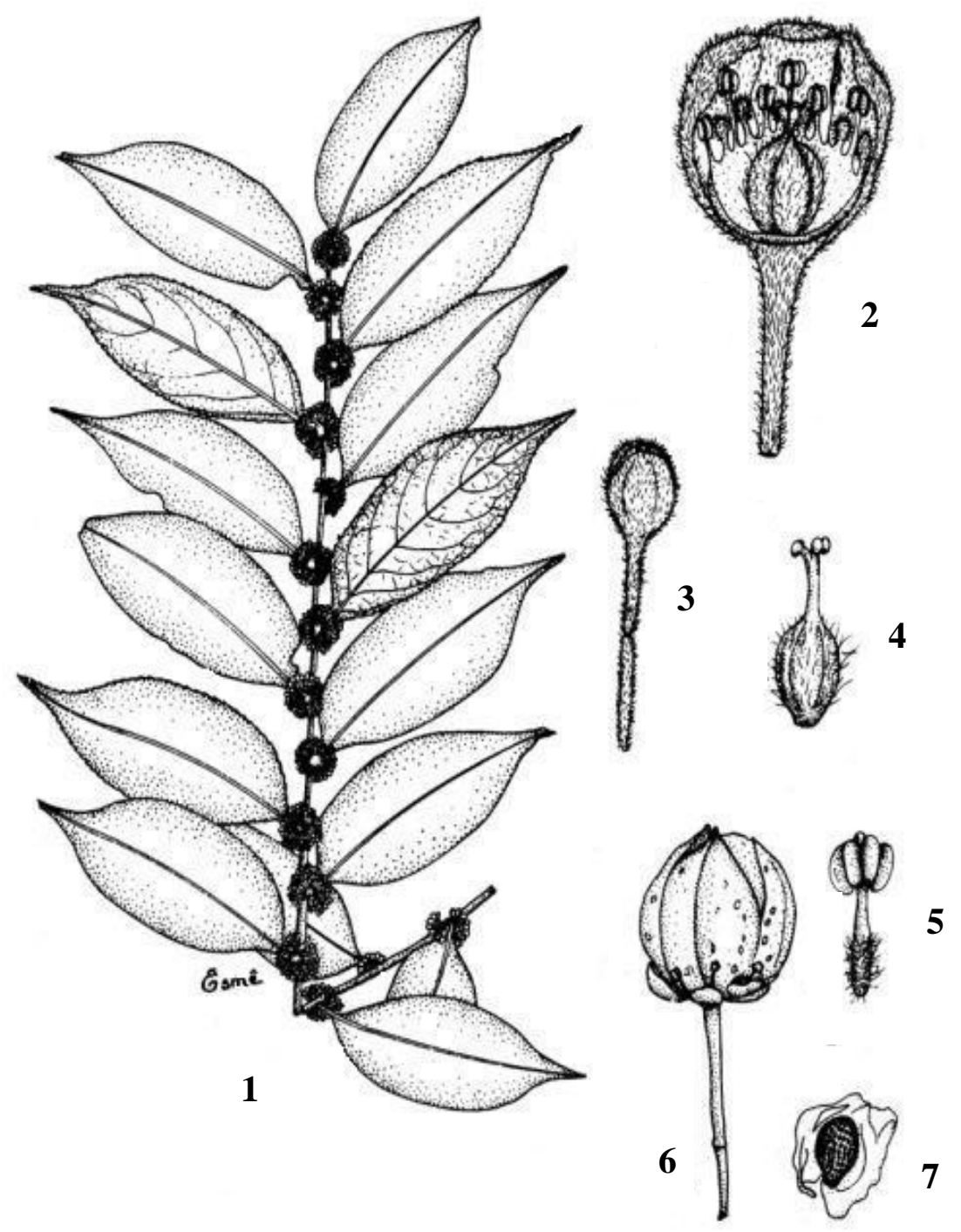

FIGURA 1.3 - Esquema da planta C. sylvestris. 1. aspecto geral do ramo; 2. flor com duas sépalas removidas; 3. botão floral; 4. gineceu; 5. antera; 6. fruto, 7. semente. (TORRES \& YAMAMOTO, 1986).

Dentre as espécies do gênero Casearia, a C. sylvestris é uma das mais amplamente utilizadas e apresenta grande variedade de aplicações populares nos diversos países em que ela é encontrada. A TAB. 1.1 mostra os usos mais comuns de C. sylvestris na medicina tradicional. Popularmente a C. sylvestris é consumida na forma de infusões preparadas a partir de aproximadamente $20 \mathrm{~g}$ de folhas secas em um litro de água. 
TABELA 1.1 - Diversos usos da Casearia sylvestris no mundo (RAINTREE-HEALTH, 2003).

\begin{tabular}{cl}
\hline País & \multicolumn{1}{c}{ Usos } \\
\hline Bolívia & $\begin{array}{l}\text { Analgésico, antiácido, antiinflamatório, antiúlcera, antitumoral, } \\
\text { anti-séptico (dental), cicatrizante, hemostático, tratamento à } \\
\text { doenças da pele, neutralização de venenos de serpentes e insetos. }\end{array}$ \\
\hline & $\begin{array}{l}\text { Antiinflamatório, antiúlcera, antitérmico, depurativo, antiviral, } \\
\text { no combate à diarréia, dores no corpo, gripe, lepra, reumatismo, } \\
\text { queimadura, sífilis, doenças da pele como eczema e vitiligo, } \\
\text { como estimulante sexual e na neutralização de venenos de } \\
\text { serpentes. }\end{array}$ \\
\hline Colômbia & No tratamento às doenças de pele, picadas de serpentes e úlceras. \\
\hline Índia & Neutralização de venenos de serpentes \\
\hline Peru & Tratamento da diarréia \\
\hline Outros países & Tratamento de feridas na pele e da lepra \\
\hline
\end{tabular}

C. sylvestris é também a espécie do gênero Casearia mais amplamente investigada em termos de composição química e atividade farmacológica. Dentre os estudos que comprovam cientificamente algumas das propriedades farmacológicas da $C$. sylvestris está o de SERTIÉ et al. (2000) que estudaram a propriedade antiulcerogênica de suas folhas frescas e de seus extratos. Foi verificado neste trabalho que a administração do extrato de Casearia sylvestris em ratos proporciona a proteção da mucosa de seus estômagos, sem que houvesse alteração do pH gástrico. No caso de úlceras crônicas, os pesquisadores concluíram que o efeito curativo dos extratos leva à redução do tamanho das ulcerações e ao aumento do número de fibroblastos e fibras de colágenos no estômago.

BORGES et al. (2000 e 2001) comprovaram que o extrato aquoso de Casearia sylvestris é eficaz na neutralização da atividade hemorrágica causada por proteases, fosfolipases A2, hemorraginas e miotoxinas presentes em venenos de diversas espécies de serpentes. O extrato teve sua eficácia comprovada também contra os venenos de algumas espécies de abelhas. 
ITOKAWA et al. (1988) identificaram nos extratos de C. sylvestris, as estruturas de seis novos diterpenos, conhecidos como casearinas A-F, aos quais foram atribuídas as atividades antitumorais destes extratos contra o sarcoma 180A em ratos. Dando continuidade a esse estudo, ITOKAWA et al. (1990) caracterizaram outras casearinas totalizando 18 novos diterpenos responsáveis pelas propriedades antitumorais dos extratos de C. sylvestris.

OBERLIES et al. (2002) identificaram três novos compostos em C. sylvestris os quais foram denominados casearvestrinas A-C, que da mesma forma que as casearinas, apresentaram bioatividade promissora tanto nos ensaios citotóxicos in vitro contra células tumorais, quanto nos ensaios antifúngicos, por meio da inibição do crescimento do Aspergillus niger.

No estudo realizado por MOSADDIK et al. (2004) com plantas originárias da Austrália pertencentes a quatro gêneros de uma mesma família (Flacourtiaceae) foi verificado que o gênero Casearia é o que mais se destaca em termos de atividade citotóxica, antioxidante e antimicrobiana. Este fato sugere que sejam desenvolvidas novas pesquisas sobre a composição química da planta e de sua relação com as propriedades biológicas apresentadas.

Mais recentemente, ESTEVES et al. (2005) estudaram as propriedades farmacológicas de óleos essenciais obtidos a partir das folhas de Casearia sylvestris. Além de verificar sua propriedade antiinflamatória, estes autores confirmaram a atividade antiulcerogênica da C. sylvestris.

Devido ao recente aumento do consumo de extratos de C. sylvestris para diversos fins medicinais, MAISTRO et al. (2004) avaliaram o potencial genotóxico destes extratos. Os resultados obtidos em ensaios in vitro indicaram que os extratos analisados não apresentam efeitos genotóxicos sendo que danos nas moléculas de DNA induzidos por 
ciclofosamida e metilmetanosulfonato em células de cultura de tecido hepatoma (HTC) e células V79 não são potencializados pelo consumo dos extratos desta planta.

\section{Casearia obliqua}

A C. obliqua, conhecida também pelos nomes populares de guaçatunga-preta, cambroé e espeteiro, é encontrada na forma de arbustos ou árvores que medem até $6 \mathrm{~m}$ de altura, apresentando ramos flexuosos e cilíndricos. Suas folhas são assimétricas oblíquas e inequiláteras na base, com dimensões de até $10 \mathrm{~cm}$ de comprimento e $4 \mathrm{~cm}$ de largura (CORRÊA, 1978). Na FIG. 1.4 é apresentada a foto da C. obliqua e na FIG. 1.5 o esquema das principais partes da planta.

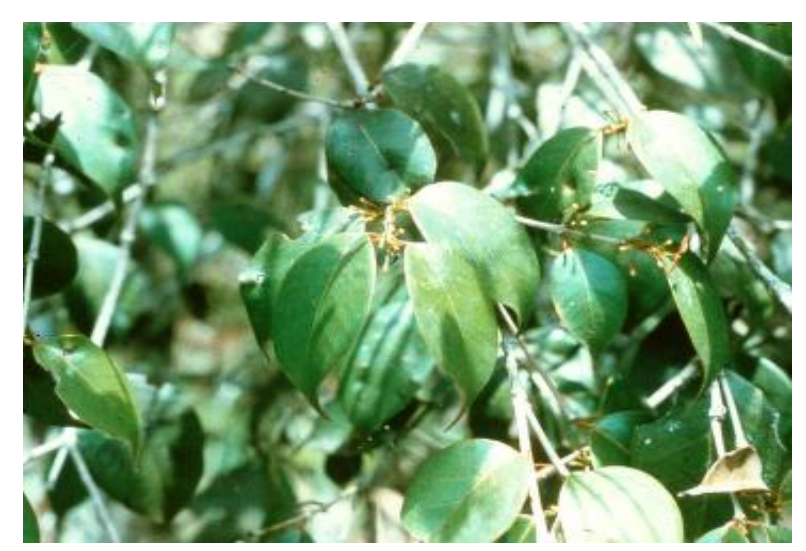

FIGURA 1.4 - Foto das folhas de Casearia obliqua

Folhas e cascas de árvore de C. obliqua são popularmente utilizadas como diurético, sudorífero, antiofídico e no combate às dermatoses e à doença de Hansen. (PLANTAS BRASILEIRAS, 2002). 


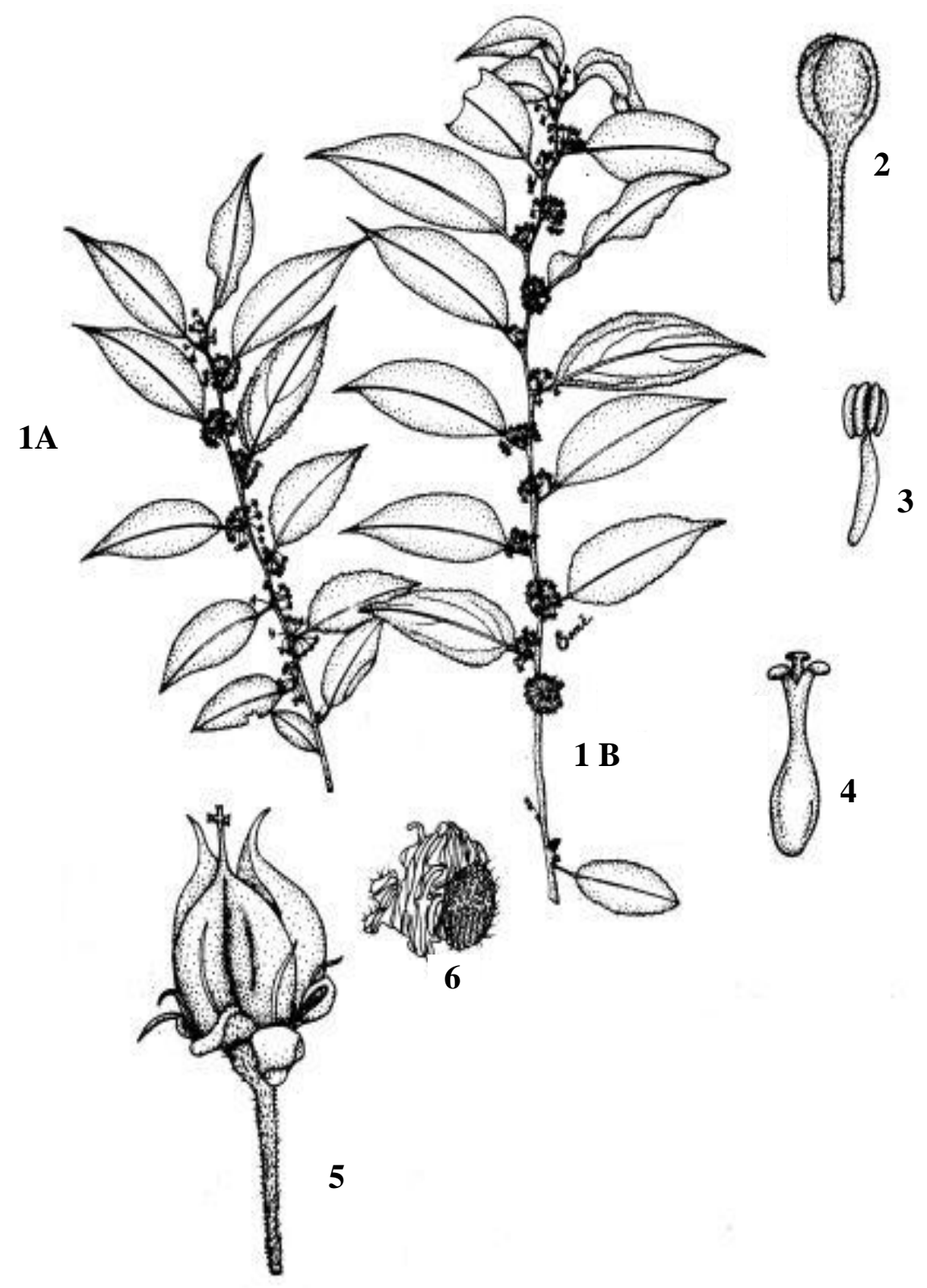

FIGURA 1.5 - Esquema da espécie C. obliqua. 1A e 1B mostram o aspecto do ramo; 2. botão floral; 3. estame; 4 . gineceu; 5 fruto; 6 . semente. (TORRES \& YAMAMOTO, 1986).

\section{Casearia decandra}

A C. decandra, vulgarmente conhecida como pitumba, guaçatunga e quina-dopará, é encontrada na forma de arbusto ou árvore, com folhas alternadas dísticas, 
salpicadas de pêlos glandulosos e serradas nas bordas. Suas flores apresentam-se em pequenas cimeiras auxiliares, são apétalas e brancas. Seus frutos são grandes e contém numerosas sementes envoltas em arilo carnoso amarelo (CORRÊA, 1978).

Popularmente, as cascas dos troncos e as folhas de C. decandra são utilizadas como antitérmico e no combate às úlceras gastroduodenais. (PLANTAS BRASILEIRAS, 2002). O esquema das principais partes da C. decandra está apresentado na FIG. 1.6.

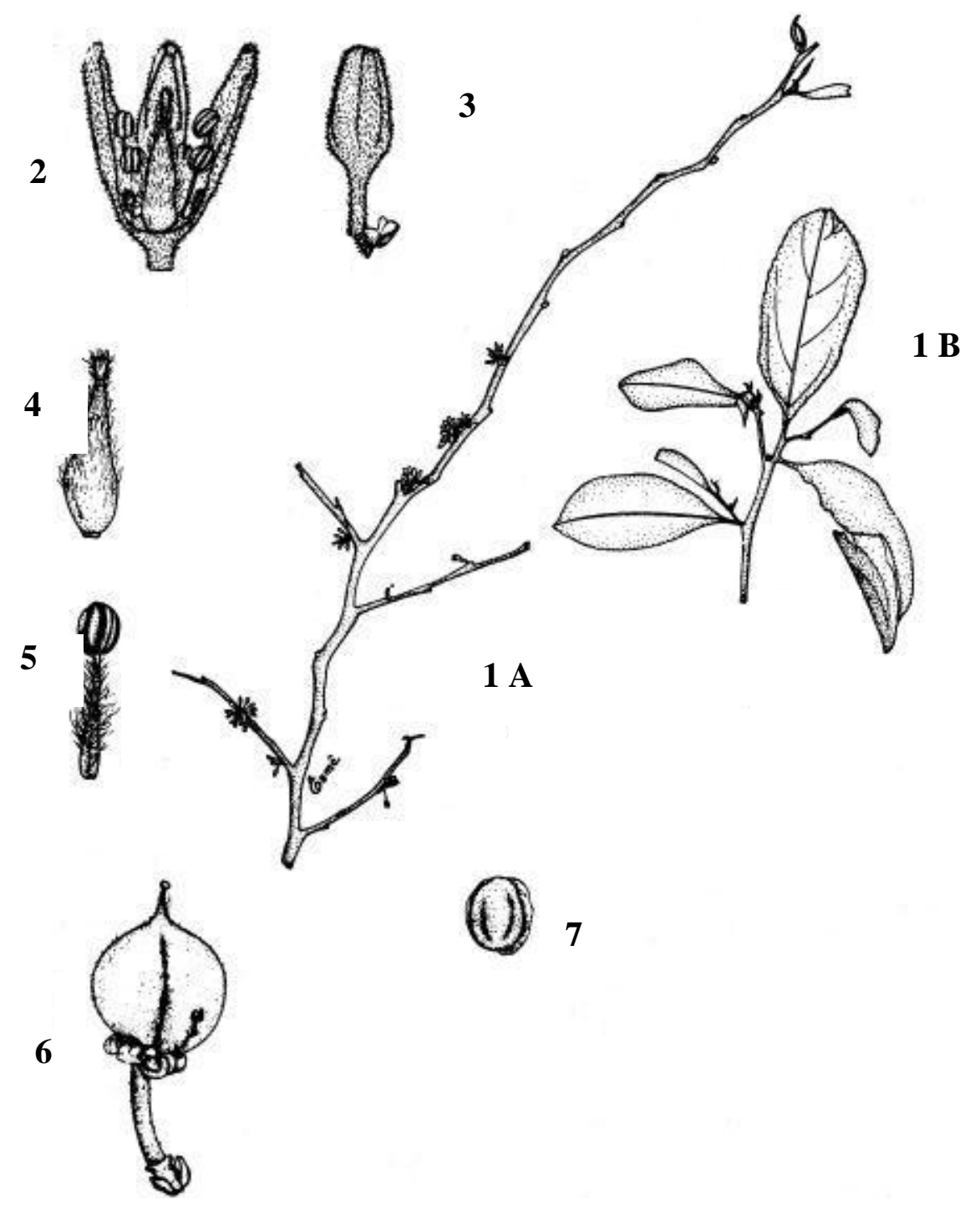

FIGURA 1.6 - Esquema da planta C. decandra. 1A e 1B mostram o aspecto do ramo; 2. flor com duas sépalas removidas; 3.botão floral; 4. gineceu; 5. estame; 6. fruto; 7. semente. (TORRES \& YAMAMOTO, 1986) 


\subsubsection{Composição elementar de plantas medicinais}

Em geral as plantas são constituídas de 85 a 90\% de água e sua matéria seca é composta de aproximadamente 44,5\% de carbono, 42,5\% de oxigênio, 6,5\% de hidrogênio, 2,5\% de nitrogênio, 1,9\% de potássio, 1,0\% de cálcio, 0,3\% de enxofre, 0,2\% de fósforo e 0,2\% de magnésio. Estes elementos são encontrados nas plantas em altas concentrações e por isso, são comumente denominados macroelementos. Existem ainda os microelementos, representados basicamente por $\mathrm{B}, \mathrm{Cl}, \mathrm{Co}, \mathrm{Cr}, \mathrm{Cu}, \mathrm{Fe}, \mathrm{Mn}, \mathrm{Mo}, \mathrm{Na}, \mathrm{Si}$ e $\mathrm{Zn}$, que embora estejam presentes em quantidades reduzidas, são essenciais ao desenvolvimento adequado das plantas (MARKERT, 1996).

Muitas vezes, a importância de um determinado elemento não está relacionada à quantidade em que está presente nos organismos vegetais. Desta forma, MARKERT (1996) sugere uma nova classificação dos elementos de acordo com as funções biológicas por eles desempenhadas nas plantas. Segundo esta classificação, existem os elementos estruturais, eletrolíticos e enzimáticos. Os estruturais, representados por C, Ca, H, N, O, P, S e Si, são aqueles que participam da construção de componentes moleculares da célula tais como proteínas, carboidratos, ácidos nucléicos, etc. Ca, Cl, K, Mg, e Na são elementos eletrolíticos, pois atuam na regulação osmótica da célula. Os elementos enzimáticos, B, Co, Cr, Cu, F, Fe, I, Mg, Mn, Mo, Ni, Sc, Sn, V e Zn, são ativadores ou catalisadores de importantes reações do metabolismo celular. Cerca de 1/3 das enzimas conhecidas necessitam da presença desses metais como parte integrante da própria molécula da enzima ou como ativador enzimático (HARPER et al., 1982).

O desenvolvimento de técnicas analíticas cada vez mais sensíveis tem contribuído enormemente para o conhecimento crescente sobre a composição elementar das plantas medicinais. A determinação dos constituintes inorgânicos das plantas medicinais é de extrema importância na avaliação do potencial farmacológico e toxicológico de determinadas espécies. Essas análises podem contribuir com os estudos 
que procuram elucidar a participação dos elementos nos processos biológicos do organismo humano e nos mecanismos de formação de substâncias fisiologicamente ativas (SFA) nas plantas. Essas substâncias, encontradas principalmente na forma de alcalóides, compostos fenólicos, taninos, terpenóides, saponinas triterpênicas, saponinas esteroidais, óleos essenciais, glicosídeos e polissacarídeos, têm sido consideradas responsáveis pelos efeitos terapêuticos característicos de muitas espécies de plantas medicinais (LOVKOVA et al., 2001).

Além disso, as análises da composição elementar de plantas medicinais contribuem de forma importante nos processos de controle de qualidade das etapas de obtenção, cultura, colheita, preparação e armazenagem das plantas medicinais, tornando o risco associado ao consumo dessas plantas cada vez menor.

\subsubsection{Estudos sobre análise elementar de plantas medicinais}

Um número cada vez maior de pesquisas sobre análise elementar de plantas medicinais vem sendo desenvolvido por meio das mais variadas técnicas analíticas. PHILLIPSON (2003) publicou uma revisão sobre a evolução das principais metodologias analíticas utilizadas nos estudos de plantas medicinais nos últimos 50 anos. Segundo este autor, destacaram-se, neste período, os métodos cromatográficos, espectroscópicos e biológicos devido às suas contribuições no aumento do conhecimento científico à respeito dos constituintes bioativos das plantas medicinais.

A revisão bibliográfica dos trabalhos encontrados na literatura a respeito da determinação da composição elementar de plantas medicinais mostra que uma grande variedade de metodologias analíticas, incluindo a análise por ativação com nêutrons, têm sido bastante utilizadas. 
VAZ et al. (1990) analisaram duas espécies de plantas medicinais, a Centella asiatica (cairuçú) e a Paulinia cupana (guaraná) e determinaram as concentrações dos elementos Al, Br, Ca, Cl, Fe, K, Mn, Na, Rb, Sc e Zn por meio da análise por ativação com nêutrons. Verificou-se que elementos com importantes funções biológicas no organismo humano foram encontrados em altas concentrações e que a determinação dos elementos tóxicos como As, $\mathrm{Cu}, \mathrm{Hg}$ e Mo não era possível pelo método instrumental. Em um outro trabalho, VAZ (1995) analisou os extratos hidroalcoólicos obtidos a partir das folhas de 7 espécies de plantas medicinais, dentre elas a Casearia sylvestris. Os elementos $\mathrm{Al}, \mathrm{Br}, \mathrm{Ca}$, Ce, Cl, Cr, Cs, Fe, K, La, Mg, Mn, Na, Rb, Sb, Sc e Zn foram determinados pelo método instrumental de análise por ativação com nêutrons, e a utilização de técnicas de separação radioquímica permitiram a determinação dos elementos Hg e Se.

SINGH \& GARG (1997), aplicando a análise instrumental por ativação com nêutrons (INAA), determinaram as concentrações de 20 elementos presentes em diversas partes de plantas (fruto, folha, casca de árvore, raiz, semente) utilizadas como medicamentos na Índia. Estes pesquisadores verificaram que a maioria das plantas são ricas em um ou mais elementos específicos, o que torna seu consumo apropriado para o tratamento à doenças específicas. A karela, uma fruta com altos teores de Cr, tem sido recomendada para indivíduos com problemas de diabetes. As folhas de bhringraj com elevadas concentrações de Zn são utilizadas popularmente no tratamento de doenças de pele. A planta jesjthmath, rica em Co é considerada uma importante fonte de vitamina $\mathrm{B}_{12}$ para o organismo humano.

RAJURKAR \& PARDESH (1997) utilizaram INAA e espectroscopia de absorção atômica (AAS) na determinação dos elementos $\mathrm{Al}, \mathrm{Ca}, \mathrm{Cd}, \mathrm{Cl}, \mathrm{Co}, \mathrm{Cr}, \mathrm{Cu}, \mathrm{Fe}$, Hg, K, Mn, Na, Ni, Pb e Zn presentes em diferentes concentrações nas várias partes de 25 plantas medicinais utilizadas no controle da diabete Mellitus. 
REDDY \& REDDY (1997), por meio da análise voltamétrica, estudaram 52 plantas de grande importância medicinal, determinando as concentrações dos elementos As, Ca, Co, Cr, Cu, Fe, K, Mg, Mn, Na, Ni, P, Pb, S, Se e Zn e comprovaram que o período e a variabilidade espacial de coletas das amostras são responsáveis pela diferença nas concentrações dos elementos em cada amostra.

RAJURKAR \& DAMANE (1998), utilizando análise por ativação com nêutrons (NAA) e AAS, determinaram as concentrações de 14 constituintes inorgânicos presentes em plantas medicinais utilizadas no tratamento de doenças do trato urinário. Ca, Fe, K, Mg, Na e Zn, que são elementos de grande importância nos estudos de problemas renais, foram alguns dos elementos determinados nas plantas medicinais analisadas neste estudo.

NAIDU et al. (1999) determinaram por NAA, as concentrações de 20 elementos presentes nas folhas de verduras e de plantas medicinais utilizadas na Índia e avaliaram os efeitos biológicos relacionados a estes elementos. Comparando seus resultados com aqueles obtidos por SINGH \& GARG (1997) para as mesmas espécies de plantas, foi verificado que as concentrações encontradas foram bastante diferentes para a maioria dos elementos, indicando a provável interferência de fatores ambientais como tipo de solo, poluição e uso de fertilizantes, na composição elementar das plantas medicinais.

SERFOR-ARMAH et al. (2001), aplicando a INAA, determinaram as concentrações de 15 elementos essenciais presentes em 5 plantas medicinais utilizadas em Gana no tratamento artrites, asma, impotência masculina, entre outras doenças.

Em um outro trabalho, SERFOR-ARMAH et al. (2002) analisaram outras 6 plantas medicinais também utilizadas em Gana para o tratamento de enxaqueca, desordens nasais, hipertensão, palpitações cardíacas, entre outras enfermidades. Por meio de INAA, foram determinadas as concentrações de $\mathrm{Al}, \mathrm{Br}, \mathrm{Ca}, \mathrm{Cl}, \mathrm{Co}, \mathrm{Cu}, \mathrm{Cr}, \mathrm{K}, \mathrm{Mn}, \mathrm{Mg}, \mathrm{Na}, \mathrm{Rb}$, 
Sb, Sc, Ta, V e Zn, e verificadas distintas concentrações desses elementos dependendo da espécie de planta estudada. Os autores atribuíram essa diferença a fatores tais como absortividade preferencial de cada planta por determinado elemento, condições climáticas ambientais e composição mineral do solo em que foram cultivadas.

LOZAK et al. (2002) utilizaram a espectrometria de massas com fonte de plasma acoplado indutivamente (ICP-MS) e AAS nas análises das folhas de ervas medicinais (hortelã e urtiga) e das infusões obtidas a partir destas ervas. As concentrações dos elementos presentes nas folhas de hortelã e nas de urtiga foram da mesma ordem de grandeza. As infusões foram preparadas segundo dois procedimentos distintos. Embora as concentrações de Co, Mg, Mn e Sr nas infusões obtidas por meio dos diferentes métodos de preparação não tenham apresentado diferenças significativas, as concentrações de Ba, Cd, Cr, Cu, I, Ni, Se, Ti e V, mostraram-se dependentes do método de preparação das infusões. Isto indicou que o modo de preparo das infusões medicinais deve ser cuidadosamente observado a fim de que se obtenha a eficácia farmacológica desejada.

OBIAJUNWA et al. (2002) utilizaram espectrometria de fluorescência de raios-X por energia dispersiva para determinar a composição elementar de vinte plantas medicinais comumente utilizadas na Nigéria. Foram detectados diversos elementos de importância vital para o metabolismo humano, tais como K, Ca, Mn, Fe, Zn, Se, Br, Rb, Sr entre outros. Elementos tóxicos, como $\mathrm{Pb}$, $\mathrm{As}$, $\mathrm{Hg}$ e $\mathrm{Cd}$, não foram detectados, o que indicou o uso seguro das espécies de plantas analisadas.

LEMBERKOVICS et al. (2002) determinaram os constituintes orgânicos e inorgânicos de infusões e de drogas de origens distintas (adquiridas comercialmente e cultivadas pelos próprios pesquisadores) da planta medicinal Helichrysi flos, tradicionalmente utilizada devido às suas propriedades diurética, detoxificante e antiinflamatória. O método utilizado nas análises foi a espectrometria de emissão atômica com fonte de plasma acoplado indutivamente (ICP-AES). A análise de variância aplicada 
aos resultados obtidos mostrou que as concentrações dos elementos $\mathrm{K}, \mathrm{Mg}, \mathrm{P}$ e $\mathrm{S}$, nas drogas de origem comercial e nas de cultivo próprio não apresentam diferenças significativas. Entretanto, para $\mathrm{Ca}$ e $\mathrm{Na}$ foram verificadas diferenças significativas dependendo da origem das drogas. Os elementos As, B, Cd, Co, Hg, Li, Mo, Pb e V apresentaram concentrações abaixo dos limites de detecção da metodologia empregada, em todas as amostras analisadas.

ALMEIDA et al. (2002) analisaram dez espécies de ervas medicinais por meio de AAS para Ca, Mg, Mn e Zn, espectrofotometria de absorção molecular para Al e Fe, e fotometria de chama para K e Na. Seus resultados indicaram que algumas espécies contêm nutrientes essenciais ao organismo humano. A Chenopodium ambrosioides pode ser considerada uma importante fonte de $\mathrm{Na}, \mathrm{K}, \mathrm{Mg}$ e Zn, e a Ageratum conyzoides, uma fonte de Ca, Mg e Fe. Embora as espécies Lippia Alba e Justicia gendarussa tenham apresentado altos teores de $\mathrm{Ca}$, de grande importância biológica, suas elevadas concentrações de $\mathrm{Al}$ tornam o consumo dessas espécies não adequado à saúde humana.

WESOLOWSKI \& KONIECZYNSKI (2003) utilizaram técnicas espectrofotométricas para determinar elementos metálicos (Ca, Mg, Fe, Mn, Cu e Zn) e não metálicos (N, P, S, Cl, I e B) em diversas partes de plantas medicinais. As raízes, rizomas e cascas de árvores apresentaram altas concentrações de $\mathrm{Ca}$ e $\mathrm{Mg}$. O Fe foi encontrado em concentrações mais elevadas nas raízes e rizomas do que nas cascas de árvore. Os demais elementos foram encontrados nos mesmos níveis de concentrações nas três partes de planta. Aplicando o teste estatístico de análise de componentes principais (PCA) aos resultados obtidos para raízes, rizomas e cascas de árvore, foi verificada a formação de grupos de amostras que se separaram segundo a espécie a que pertenciam.

SALVADOR et al. (2003) utilizaram espectrometria de fluorescência de raiosX para determinar a composição elementar de três espécies de plantas medicinais e nos seus extratos. Os elementos $\mathrm{P}, \mathrm{S}, \mathrm{K}, \mathrm{Ca} \mathrm{Ti}, \mathrm{Mn}, \mathrm{Fe}, \mathrm{Cu}, \mathrm{Zn}, \mathrm{Rb}$ e $\mathrm{Sr}$ foram determinados 
em todas as amostras. Além desses, $\mathrm{Al}, \mathrm{Si}, \mathrm{Cl}, \mathrm{Ni}, \mathrm{Br}, \mathrm{Rb}, \mathrm{Sb}, \mathrm{Cd}, \mathrm{Sn}, \mathrm{Hg}, \mathrm{Ce}$ e Pb foram detectados em algumas das amostras. A presença dos elementos tóxicos Cd, Sn, Sb, Hg e Pb foi atribuída à contaminação do ambiente, indicando a possibilidade do uso potencial dessas plantas nos estudos sobre biomonitoração ambiental.

MOHANTA et al. (2003) determinaram As, Br, Co, Cu, Fe, Ga, Mn, Ni, Pb, Rb, Sr, Y, Zn e Zr em raízes, folhas, sementes e cascas de árvore de plantas utilizadas na medicina tradicional da Índia, aplicando a técnica analítica de espectroscopia de emissão de raios $\mathrm{X}$ induzidos por prótons. Segundo estes pesquisadores, a concentração de Co relativamente alta obtida nas plantas justifica o seu uso no tratamento de anemia. Sabe-se que o Co tem um papel modulatório indireto na síntese de radicais heme que são constituintes importantes das moléculas de hemoglobina do sangue. Os resultados indicaram também que as concentrações mais altas de Cu foram obtidas em amostras cujas concentrações de Fe eram altas e as de Co e Ni baixas. O elemento $\mathrm{Pb}$ foi encontrado apenas nas amostras que continham altos teores de Zn, e, além disso, foi observado que os teores mais elevados de $\mathrm{Zn}$ foram determinados nas plantas utilizadas tradicionalmente no tratamento de doenças oculares.

FALCÓ et al. (2003) utilizaram ICP-MS para determinar os elementos tóxicos As, $\mathrm{Cd}, \mathrm{Hg}$ e $\mathrm{Pb}$ presentes em plantas medicinais, preparadas na forma de infusões, comumente utilizadas na Espanha. Considerando um consumo diário de duas xícaras de chá de plantas medicinais, e baseando-se nas quantidades de elementos recomendadas e toleráveis pela WHO, estes pesquisadores concluíram que as quantidades de As, $\mathrm{Pb}$ e Cd ingeridas não aumentam significativamente as chances de desenvolvimento de problemas tóxicos ou carcinogênicos.

GOMEZ et al. (2003), analisando os derivados farmacêuticos da planta medicinal Hypericum perforatum, determinaram as concentrações de $\mathrm{Li}$, Na e $\mathrm{K}$ por espectrometria de emissão atômica (AES) e de Ca, Cu, Mg, Mn e Zn por AAS. As 
concentrações de todos os elementos encontrados nessa espécie de planta apresentaram-se dentro dos limites recomendados pela WHO.

Mais recentemente, DIM et al. (2004) utilizaram INAA na determinação dos elementos Al, Ba, Br, Ca, Co, Cr, Fe, K, Mg, Mn Na, Rb, Sc, Sr, V e Zn presentes na planta medicinal Ageratum conyzoides, amplamente utilizada na Nigéria. Foi detectada a presença de elementos essenciais à saúde humana, bem como elementos potencialmente tóxicos, o que indicou que o consumo de seus extratos não deve ser feito de forma indiscriminada.

CALDAS \& MACHADO (2004), determinando Cd, Hg e Pb em dez plantas medicinais brasileiras por meio da espectrofotometria de absorção atômica, avaliaram o risco potencial do consumo de plantas medicinais as quais apresentam concentrações significativas de metais tóxicos.

Conforme se pode observar, a determinação multielementar de plantas medicinais e de seus extratos tem sido objeto de estudo de inúmeras pesquisas científicas que fazem uso das mais variadas metodologias de análise. Isto se deve principalmente ao aumento da popularidade e do consumo dessas plantas no combate a diversas doenças e ao conhecimento cada vez maior da função e toxicidade de cada elemento no organismo humano

\subsection{Funções biológicas dos elementos no organismo humano}

Embora nem todos os elementos possuam funções biológicas descritas de forma precisa, a maioria deles é responsável por importantes atividades no metabolismo humano, e estão, portanto, intimamente relacionados com a manutenção da saúde e o funcionamento adequado do organismo. A seguir, são apresentadas as funções biológicas 
no organismo humano desempenhadas pelos elementos mais comumente encontrados nas plantas.

O cálcio é um elemento encontrado nas plantas e presente nos organismo humanos na forma de hidroxiapatita, sendo o principal elemento constituinte dos ossos e dentes. Mais de 99\% do cálcio presente no organismo encontra-se no esqueleto e o restante nos fluidos corpóreos e nas células. Essa pequena quantidade de cálcio presente nos fluidos corpóreos e nas células é responsável pelo funcionamento adequado de nervos e músculos, pela coagulação sangüínea e pelo controle da permeabilidade das membranas celulares. A deficiência de cálcio no organismo pode provocar doenças tais como a osteoporose, o raquitismo (calcificação defeituosa dos ossos) e o raquitismo renal (diminuição da absorção intestinal de cálcio e fósforo) (HARPER et al., 1982; MARTIN et al., 1985).

O potássio participa ativamente na manutenção do ritmo cardíaco e controla a pressão osmótica e o equilíbrio ácido-base dos fluidos corpóreos. Porém, em excesso, o potássio pode causar a hipercalemia, que provoca variações eletrocardiográficas significativas no coração (MARTIN et al., 1985).

O magnésio está presente em todas as células do organismo e é um co-fator importante de mais de 300 reações do metabolismo humano (BERDANIER, 1994). Este elemento participa de todas as reações em que a molécula de trifosfato de adenosina (ATP) participa como substrato, o que indica que a formação de proteínas, ácidos nucléicos, lipídeos e carboidratos, depende da presença deste elemento. No caso de consumo excessivo de proteínas, de cálcio e de fosfatos, ou em situações de diarréia crônica e alcoolismo, há diminuição da absorção de magnésio pelo intestino e a deficiência deste elemento pode causar distúrbios neurológicos e metabólicos no organismo humano (MARTIN et al., 1985). 
Cloro e sódio, assim como o potássio, são elementos responsáveis pelo equilíbrio ácido-base e pela estabilidade osmótica das células. Mesmo as pequenas alterações dos níveis normais de cloro e sódio podem provocar doenças e mau funcionamento do organismo humano (SILVA \& WILLIAMS, 1993). O cloro é um importante agente oxidante e o principal elemento encontrado no suco gástrico. O sódio atua ativamente na condução de impulsos nervosos e na formação da apatita, importante mineral constituinte dos ossos (BERDANIER, 1994). O consumo excessivo de sódio pode causar ou agravar problemas de hipertensão (MARTIN et al., 1985).

O cobalto é um componente da cobalamina, a vitamina $B_{12}$, que participa como coenzima de importantes reações enzimáticas (BERDANIER, 1994). Indivíduos com problemas de fígado podem ter absorção de cobalto significativamente aumentada, entretanto, como a toxicidade deste elemento tem sido considerada baixa, o excesso de cobalto não tem causado prejuízo à saúde humana (MARTIN et al., 1985).

O crômio tem o papel de regular o metabolismo de ácidos nucléicos, lipoproteínas e carboidratos e de potencializar a ação da insulina (KAPLAN et al., 2003). A deficiência de crômio no organismo pode provocar elevação dos níveis de triglicérides e colesterol no sangue, opacidade da córnea e neuropatia. O seu excesso pode provocar câncer de pulmão e dermatite de contato (SILVA \& WILLIAMS, 1993, KAPLAN et al., 2003). A toxicidade do crômio está relacionada com seu estado de oxidação. $\mathrm{O} \mathrm{Cr}^{6+}$ é considerado altamente tóxico, enquanto o $\mathrm{Cr}^{3+}$ é considerado inofensivo. Alguns compostos de $\mathrm{Cr}^{6+}$ são carcinogênicos (REIMANN \& CARITAT, 1998).

O ferro é o principal componente da hemoglobina, responsável pelo transporte de oxigênio a todas as células do organismo (MARTIN et al., 1985). Ele atua também como enzima da cadeia respiratória e sua deficiência no organismo causa fraqueza e 
anemia. Por outro lado, o excesso de ferro pode causar hemocromatose, caracterizada principalmente por pigmentação da pele, e cirrose hepática (SILVA \& WILLIAMS, 1993).

O zinco é constituinte de mais de 200 enzimas que participam da regulação da expressão gênica, do processo de divisão celular, da síntese de RNA e da transcriptase reversa (SILVA \& WILLIAMS, 1993), do desenvolvimento de células epiteliais (ZINPRO COORPORATION, 2000) e da manutenção do sistema imunológico. A deficiência de zinco no organismo pode provocar lesões na pele, diarréia, irritabilidade, queda de cabelo, retardo de crescimento e aumento da susceptibilidade a infecções (KAPLAN et al., 2003).

O manganês é um elemento necessário para ativação de enzimas responsáveis pela síntese de açúcares e proteínas (MARTIN et al., 1985). Ele é importante no metabolismo de carboidratos e lipídeos e nas funções reprodutivas. Especialmente em crianças, a deficiência de manganês pode causar deformações do esqueleto e epilepsia (KAPLAN et al., 2003).

O cobre é um elemento tóxico ou essencial dependendo do teor em que é encontrado nos organismos. Em altas concentrações pode provocar amnésia, além de danos ao estômago, intestino, fígado e rins (REIMANN \& CARITAT, 1998).

O selênio, assim como o cobre, é um elemento essencial porém tóxico se presente em concentrações elevadas. Tanto a deficiência quanto o excesso deste elemento podem ocasionar importantes problemas à saúde. Sua essencialidade está na constituição da enzima peroxidase glutationa, que tem função antioxidante e protege o organismo contra danos celulares causados por radicais livres. Níveis não apropriados de Se no organismo humano, muitas vezes podem ocasionar dilatação do coração e falência cardíaca (MARTIN et al., 1985), além de provocar queda de cabelos e unhas (SILVA \& 
WILLIAMS, 1993), danos no sistema nervoso periférico e circulatório, rins e fígado (REIMANN \& CARITAT, 1998).

Elementos tóxicos são aqueles que mesmo em pequenas quantidades podem causar prejuízo à saúde humana. Algumas plantas são acumuladoras destes elementos e, portanto, o consumo destes vegetais, seja para finalidades nutricionais quanto medicinais, não deve ser feito de forma indiscriminada. Cabe lembrar que qualquer elemento, se ingerido em quantidades excessivas, pode causar prejuízo ao organismo. A seguir são apresentados os elementos tóxicos encontrados em algumas espécies de plantas.

O arsênio é um elemento tóxico porém considerado essencial a alguns organismos. Sua toxicidade está relacionada ao estado de oxidação do elemento. Compostos de $\mathrm{As}^{3+}$ são considerados mais tóxicos que os de $\mathrm{As}^{5+}$ (REIMANN \& CARITAT, 1998).

O antimônio é considerado um elemento tóxico e não essencial aos organismos. Em altas concentrações este elemento pode ser mais tóxico que As e Pb. A ingestão de água com quantidades excessivas de Sb pode causar náusea, vômitos e diarréia. O Sb é considerado também potencialmente carcinogênico (REIMANN \& CARITAT, 1998).

O cádmio é considerado um elemento tóxico, porém essencial a alguns animais em baixíssimas concentrações. É considerado carcinogênico e a sua ingestão excessiva pode provocar náusea, vômito, diarréia, distúrbios sensoriais, falência renal além de danos no fígado, ossos e sangue (REIMANN \& CARITAT, 1998).

O chumbo é tóxico, não essencial e sua concentração nas plantas é mais alta se estas são cultivadas em solos com $\mathrm{pH}<5$. No organismo humano, níveis elevados de chumbo interferem no metabolismo das hemáceas, provocam aumento da pressão 
sangüínea, derrame, doença renal e câncer. Em crianças, as altas concentrações de chumbo causam atraso no desenvolvimento mental e físico, deficiência de aprendizagem e de audição (REIMANN \& CARITAT, 1998).

O mercúrio é um elemento não essencial extremamente tóxico e teratogênico. Altas concentrações deste elemento causam danos severos aos rins em curto espaço de tempo (REIMANN \& CARITAT, 1998).

Existem ainda aqueles elementos cujas funções biológicas não são completamente conhecidas, como por exemplo Al, B, Ba, Br, Cs, La, Rb, Sc Sr e Ti. Dentre estes elementos, Al, Ba, Rb, Sr e Ti já são considerados essenciais, mesmo que suas ações no metabolismo humano não tenham sido descritas de forma detalhada (MARKERT, 1996).

1.3 Relação entre os elementos presentes nos solos e nas plantas

A composição elementar das plantas, em geral, está relacionada com a idade da planta, absortividade preferencial de cada vegetal por determinados elementos, condições climáticas, e também com a constituição química do solo em que elas foram cultivadas.

Os solos apresentam composição mineral extremamente complexa, sendo formados por componentes minerais e orgânicos. A constituição do material rochoso original, processos pedogênicos e fatores externos tais como as práticas agrícolas e poluição interferem na composição química dos solos. Os solos são compostos de três fases (sólida, líquida e gasosa) em equilíbrio dinâmico, conforme o esquema apresentado na FIG. 1.7. 


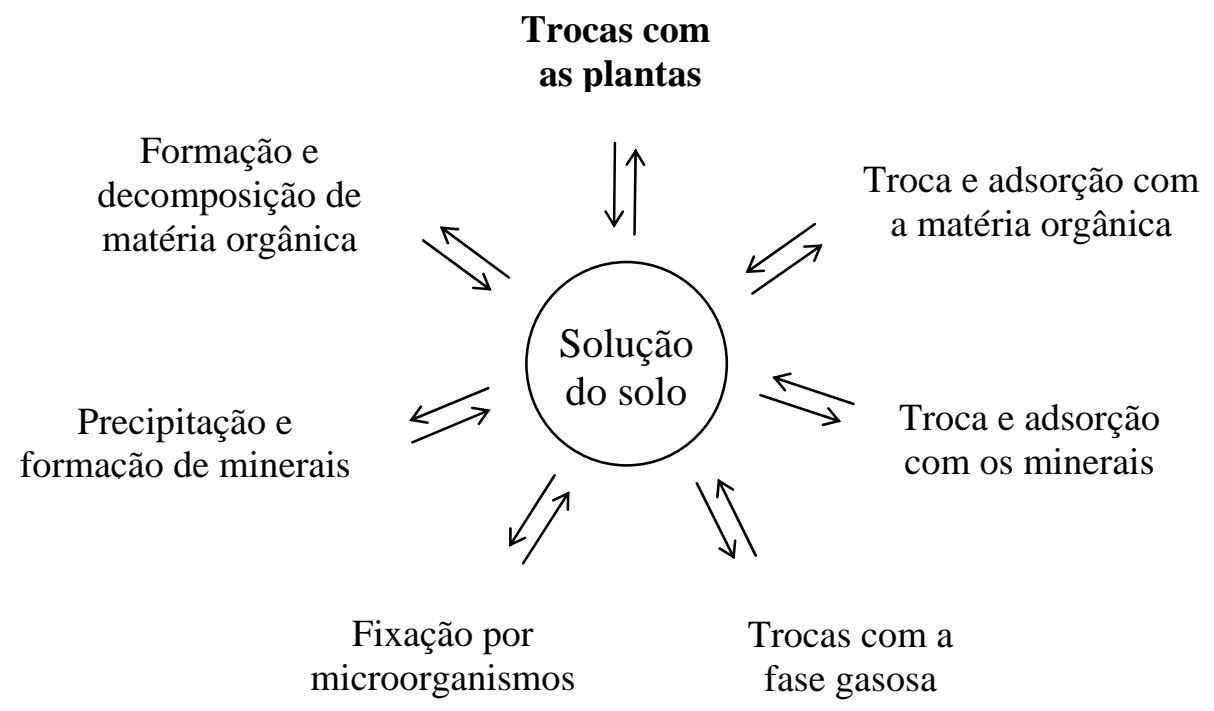

FIGURA 1.7 - Equilíbrio dinâmico entre os componentes do solo (KABATA-PENDIAS \& PENDIAS, 1984).

A biodisponibilidade, assim como o grau de mobilidade dos elementos, está relacionada com a solubilidade destes elementos na solução do solo (fase líquida). Desta forma, fatores como $\mathrm{pH}$, temperatura, potencial redox, competição com outros metais, ligação com ânions, entre outros, interferem na solubilidade do elemento e alteram significativamente a biodisponibilidade de nutrientes presentes no solo (OLIVEIRA, 2004).

$\mathrm{O} \mathrm{pH}$ do solo, especificamente, pode atuar de forma direta no processo de absorção de nutrientes pelas plantas. Ele está associado à perda da integridade das membranas radiculares e, conseqüentemente, à perda da capacidade de troca iônica destas células. No entanto, a principal influência do $\mathrm{pH}$ do solo na biodisponibilidade de nutrientes acontece de forma indireta, por meio da competição de prótons e cátions metálicos por ligantes presentes no solo, e do ataque dos prótons aos minerais também 
encontrados no solo. Ambos os mecanismos tendem a produzir cátions metálicos livres e, assim aumentar a disponibilidade desses metais no solo (SPOSITO, 1989).

A maioria das plantas apresenta desenvolvimento adequado quando cultivada em solo levemente ácido. Entretanto, solos com esta característica podem apresentar deficiência em alguns elementos como $\mathrm{Ca}, \mathrm{Mg}$ e $\mathrm{K}$, e ainda, os solos fortemente ácidos podem conter elementos como Al, Fe, Cu, Zn e Mn em quantidades tóxicas (TAN, 1994).

Segundo KABATA-PENDIAS \& PENDIAS (1984), solos neutros e alcalinos disponibilizam para as plantas, elementos em quantidades reduzidas durante um extenso período de tempo. Nos solos ácidos a disponibilização dos elementos é elevada, tornando comum a escassez de determinados micronutrientes do solo em curto espaço de tempo.

Várias técnicas analíticas têm sido aplicadas nas análises de amostras de solos e plantas e inúmeras investigações procuram examinar a relação existente entre as características do solo e as concentrações de elementos presentes nas plantas nele cultivadas. MORENO et al. (1992) analisaram os elementos tóxicos Cu, Cd, Pb, Zn e Y em solos e plantas coletados em regiões com diferentes níveis de atividade industrial, em Madri. Seus resultados não indicaram uma correlação significativa entre os elementos encontrados nas plantas e nos solos. A razão entre a concentração do elemento na planta e no solo (coeficiente de absorção biológico) mostrou que 50\% das plantas analisadas eram acumuladoras de Cd. O Zn foi acumulado por 20\% das plantas analisadas, o $\mathrm{Cu}$ por 15\% delas e não foi observado acúmulo de $\mathrm{Pb}$ em nenhuma das plantas analisadas.

WYTTENBACH et al. (1998) determinaram os elementos de terras raras La, Ce, Nd, Sm Eu, Tb, Yb e Lu, por meio de NAA, em plantas e solos, coletados em 6 pontos diferentes de uma mesma região de Chanéaz, na Suíça. O baixo coeficiente de variação obtido entre as amostras de solos indicou uma grande uniformidade do solo da região estudada. Para as plantas não foi verificada esta uniformidade e a variabilidade entre as 
amostras indicou que as concentrações dos elementos nas plantas não refletiram a composição dos solos em que estas plantas foram cultivadas. Apesar dos elementos de terras raras apresentarem propriedades químicas semelhantes, nem todos foram absorvidos pelas plantas de forma similar. O Ce foi o elemento que apresentou comportamento anômalo o qual foi atribuído ao fato de que, ao contrário dos demais elementos de terras raras que formam íons trivalentes na solução do solo, o Ce pode formar também íons tetravalentes que são absorvidos pelas plantas em quantidades menores.

MOHAMED (1998) utilizou a espectrometria de absorção atômica com chama (FAAS) na determinação dos elementos Ag, $\mathrm{Au}, \mathrm{Ca}, \mathrm{Co}, \mathrm{Cr}, \mathrm{Cu}, \mathrm{Fe}, \mathrm{K}, \mathrm{Mg}, \mathrm{Mn}, \mathrm{Na}, \mathrm{Ni}$, $\mathrm{Pb}$, Sr e Zn em amostras de cana-de-açúcar e de solos coletados próximos às raízes destas plantas. Este pesquisador verificou também que os nutrientes presentes no solo à profundidade de $30 \mathrm{~cm}$ são mais absorvidos pelas plantas que aqueles encontrados na superfície ou à $60 \mathrm{~cm}$ de profundidade.

REIMANN et al. (2001) determinaram 37 elementos por meio das técnicas de espectrometria de massas com plasma induzido (ICP-MS), espectroscopia de emissão atômica com plasma induzido (ICP-AES) e espectrometria de absorção atômica a vapor a frio (CV-AAS) em espécies distintas de plantas coletadas em 9 diferentes locais espalhados em uma área de $1.500 .000 \mathrm{~km}^{2}$ do norte europeu. As concentrações de determinados elementos, como $\mathrm{Ba}, \mathrm{Cd}, \mathrm{Co}, \mathrm{Pb}, \mathrm{C}$ e $\mathrm{Y}$, variaram consideravelmente entre as diferentes plantas apesar de terem sido cultivadas numa mesma região, enquanto que outros elementos, como $\mathrm{Rb}, \mathrm{S}, \mathrm{Cu}, \mathrm{K}, \mathrm{Ca}, \mathrm{P}$ e $\mathrm{Mg}$ foram determinados em níveis similares em todas as plantas. Os fatores de concentração maiores que 1 indicaram que a maioria das plantas analisadas eram acumuladoras de S, K, B, Ca, P, Mn, Cd, Sr, Zn, Ba e Ag.

GÜLERYÜZ et al. (2002), aplicando a FAAS, determinaram os elementos Ca, $\mathrm{K}, \mathrm{Fe}, \mathrm{Mg}, \mathrm{Mn}$ e $\mathrm{Zn}$ em plantas alpinas e sub-alpinas e verificaram variações das concentrações dos elementos com à proximidade da mina de tungstênio de Monte Uludag, 
na Turquia. Os resíduos gerados pela atividade mineradora alteravam a acidez do solo e com isso a disponibilidade dos elementos à absorção pelas plantas. Nas regiões próximas à mina os solos apresentaram pH mais elevado e as mais altas concentrações de $\mathrm{Ca}, \mathrm{Cu}, \mathrm{Fe}$, Mg, Mn e Zn.

CHIZZOLA et al. (2003) monitoraram Cd, Cu, Fe, Mn, Pb e Zn presentes em plantas medicinais cultivadas em diferentes regiões da Áustria. A técnica aplicada nas análises foi a AAS. Seus resultados mostraram que as altas concentrações de Cd estão restritas a algumas das espécies de plantas analisadas, e não às de uma região específica da Áustria. Este dado mostrou que os níveis de Cd foram mais dependentes da espécie da planta do que de sua origem. Por outro lado, foi verificado que a concentração de Zn na planta depende das características do solo e, no caso, foram obtidas concentrações mais elevadas deste elemento nas amostras coletadas em Viena do que nas coletadas nas demais regiões estudadas.

BARGAGLI et al. (2003) comprovaram que em ambientes relativamente nãopoluídos as concentrações médias de elementos presentes nas folhas de várias espécies de carvalho eram constantes, enquanto que em regiões que apresentavam anomalias geoquímicas as concentrações de determinados elementos nas folhas variaram significativamente. Estes pesquisadores demonstraram que o carvalho evita a absorção dos elementos não-essenciais assim como os potencialmente tóxicos $\mathrm{Cd}, \mathrm{Cr}, \mathrm{Cu}, \mathrm{Ni}, \mathrm{Pb}$.

EN et al. (2003) aplicando INAA determinaram os elementos presentes em plantas (algodoeiro e beterraba) coletadas em três diferentes fases de seu crescimento e também nos solos onde foram cultivadas. No caso, foram analisados também os solos aos quais foram adicionados fertilizantes minerais e biológicos, com o intuito de examinar a relação existente entre os elementos disponíveis nos solos e os encontrados nas plantas. Segundo estes autores, as concentrações de elementos essenciais, como o Mn, nos organismos vivos tendem a ser relativamente constantes, independente dos níveis de 
concentração de elementos encontrados no ambiente. Entretanto se cultivadas em solos com quantidades excessivas de $\mathrm{Ba}$ e $\mathrm{Sr}$, por exemplo, as plantas podem facilmente acumular níveis tóxicos destes elementos.

RAZIC et al. (2003), aplicaram FAAS e espectrometria de emissão atômica com chama (FAES) para analisar as diferentes partes (raiz e parte superior) da planta medicinal Echinacea purpúrea, utilizada no tratamento de infecções crônicas do trato respiratório e urinário. Além da planta foram analisados os seus extratos e o solo onde ela foi cultivada. A variabilidade entre as concentrações de elementos obtidas nas diferentes partes da planta foi atribuída às diferenças nas estruturas botânicas de cada parte e também à composição do solo em que foram cultivadas

AJASA et al. (2004) empregaram AAS para determinação de micro e macronutrientes em dez espécies de plantas medicinais coletadas em diferentes regiões da Nigéria e obtiveram concentrações de Ca, Fe, K, Mg e P na faixa de 10 a 51.000 ppm, enquanto as concentrações do elemento tóxico Pb foram inferiores a 0,5 ppm.

POUTARAUD \& GIRARDIN (2004) analisaram sementes de Colchicum autumnale utilizadas para fins medicinais e os solos em que a planta foi cultivada. Por meio da regressão linear das características analisadas nos solos $(\mathrm{pH}$, matéria orgânica, concentrações de C, N, Ca, Mg, K, Na, B, Cd, Co, Cr, Fe, Mn, Mo, Ni, Pb e Zn) e dos conteúdos de alcalóides encontrado nas sementes, foi verificado que os alcalóides, responsáveis pela propriedade farmacológica da semente, apresentam uma correlação significativa com as concentrações de Ca e Co encontrados nos solos.

YAN et al. (2004) examinaram a variação entre as concentrações de um princípio ativo encontrado na raiz da planta medicinal Rhodiola sachalinensis com as características do solo em que foram cultivadas. Segundo estes pesquisadores, as plantas com altas concentrações do princípio ativo de interesse na planta medicinal foram aquelas 
cultivadas em solos que apresentavam $\mathrm{pH}$ em torno de 4, com biodisponibilidade de $\mathrm{N}$ alta e as de $\mathrm{P}$ e $\mathrm{K}$ baixas.

Conforme se pode observar, os trabalhos sobre a relação entre a composição elementar de plantas e dos solos em que elas foram cultivadas tem sido extensivamente estudadas em pesquisas de interesse nas áreas de saúde, monitoração ambiental e nutrição. Estes estudos podem fornecer importantes informações sobre a interferência das características do solo na composição elementar das plantas, permitindo que as plantas medicinais sejam cultivadas em condições de solo adequadas, de tal forma que as concentrações de princípios ativos produzidos pelas plantas sejam elevadas. 


\section{OBJETIVOS}

O objetivo do trabalho foi realizar um estudo comparativo entre os elementos presentes nas folhas e nos extratos hidroalcoólicos 75\% de diferentes espécies da planta medicinal do gênero Casearia (C. sylvestris, C. obliqua e C. decandra) coletadas em diferentes regiões da Mata Atlântica, bem como verificar se existe uma relação entre a composição elementar da planta com as características do solo em que ela foi cultivada. A idéia deste trabalho é também posteriormente verificar a relação existente entre a composição elementar das plantas com o efeito farmacológico de seus extratos.

Estas determinações constituem uma contribuição importante para escolha da espécie da planta Casearia e da região ou do solo apropriado para seu cultivo de tal modo que sejam obtidos extratos medicinais que apresentem a maior atividade farmacológica.

O método utilizado neste estudo foi a análise instrumental por ativação com nêutrons. Para o desenvolvimento deste trabalho foram estabelecidas as condições experimentais adequadas para as análises de folhas de planta, de seus extratos e de solo, validados os parâmetros de qualidade analítica com relação à exatidão e precisão dos resultados, e determinados os valores de limites de detecção e determinação dos elementos para avaliar a sensibilidade da técnica analítica aplicada. 


\section{MÉTODO DE ANÁLISE POR ATIVAÇÃO COM NÊUTRONS}

3.1 Considerações gerais sobre análise por ativação

A análise por ativação é uma técnica altamente sensível e seletiva que permite determinar qualitativa e quantitativamente a maioria dos elementos da tabela periódica, na concentração de partes por milhão (ppm) ou partes por bilhão (ppb), presentes em uma amostra (DE SOETE et al., 1972). A descoberta da reação de ativação, isto é, da obtenção substâncias radioativas a partir do choque entre núcleos dos elementos com partículas ou núcleos de outros elementos, foi feita por Iréne e Frédéric Joliot Curie, em 1934. Em 1936, Hevesy e Levi utilizaram nêutrons para bombardear disprósio e európio, sugerindo a aplicação do método de ativação com nêutrons em análises elementares (ALFASSI, 1990).

A análise por ativação baseia-se na produção de radionuclídeos artificiais a partir de elementos estáveis, que ao emitirem raios gama característicos durante o processo de decaimento radioativo, permitem sua identificação e quantificação. Embora a conversão do isótopo estável em um núcleo radioativo possa ocorrer por meio do bombardeamento de partículas energeticamente carregadas (alfa, prótons, dêuterons), fótons de alta energia ou nêutrons, este último é, notadamente, o mais amplamente utilizado (BODE \& GOEIJ, 1998).

O desenvolvimento dos reatores nucleares principalmente na década de 40 possibilitou a obtenção de fluxos da ordem de $10^{12}$ nêutrons $\mathrm{cm}^{-2} \mathrm{~s}^{-1}$ e a análise por ativação com nêutrons passou a ter um campo de aplicação ainda mais amplo. A produção 
de detectores de germânio nos anos 60 e o desenvolvimento de softwares e hardwares nos anos 70 e 80 revolucionaram a análise por ativação com nêutrons. Atualmente ela é uma ferramenta importante na determinação de elementos traço de interesse em diversas áreas da ciência e tecnologia, como nas análises de materiais de alto grau de pureza da indústria microeletrônica, nas análises de materiais geoquímicos e cosmoquímicos, em análises ambientais e biomédicas, que incluem tanto a determinação dos elementos essenciais quanto os tóxicos à saúde dos seres vivos (MEYERS, 1998).

Os reatores nucleares de pesquisa são a principal fonte de nêutrons para a análise por ativação e, em geral, seu fluxo varia de $10^{11}$ a $10^{14}$ nêutrons $\mathrm{cm}^{-2} \mathrm{~s}^{-1}$. Em relação às outras fontes de nêutrons (geradores, aceleradores), o reator nuclear apresenta algumas vantagens (BODE \& GOEIJ, 1998):

- $\quad$ Fluxo intenso de nêutrons e altas secções de choque dos elementos, que possibilitam a detecção de um grande número de elementos;

- Obtenção de fluxos relativamente homogêneos de nêutrons que apresentam grande poder de penetração nos materiais;

- $\quad$ Aquecimento relativamente pequeno da amostra.

Os nêutrons originados nos reatores nucleares de pesquisa podem ser classificados, segundo sua energia cinética em:

- $\quad$ nêutrons de fissão (ou rápidos): são gerados a partir da fissão do ${ }^{235} \mathrm{U}$ e apresentam energia de100 keV a $25 \mathrm{MeV}$;

- $\quad$ nêutrons epitérmicos: resultam da perda de velocidade do nêutron ao colidir com núcleos do moderador e têm energia de 0,5 eV a $100 \mathrm{keV}$;

- nêutrons térmicos: estão em equilíbrio térmico com o moderador. A distribuição de energia destes nêutrons é maxwelliana e a energia mais provável corresponde a 0,025 eV. 
A maioria das análises por ativação é realizada com fluxos de nêutrons térmicos, porém, nos casos específicos de alguns elementos que apresentam baixa secção de choque para nêutrons térmicos, nêutrons epitérmicos são os preferidos para ativação.

A medida de radiação gama é a mais comum nas análises por ativação. Isto se deve, entre outros fatores, ao número considerável de elementos que produzem radionuclídios emissores de raios gama, e à existência de instrumentação adequada que permitem distinguir as energias de radiação gama com alta resolução.

Os equipamentos mais utilizados na detecção dos raios gama emitidos nas análises por ativação são os espectrômetros de radiação gama de alta resolução. Eles são constituídos basicamente de um detector semicondutor, sendo os mais modernos de germânio hiperpuro, e um sistema eletrônico para o amplificação e processamento dos pulsos elétricos gerados. Nos espectros obtidos são discriminados picos de absorção total em energias características, que permitem identificar o radioisótopo presente na amostra. A área sob cada pico é proporcional a quantidade do elemento correspondente. O esquema apresentado na FIG. 3.1 mostra as principais partes do espectrômetro de radiação gama de alta resolução, em sua configuração vertical.

Blindagem

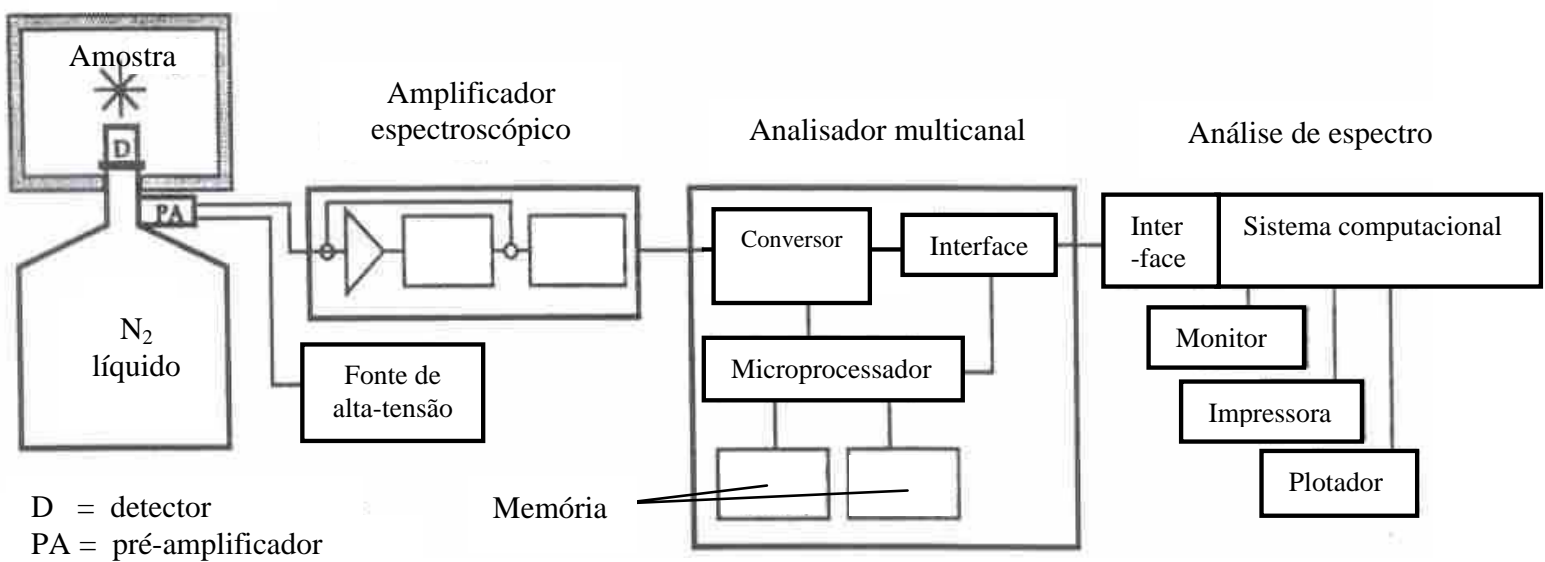

FIGURA 3.1 - Diagrama esquemático de um espectrômetro de radiação gama de alta resolução, na configuração vertical (KELLNER et al., 1998). 
3.2 Princípio do método de análise por ativação com nêutrons

No método de análise por ativação com nêutrons, radionuclídeos artificiais (B) são produzidos a partir do isótopo estável (A) de um determinado elemento por meio do bombardeamento do núcleo alvo com nêutrons (x). Essa reação pode ser representada da seguinte forma:

$$
\mathrm{A}+\mathrm{x} \rightarrow(\mathrm{C}) \rightarrow \mathrm{B}+\mathrm{y}+\mathrm{Q}
$$

onde (C) é o núcleo-composto, cujo tempo de meia-vida varia de $10^{-20}$ a $10^{-14} \mathrm{~s}$ (KELLNER et al., 1998), y é a partícula emitida após a reação (no caso, a radiação gama) e Q representa a quantidade de energia liberada ou absorvida na reação.

O núcleo composto no estado excitado inicia imediatamente o processo de decaimento emitindo raios gama pronto $\left(\gamma_{\mathrm{p}}\right)$. O núcleo radioativo originado também decai emitindo um ou mais raios gama de decaimento $\left(\gamma_{\mathrm{d}}\right)$, a uma taxa que depende do tempo de meia-vida do radionuclídeo, até que se torne um núcleo estável. A FIG. 3.2 ilustra as etapas envolvidas na reação nuclear do tipo $(n, \gamma)$.

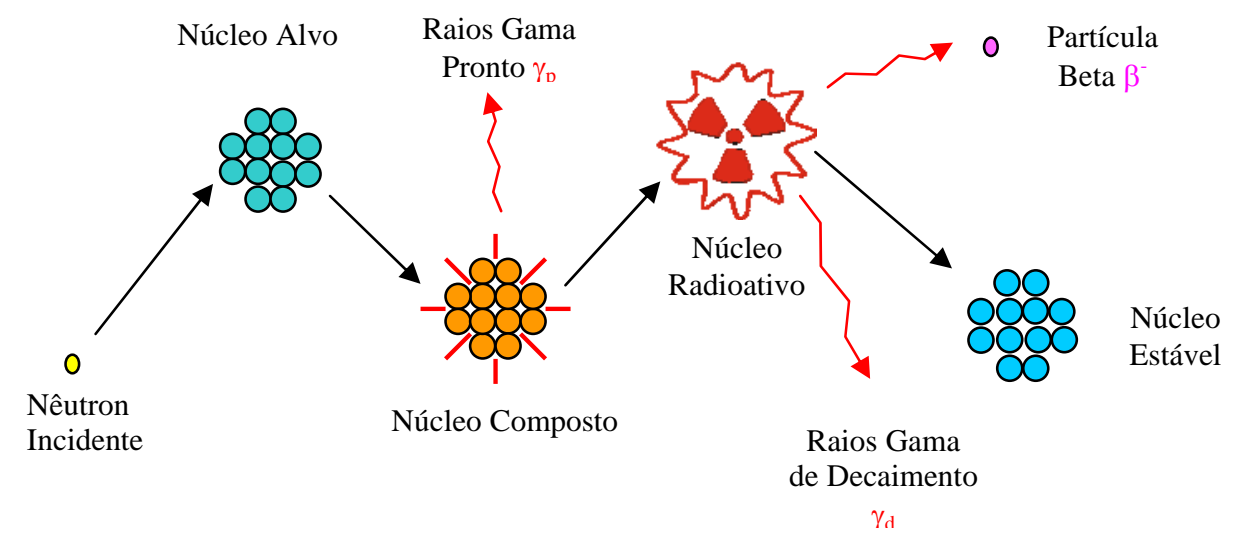

FIGURA 3.2 - Seqüência de eventos do mecanismo da reação nuclear do tipo (n, $\gamma$ ) (IAEA, 1990). 
As energias dos raios gama de decaimento emitidos pelos núcleos radioativos são característicos de cada radioisótopo e, portanto, a análise qualitativa dos elementos presentes em uma amostra pode ser feita através da identificação dos radioisótopos destes elementos, levando em consideração sua meia vida e as energias dos raios gama emitidos.

3.3 Equação fundamental da análise por ativação com nêutrons

A taxa de formação de um núcleo radioativo a partir de um único isótopo, quando exposto a um fluxo de nêutrons é dada por:

$$
\mathrm{dN}^{*} / \mathrm{dt}=\mathrm{N} \phi \sigma
$$

onde $\mathrm{dN}^{*}$ / dt é a taxa de formação de partículas radioativas, $\mathrm{N}$ é o número de átomos estáveis, $\phi$ é o fluxo médio de nêutrons em $\mathrm{cm}^{-2} \mathrm{~s}^{-1}$, e $\sigma$ é a secção de choque para ativação dada em $\mathrm{cm}^{2}$ / núcleo-alvo. A secção de choque é a medida da probabilidade dos átomos interagirem com um nêutron de uma determinada energia.

Uma vez formados, os núcleos radioativos iniciam o processo de decaimento ou desintegração radioativa. A velocidade com que ocorre o decaimento é dada pela seguinte expressão:

$$
-\mathrm{dN}^{*} / \mathrm{dt}=\lambda \mathrm{N}^{*}
$$

onde $\mathrm{N}^{*}$ representa o número de núcleos radioativos de uma espécie particular na amostra em um instante t e $\lambda$ é a constante de decaimento característica de cada radioisótopo.

Rearranjando a equação e integrando em um intervalo entre $t=0$ e $t=t$, obtemos: 


$$
\ln \mathrm{N}^{*} / \mathrm{N}_{0} *=-\lambda \mathrm{t}
$$

A meia-vida ( $\left.\mathrm{t}_{1 / 2}\right)$ de um isótopo radioativo é definida como o tempo necessário para que metade do número de átomos radioativos em uma amostra sofra decaimento, ou seja, que $\mathrm{N}^{*}$ seja igual a $\mathrm{N}_{0} * / 2$.

$$
\mathrm{t}_{1 / 2}=\ln 2 / \lambda \cong 0,693 / \lambda
$$

Durante a irradiação com fluxo uniforme de nêutrons, a taxa de formação de partículas radioativas em função do tempo é dada por:

$$
\mathrm{dN}^{*} / \mathrm{dt}=\mathrm{N} \phi \sigma-\lambda \mathrm{N}^{*}
$$

Integrando também essa equação do instante 0 até o $t_{\mathrm{i}}$, e considerando que não há nuclídeos radioativos no início da irradiação obtém-se:

$$
\mathrm{N}^{*}\left(\mathrm{t}_{\mathrm{i}}\right)=\mathrm{N} \phi \sigma\left(1-e^{-\lambda \mathrm{ti}}\right) / \lambda
$$

onde $t_{i}$ é o tempo de irradiação.

Substituindo a equação (3.5) em (3.7), obtém-se:

$$
\mathrm{N}^{*}\left(\mathrm{t}_{\mathrm{i}}\right)=\mathrm{N} \phi \sigma\left(1-e^{-0,693 \mathrm{ti} / \mathrm{t}^{1 / 2}}\right) / \lambda
$$

A atividade D de um radionuclídeo, dada em termos de desintegrações por segundo, é proporcional ao número de átomos $\mathrm{N}$ presentes:

$$
\mathrm{D}=\lambda \mathrm{N}^{*}
$$


Substituindo (3.8) em (3.9), obtém-se:

$$
\mathrm{D}=\mathrm{N} \phi \sigma\left(1-e^{-0,693 \mathrm{ti} / \mathrm{t}^{1 / 2}}\right)
$$

Medindo uma fração z do número real de desintegrações, ou seja, a atividade observada experimentalmente, obtém-se:

$$
\mathrm{A}=\mathrm{z} \lambda \mathrm{N}=\mathrm{zD}
$$

onde z é o coeficiente de detecção, que depende do instrumento de detecção utilizado, da eficiência do detector utilizado, e do arranjo geométrico tanto da amostra quanto do detector.

Substituindo (3.11) em (3.10), obtém-se a expressão geral:

$$
\mathrm{A}=\mathrm{zN} \phi \sigma\left(1-e^{-0,693 \mathrm{t} \mathrm{i} / \mathrm{t} 1 / 2}\right)
$$

A equação anterior pode ser escrita de forma mais prática se relacionar o número de átomos presentes na amostra, com o número de Avogadro e a massa do elemento a ser determinado:

$$
\mathrm{N}=\left(\mathrm{N}_{\mathrm{A}} \mathrm{w} \theta\right) / \mathrm{M}
$$

onde : $\quad \mathrm{N}_{\mathrm{A}}=$ número de Avogadro $\left(6,23 \times 10^{23}\right)$;

$\mathrm{w}$ = massa do elemento irradiado em gramas;

$\theta$ = abundância isotópica do nuclídeo ativado;

$\mathrm{M}=$ massa atômica do elemento. 
A atividade induzida em um dado elemento $A\left(t_{0}\right)$ após certo tempo de irradiação $t_{i}$ e tempo de decaimento $t=0$ pode então ser obtida da seguinte forma:

$$
\mathrm{A}\left(\mathrm{t}_{0}\right)=\mathrm{wz} \mathrm{N}_{\mathrm{A}} \phi \sigma \theta\left(1-e^{-0,693 \mathrm{ti} / \mathrm{t}^{1 / 2}}\right) / \mathrm{M}
$$

3.3.1 Método comparativo para determinação da concentração elementar

A atividade de um elemento pressente na amostra e no padrão pode ser obtida reescrevendo a equação (3.14). Considerando que amostra e padrão sejam irradiados em condições idênticas (mesmos parâmetros $\theta, \sigma$, z e $\phi$ ) e por mesmo período de tempo $\left(\mathrm{t}_{\mathrm{i}}\right)$, temos:

$$
\begin{aligned}
& \mathrm{A}_{\mathrm{p}}\left(\mathrm{t}_{0}\right)=\mathrm{w}_{\mathrm{p}} \mathrm{z} \mathrm{N}_{\mathrm{A}} \phi \sigma \theta\left(1-e^{-0,693 \mathrm{ti} / \mathrm{t}^{1 / 2}}\right) / \mathrm{M} \\
& \mathrm{A}_{\mathrm{a}}\left(\mathrm{t}_{0}\right)=\mathrm{w}_{\mathrm{a}} \mathrm{z} \mathrm{N}_{\mathrm{A}} \phi \sigma \theta\left(1-e^{-0,693 \mathrm{ti} / \mathrm{t}^{1 / 2}}\right) / \mathrm{M}
\end{aligned}
$$

onde os índices p e a referem-se respectivamente ao padrão e à amostra.

Dividindo a equação (3.15) pela (3.16), tem-se:

$$
\mathrm{A}_{\mathrm{p}}\left(\mathrm{t}_{0}\right) / \mathrm{A}_{\mathrm{a}}\left(\mathrm{t}_{0}\right)=\mathrm{w}_{\mathrm{p}} / \mathrm{w}_{\mathrm{a}}
$$

ou seja,

$$
\mathrm{w}_{\mathrm{a}}=\mathrm{w}_{\mathrm{p}} \mathrm{A}_{\mathrm{a}}\left(\mathrm{t}_{0}\right) / \mathrm{A}_{\mathrm{p}}\left(\mathrm{t}_{0}\right)
$$

Como os tempos de decaimento do elemento no padrão e na amostra são diferentes, faz-se uma correção utilizando-se a equação (3.19) que relaciona a atividade com o tempo de decaimento:

$$
A=A\left(t_{0}\right) e^{-\lambda t}
$$


onde t é o tempo de decaimento.

Substituindo (3.19) em (3.18) obtém-se:

$$
w_{a}=w_{p} A_{a} e^{\lambda(t a-t p)} / A_{p}
$$

onde $\lambda=0,693 / \mathrm{t}_{1 / 2}$ é a constante de decaimento, $\mathrm{A}_{\mathrm{a}}$ é a taxa de contagens da amostra para tempo de decaimento $t_{a}$ e $A_{p}$ é a taxa de contagens do padrão para tempo de decaimento $t_{p}$.

A concentração do elemento na amostra é dada por:

$$
\mathrm{C}_{\mathrm{a}}=\mathrm{w}_{\mathrm{a}} / \mathrm{M}_{\mathrm{a}}
$$

onde $\mathrm{M}_{\mathrm{a}}$ é a massa total da amostra.

Logo, a concentração do elemento na amostra pode ser obtida aplicando-se a seguinte fórmula:

$$
C_{a}=w_{p} A_{a} e^{\lambda(t a-t p)} / A_{p} \cdot M_{a}
$$

3.4 Vantagens e desvantagens do método de análise por ativação

Ao contrário de outras técnicas bastante utilizadas em análises multielementares como ETAAS (espectrometria de absorção atômica eletrotérmica), ICPAES (espectrometria de emissão atômica com plasma acoplado indutivamente), ICP-MS (espectrometria de massas com plasma acoplado indutivamente), entre outras, a análise instrumental de ativação com nêutrons é um método não-destrutivo. Não há necessidade de 
decomposição da amostra, nem tampouco da separação do analito de sua matriz, o que torna a análise simples e rápida.

Outra grande vantagem da INAA é a não necessidade de se analisar o branco, pois não há utilização de reagentes para digestão ou separação de amostras, e não há possibilidade de introdução de contaminantes após a irradiação das mesmas. Além disso, é uma técnica que se destaca pela universalidade (existem aproximadamente 70 elementos detectáveis por INAA), possibilita análises multielementares e requer quantidades reduzidas de amostras. É também uma técnica bastante seletiva, ou seja, permite a identificação de um elemento mesmo em presença de outros que emitam sinais da mesma natureza, e apresenta alta especificidade, ou seja, permite correlacionar, de forma específica, o sinal obtido com o elemento identificado.

Entre as desvantagens da técnica estão a dependência da utilização de um reator nuclear e a necessidade de manipulação de material radioativo nas análises. Alguns elementos de baixo número atômico como H, He, Be, Li, B, C, N e O, e outros de elevado número atômico como $\mathrm{Bi}$, Tl e $\mathrm{Pb}$ apresentam baixa secção de choque para ativação e/ou seus produtos de ativação têm tempos de meia-vida muito curtos, o que impossibilita a análise destes elementos por ativação neutrônica (BODE \& GOEIJ, 1998). Além disso, a análise por ativação não permite a identificação da forma química em que um elemento é encontrado na amostra por se tratar de um método baseado em reações que acontecem no nível do núcleo atômico e não de sua esfera eletrônica. 


\section{PARTE EXPERIMENTAL}

4.1 Obtenção das amostras analisadas

As amostras para o presente trabalho foram fornecidas pelo Instituto de Ciências Biomédicas da Universidade de São Paulo (ICB-USP). Sete amostras eram de folhas de diferentes espécies do gênero Casearia (C. sylvestris, C.decandra e C.obliqua), seis de solos correspondentes aos locais em que essas plantas foram cultivadas e três de extratos das diferentes espécies de plantas analisadas. As amostras foram coletadas em localidades e datas distintas, e assim que recebidas foram codificadas conforme mostram as TAB. 4.1 e 4.2 .

TABELA 4.1 - Relação das amostras de folhas e extratos de Casearia e dados sobre os locais de coleta.

\begin{tabular}{cccc}
\hline $\begin{array}{c}\text { Código das } \\
\text { folhas }\end{array}$ & $\begin{array}{c}\text { Código dos } \\
\text { extratos }\end{array}$ & Espécie da planta & Local da coleta \\
\hline J1 & & C. sylvestris & IQUSP* (cultivada) \\
J2 & E2 & C. obliqua & Reserva Morro Grande (nativa) \\
J3 & E3 & C. decandra & Reserva Morro Grande (nativa) \\
J4 & E4 & C. sylvestris & Reserva Morro Grande (nativa) \\
J5 & & C. sylvestris & Reserva Morro Grande (nativa) \\
J6 & & C. sylvestris & Reserva Morro Grande (cultivada) \\
J7 & & C. obliqua & Reserva Morro Grande (nativa) \\
\hline
\end{tabular}

* Instituto de Química da USP 
Conforme indicado na TAB. 4.1, as amostras de plantas identificadas com os códigos J2, J3, J4, J5 e J7 correspondem às amostras nativas da região, enquanto que as de código J1 e J6 correspondem a amostras cultivadas nestes locais. Além disso, as amostras nativas J2 e J5 desenvolveram-se sob o sol e as amostras J4 e J7 à sombra.

TABELA 4.2 - Relação das amostras de solo e dados sobre os locais de coleta.

\begin{tabular}{cc}
\hline $\begin{array}{c}\text { Código dos } \\
\text { solos }\end{array}$ & \multicolumn{1}{c}{ Local da coleta } \\
\hline K1 & IQUSP * \\
K2 & Reserva Morro Grande \\
K3 & Reserva Morro Grande \\
K4 & Reserva Morro Grande \\
K56 & Reserva Morro Grande \\
K7 & Reserva Morro Grande \\
\hline * Instituto de Química da USP &
\end{tabular}

4.2 Preparação das amostras para as análises

\subsubsection{Preparação das amostras de folhas}

Folhas inteiras e secas das plantas medicinais foram fragmentadas manualmente e lavadas com água deionizada. Estes fragmentos de folhas foram colocados no congelador por aproximadamente 15 horas e em seguida foram secos pelo processo de liofilização por 12 horas à uma pressão de $5 \times 10^{-2} \mathrm{mbar}$, no liofilizador da marca Micro Modulyo.

Após a secagem, a moagem destas folhas foi feita usando um micro moinho vibratório de ágata "Pulverisette 0” da Fritsch GmbH (FIG. 4.1). Cerca de 15 g de cada amostra foram moídas durante 15 minutos, com amplitude de vibração em torno de 1,5, 
obtendo-se amostras na forma de fino pó que foram guardadas em frascos plásticos vedados com parafilme e mantidos em dessecador.

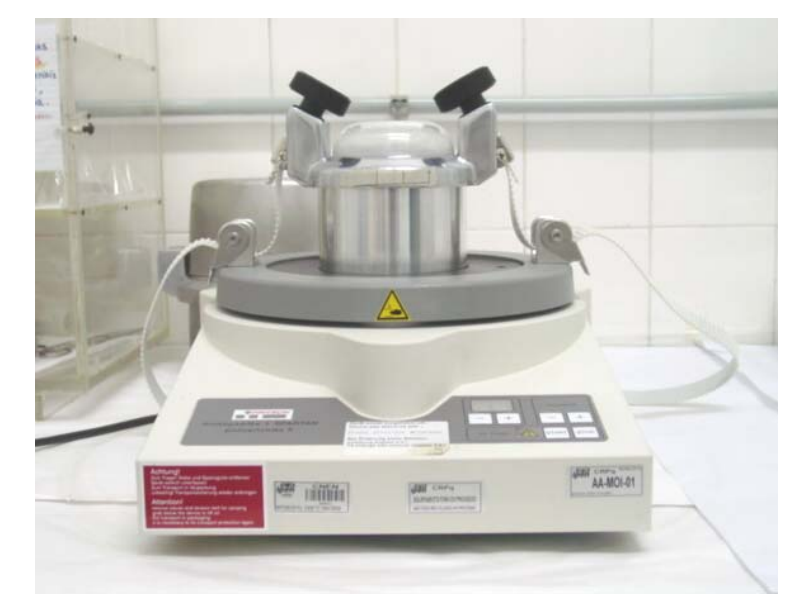

FIGURA 4.1 - Micro moinho vibratório de ágata utilizado na moagem das amostras de folhas.

\subsubsection{Preparação das amostras de extrato}

Os extratos das plantas foram obtidos no Laboratório de Farmacologia e Toxicologia de Produtos Naturais do ICB-USP, segundo o procedimento descrito na FARMACOPÉIA BRASILEIRA (1977). As folhas secas foram maceradas e a extração foi feita pelo método de sonicação, em álcool etílico 75\%, à temperatura ambiente, na proporção de $200 \mathrm{~g}$ de folha para $1000 \mathrm{~mL}$ de solvente. O extrato obtido foi concentrado sob pressão reduzida à temperatura de $50^{\circ} \mathrm{C}$ obtendo-se um líquido viscoso o qual foi submetido à secagem por liofilização antes das análises.

\subsubsection{Preparação das amostras de solo}

Foram retirados manualmente das amostras de solo, os fragmentos de galhos, folhas e raízes. Em seguida, as amostras foram moídas e homogeneizadas em almofariz de ágata e peneiradas, obtendo-se o solo na forma de fino pó. Entre a homogeneização de 
cada amostra de solo, o almofariz e o pistão foram lavados com água purificada Milli-Q, ácido nítrico diluído p.a. diluído e álcool etílico p.a. A tela da peneira utilizada foi de nylon para evitar eventual contaminação das amostras.

Como algumas amostras de solo apresentaram-se úmidas, foram realizadas determinações da percentagem de perda de peso nas secagens e os dados obtidos foram utilizados nos cálculos das concentrações dos elementos em sua base seca. Para este procedimento, cerca de $200 \mathrm{mg}$ de cada amostra de solo foram pesados e secos em estufa de secagem e de esterilização, modelo 515C da FANEM, a uma temperatura de $80^{\circ} \mathrm{C}$. A primeira pesagem foi feita após 4 horas de secagem e uma segunda pesagem após 24 horas de secagem, quando se obteve massa constante de amostra. Os valores das porcentagens de perda de peso obtidos na secagem das amostras de solo estão apresentados na TAB. 4.3.

TABELA 4.3 - Porcentagens de perda de peso na secagem das amostras de solo

\begin{tabular}{cc}
\hline Código das amostras & Perda de peso (\%) \\
\hline K1 & 1,08 \\
K2 & 1,47 \\
K3 & 1,47 \\
K4 & 1,59 \\
K56 & 7,54 \\
K7 & 14,54 \\
\hline
\end{tabular}

\subsection{Preparação dos padrões sintéticos}

Foram utilizadas neste trabalho soluções padrão estoques adquiridas do Spex Certiprep. Volumes adequados das soluções estoque foram diluídos com água MilliQ para obtenção das soluções padrão simples ou mistas. No caso das soluções padrão mistas, os elementos que compõe o padrão foram selecionados pela meia vida de seu radioisótopo e de forma que não ocorresse interferência de fotopicos no espectro de raios gama. Os balões 
volumétricos e pipetadores automáticos, previamente verificados quanto a sua calibração, foram utilizados para preparação das soluções padrão. Estas soluções diluídas foram armazenadas em frascos de polietileno e mantidas na geladeira.

Para preparação dos padrões sintéticos, $50 \mu \mathrm{L}$ de soluções padrão, contendo um ou mais elementos, foram pipetados sobre tiras de papel de filtro Whatman no. 41, de dimensões aproximadas de 6,0 cm x 2,0 cm. Foi utilizado o pipetador automático Sealpette com capacidade para 10-100 $\mu \mathrm{L}$ da marca Jencons, previamente verificado quanto a sua calibração.

As tiras de papel de filtro foram secas em um dessecador à temperatura ambiente por aproximadamente 8 horas. Após a secagem, estas tiras foram dobradas com auxílio de pinças e colocadas em invólucros de polietileno. Estes invólucros haviam sido confeccionados com folhas de polietileno previamente lavadas com solução de ácido nítrico p.a. Merck diluído e água purificada MilliQ. Posteriormente, com auxílio de uma folha de celofane e ferro elétrico para solda, os invólucros de polietileno contendo os padrões sintéticos foram selados.

As massas dos elementos nos padrões sintéticos simples e mistos variaram de 0,08 a $1000 \mu \mathrm{g}$. A TAB. 4.4 apresenta os códigos dos padrões sintéticos e as massas dos elementos presentes. Os padrões codificados como F3, L3, S3, Br2 e Na2 foram utilizados nas análises de folhas e extratos de plantas, por meio da irradiação longa, e Na2, Cl2, M1 e A1 nas irradiações curtas das mesmas amostras.

Na TAB. 4.5 encontram-se os elementos presentes nos padrões sintéticos utilizados nas irradiações longas de amostras de solos e suas respectivas concentrações. CH4, LN4 e U4 desta Tabela são os códigos dos padrões sintéticos. Além destes, o padrão F3 da TAB. 4.4 também foi utilizado nas análises das amostras de solo. 
TABELA 4.4 - Massas dos elementos presentes nos padrão sintéticos utilizados nas análises de folhas e extratos de planta.

\begin{tabular}{|c|c|c|}
\hline Padrão sintético & Elemento & Massa do elemento ( $\mu \mathrm{g})$ \\
\hline \multirow{4}{*}{ A1 } & $\mathrm{Al}$ & 99,81 \\
\hline & $\mathrm{Cu}$ & 1,502 \\
\hline & $\mathrm{Mn}$ & 1,496 \\
\hline & $\mathrm{V}$ & 1,998 \\
\hline Br2 & $\mathrm{Br}$ & 5,0 \\
\hline $\mathrm{Cl} 2$ & $\mathrm{Cl}$ & 200,0 \\
\hline \multirow{4}{*}{ F3 } & $\mathrm{Ca}$ & 1001,2 \\
\hline & $\mathrm{Fe}$ & 350,07 \\
\hline & $\mathrm{Rb}$ & 10,01 \\
\hline & $\mathrm{Zn}$ & 34,965 \\
\hline \multirow{6}{*}{ L3 } & $\mathrm{Cd}$ & 10,02 \\
\hline & Co & 0,150 \\
\hline & Cs & 0,600 \\
\hline & $\mathrm{K}$ & 1002,4 \\
\hline & $\mathrm{La}$ & 0,609 \\
\hline & Sc & 0,075 \\
\hline \multirow{2}{*}{ M1 } & $\mathrm{Mg}$ & 1000,0 \\
\hline & $\mathrm{K}$ & 1012,5 \\
\hline $\mathrm{Na} 2$ & $\mathrm{Na}$ & 100,18 \\
\hline \multirow{6}{*}{ S3 } & As & 1,500 \\
\hline & $\mathrm{Cr}$ & 2,004 \\
\hline & $\mathrm{Cu}$ & 100,12 \\
\hline & Mo & 3,002 \\
\hline & $\mathrm{Sb}$ & 0,599 \\
\hline & Se & 8,032 \\
\hline
\end{tabular}


TABELA 4.5 - Massas dos elementos presentes nos padrão sintéticos utilizados nas análises de solos.

\begin{tabular}{ccc}
\hline \multirow{2}{*}{ Padrão sintético } & Elemento & Massa do elemento (ng) \\
\hline \multirow{3}{*}{ CH4 } & Ce & 3967,0 \\
& Hf & 987,6 \\
& Th & 986,1 \\
\hline \multirow{2}{*}{ LN4 } & Eu & 98,664 \\
& La & 984,2 \\
& Lu & 147,25 \\
& Nd & 2083,4 \\
& Sc & 98,168 \\
& Sm & 492,33 \\
& Tb & 158,16 \\
& Yb & 296,49 \\
\hline U4 & U & 4968,0 \\
\hline
\end{tabular}

4.4 Procedimento para irradiação dos materiais

Aproximadamente $150 \mathrm{mg}$ de amostra de folhas de Casearia foram pesados em envelopes de polietileno previamente lavados com água destilada e ácido nítrico. Foi utilizada a balança analítica da marca Mettler modelo H16, com precisão de 0,05 mg. Os envelopes de polietileno contendo os materiais para análise foram selados com auxílio de ferro elétrico para solda e folha celofane. No caso das amostras de solo e de extrato, a massa utilizada foi de cerca de $100 \mathrm{mg}$.

As irradiações foram efetuadas em duas condições distintas de tempos de irradiação e fluxos de nêutrons, para que um maior número de elementos pudesse ser determinado. 


\subsubsection{Irradiação curta}

Para determinação dos elementos de meia-vida curta, como $\mathrm{Na}, \mathrm{K}, \mathrm{Mn}, \mathrm{Mg}$ e $\mathrm{Cl}$, em folhas e extratos de plantas, as amostras e os padrões foram irradiados durante 5 minutos, sob fluxo de nêutrons térmicos de $5,0 \times 10^{11} \mathrm{n} \mathrm{cm}^{-2} \mathrm{~s}^{-1}$, na estação pneumática do Reator de Pesquisa IEA-R1 do IPEN-CNEN/São Paulo.

Antes da irradiação, amostras e padrões foram colocados juntos em um único envelope de polietileno com dimensões aproximadas de $2,5 \mathrm{~cm} \mathrm{x} \mathrm{4,0} \mathrm{cm.} \mathrm{Este} \mathrm{envelope,}$ por sua vez, foi acondicionado em um dispositivo próprio para irradiação na estação pneumática denominado “coelho”. A FIG.4.2 (a) mostra o coelho de polietileno utilizado nas irradiações curtas.

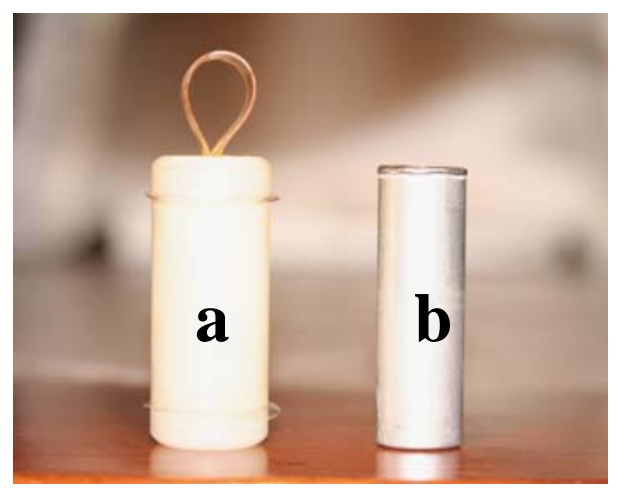

FIGURA 4.2 - Dispositivo utilizados para irradiação de material no reator nuclear. (a) “coelho" de polietileno utilizado nas irradiações curtas; (b) "coelho" de alumínio utilizado nas irradiações longas (Escala 1:2)

Após a irradiação as amostras e os padrões foram fixados em suportes de aço inoxidável para que fossem feitas as medidas de atividade gama no detector. Foi utilizado um detector de Ge hiperpuro (HPGe), modelo GX2020 da Canberra, acoplado a um processador integrado de sinais modelo 1510 e placa analisadora Multicanal Sistema 100. A FIG. 4.3 mostra a foto do equipamento utilizado nas análises. 


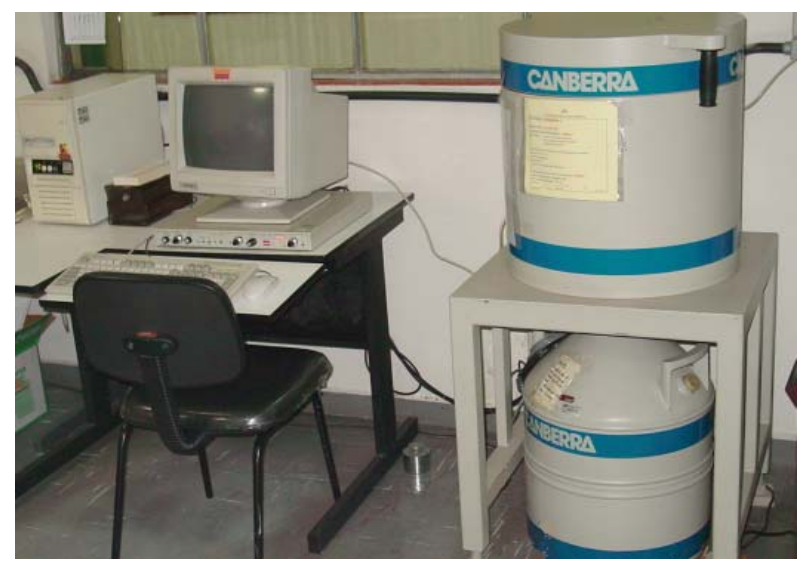

FIGURA 4.3 - Espectrômetro de raios gama de alta resolução Canberra utilizado nas análises.

A resolução do sistema utilizado foi de $1,0 \mathrm{keV}$ para o pico $122 \mathrm{keV}$ do ${ }^{57} \mathrm{Co}$ e de $1,8 \mathrm{keV}$ para o pico de $1332 \mathrm{keV}$ do ${ }^{60} \mathrm{Co}$. Diariamente foi realizado o teste de verificação do sistema de contagem para avaliar o seu funcionamento com relação à reprodutibilidade das medidas de taxas de contagens, resolução e energia dos raios gama.

Foram realizadas duas séries de medidas de atividade gama das amostras e dos padrões em diferentes tempos de decaimento, reduzindo desta forma, eventuais problemas de interferência de fotopicos. Na primeira série de medidas os padrões e as amostras foram contados durante 300 segundos. Na segunda série, os padrões foram contados por 300 segundos e as amostras por 600 segundos. Um cronômetro foi utilizado para marcar o início e o término de cada contagem para que nos cálculos de concentração efetuados posteriormente, o tempo de decaimento pudesse ser corrigido.

O programa utilizado para aquisição dos espectros foi o S100 da Canberra. Os espectros gama obtidos foram gravados em disquetes e processados usando o programa VERSAO2 que fornece as taxas de contagens e as energias dos raios gama. Os radioisótopos formados foram identificados por meio da meia-vida e da energia dos raios gama de decaimento, utilizando as informações nucleares de cada radioisótopo (IAEA, 1990). A TAB. 4.6 apresenta os radioisótopos utilizados e seus valores de meia-vida e energia dos raios gama característicos. 
TABELA 4.6 - Características nucleares dos radioisótopos utilizados neste trabalho (IAEA, 1990).

\begin{tabular}{|c|c|c|c|}
\hline Elemento & Radioisótopo & Meia-Vida & $\begin{array}{l}\text { Energia Gama } \\
\quad(\mathrm{keV})\end{array}$ \\
\hline As & ${ }^{76}$ As & 26,32 horas & 559,10 \\
\hline $\mathrm{Br}$ & ${ }^{82} \mathrm{Br}$ & 35,3 horas & 776,52 \\
\hline \multirow{2}{*}{$\mathrm{Ca}$} & ${ }^{47} \mathrm{Ca}$ & 4,54 dias & 1297,09 \\
\hline & ${ }^{47}$ Sc & 3,35 dias & 159,38 \\
\hline $\mathrm{Ce}$ & ${ }^{141} \mathrm{Ce}$ & 32,5 dias & 145,44 \\
\hline $\mathrm{Cl}$ & ${ }^{38} \mathrm{Cl}$ & 37,24 minutos & 1642,69 \\
\hline Co & ${ }^{60} \mathrm{Co}$ & 5,27 anos & 1173,$24 ; 1332,50$ \\
\hline $\mathrm{Cr}$ & ${ }^{51} \mathrm{Cr}$ & 27,7 dias & 320,08 \\
\hline Cs & ${ }^{134} \mathrm{Cs}$ & 2,06 anos & 795,85 \\
\hline $\mathrm{Eu}$ & ${ }^{152} \mathrm{Eu}$ & 13,33 anos & 1408,00 \\
\hline $\mathrm{Fe}$ & ${ }^{59} \mathrm{Fe}$ & 44,5 dias & 1099,$25 ; 1291,60$ \\
\hline Hf & ${ }^{181} \mathrm{Hf}$ & 42,39 dias & 482,18 \\
\hline $\mathrm{K}$ & ${ }^{42} \mathrm{~K}$ & 12,36 horas & 1524,58 \\
\hline $\mathrm{La}$ & ${ }^{140} \mathrm{La}$ & 40,27 horas & 1596,21 \\
\hline $\mathrm{Lu}$ & ${ }^{177} \mathrm{Lu}$ & 6,71 dias & 208,36 \\
\hline $\mathrm{Mg}$ & ${ }^{27} \mathrm{Mg}$ & 9,46 minutos & 843,$76 ; 1014,43$ \\
\hline $\mathrm{Mn}$ & ${ }^{56} \mathrm{Mn}$ & 2,58 horas & 846,$76 ; 1810,72$ \\
\hline $\mathrm{Na}$ & ${ }^{24} \mathrm{Na}$ & 14,96 horas & 1368,60 \\
\hline $\mathrm{Nd}$ & ${ }^{147} \mathrm{Nd}$ & 10,98 dias & 531,01 \\
\hline $\mathrm{Rb}$ & ${ }^{86} \mathrm{Rb}$ & 18,66 dias & 898,07 \\
\hline $\mathrm{Sb}$ & ${ }^{122} \mathrm{Sb}$ & 2,70 dias & 564,24 \\
\hline Sc & ${ }^{46} \mathrm{Sc}$ & 86,83 dias & 889,28 \\
\hline Se & ${ }^{75} \mathrm{Se}$ & 119,77 dias & 264,66 \\
\hline $\mathrm{Sm}$ & ${ }^{153} \mathrm{Sm}$ & 46,27 horas & 103,18 \\
\hline $\mathrm{Tb}$ & ${ }^{160} \mathrm{~Tb}$ & 72,3 dias & 879,38 \\
\hline Th & ${ }^{233} \mathrm{~Pa}$ & 27,0 dias & 312,01 \\
\hline $\mathrm{U}$ & ${ }^{239} \mathrm{~Np}$ & 2,36 dias & 277,60 \\
\hline & ${ }^{169} \mathrm{Yb}$ & 32,02 dias & 177,21 \\
\hline $\mathrm{Yb}$ & ${ }^{175} \mathrm{Yb}$ & 4,19 dias & 396,33 \\
\hline $\mathrm{Zn}$ & ${ }^{65} \mathrm{Zn}$ & 243,9 dias & 1115,55 \\
\hline
\end{tabular}


Para determinar as concentrações dos elementos identificados nos espectros utilizou-se o programa PAKI que faz uso da relação (3.22) do método comparativo de análise para efetuar os cálculos.

\subsubsection{Irradiação longa}

Fluxos de nêutrons térmicos da ordem de $10^{12} \mathrm{n} \mathrm{s}^{-1} \mathrm{~cm}^{-2}$ do reator nuclear de pesquisa IEA-R1 foram utilizados na irradiação de amostras de folhas e extratos de plantas durante 16 horas. Neste caso, foram determinados os elementos de meia vida longa As, $\mathrm{Br}$, Ca, Co, Cr, Cs, Fe, La, Rb, Sb, Sc, Se e Zn.

As amostras de solo foram irradiadas sob um fluxo da ordem de $10^{12} \mathrm{n} \mathrm{s}^{-1} \mathrm{~cm}^{-2}$ durante 8 horas. Nestas amostras, os elementos Ca, Ce, Eu, Fe, Hf, La, Lu, Nd, Rb, Sc, Sm, Tb, Th, U e Zn foram determinados.

Para as irradiações longas, as amostra e os padrões foram envoltos individualmente em folhas de alumínio e só então acondicionados em dispositivos de alumínio, chamados de “coelho”, próprios para irradiações no núcleo do reator. A FIG. 4.2 (b) apresenta a foto do coelho de alumínio utilizado nas irradiações longas. Após adequados tempos de decaimento, foi realizada a abertura do coelho, as folhas de alumínio foram removidas e as amostras e os padrões, assim como no procedimento da irradiação curta, foram fixados em suportes de aço inoxidável para posterior detecção de suas atividades gama.

As medidas das atividades gama foram realizadas em 3 tempos de decaimento diferentes a fim de evitar problemas de interferência de fotopicos. As amostras folhas e extratos de planta foram medidas após cerca de 4, 11 e 20 dias de decaimento. No caso das amostras de solo as contagens foram realizadas após aproximadamente 7, 14 e 21 dias de 
decaimento. Os padrões foram contados durante 5400 segundos e as amostras de 20000 a 50000 segundos.

Os radioisótopos formados foram identificados por meio de sua meia-vida e sua energia gama de decaimento. As informações nucleares dos elementos determinados nas análises foram apresentados anteriormente na TAB. 4.6.

4.5 Procedimento para medida de $\mathrm{pH}$ das amostras de solo

Para realização das medidas de $\mathrm{pH}$, a amostra de solo na forma de fino pó e água purificada Milli-Q foram adicionados na proporção de 1 : 2,5 (RAIJ et al., 1987) em tubos tronco-cônicos graduados de plástico. Estes tubos foram submetidos à agitação manual vigorosa e deixados em repouso durante uma hora para decantação da suspensão. Soluções tampão de pH 7,0 e 4,0 foram utilizadas na calibração do peagômetro digital da marca Hellige, modelo 7-60. A leitura dos valores de $\mathrm{pH}$ das amostras de solo foi feita no sobrenadante, sem agitação. Entre cada leitura de pH o eletrodo foi lavado com água MilliQ e levemente enxugado com papel toalha de textura fina (RAIJ et al., 1987).

\subsection{Análise dos materiais de referência certificados}

Para avaliar a precisão e exatidão da metodologia aplicada nas análises de plantas foram utilizados os materiais de referência certificados Tomato leaves (NIST, 1993), Apple leaves (NIST, 1995), certificados pela National Institute of Standards and Technology (NIST) dos USA, e Tea Leaves (INCT-TL-1) certificado pelo Institute of Nuclear Chemistry and Technology (INCT) da Polônia. Para validação da metodologia aplicada nas análises dos solos foram analisados os materiais de referência certificados Soil 
7 da International Atomic Energy Agency (IAEA-Soil-7, 2000) e W1 da United States Geological Survey (GLADNEY et al., 1983).

Seguindo o mesmo procedimento adotado na determinação do teor de umidade das amostras de solo (item 4.2.2), subamostras de cerca de $150 \mathrm{mg}$ dos materiais de referência foram pesadas e secas em estufa até que atingissem peso constante. Os valores obtidos nas secagens estão apresentados na TAB. 4.7 e foram utilizados nos cálculos das concentrações elementares destes materiais de referência em sua base seca, conforme recomendado em seus respectivos certificados de análise.

TABELA 4.7 - Porcentagens de perda de peso na secagem das amostras de solo

\begin{tabular}{cc}
\hline Materiais de referência certificados & $\begin{array}{c}\text { Perda de peso } \\
(\%)\end{array}$ \\
\hline Apple Leaves & 3,70 \\
Tomato Leaves & 5,05 \\
Tea Leaves & 4,63 \\
Soil 7 & 0,66 \\
W1 & 0,33 \\
\hline
\end{tabular}

Aproximadamente 150 mg de material de referência certificado foram pesados e analisados nas mesmas condições a que foram submetidas as amostras de folhas, extratos e solos. Amostras e materiais de referência foram irradiados juntos, durante o decorrer das análises, assegurando a qualidade dos resultados obtidos ao longo de todo o trabalho.

\subsection{Cálculos dos limites de detecção e determinação}

Para avaliar a sensibilidade da metodologia utilizada neste trabalho, foram calculados os valores de limite de detecção e de determinação dos elementos analisados nas plantas e nos solos. 
O limite de detecção de um elemento $\left(\mathrm{L}_{\mathrm{D}}\right)$ é a menor concentração que permite sua detecção qualitativa com nível de confiança razoável para um dado procedimento analítico. O limite de determinação $\left(\mathrm{L}_{\mathrm{Q}}\right)$ é a concentração que permite a determinação quantitativa de um elemento com precisão satisfatória. Para a International Union of Applied Chemistry (IUPAC) as capacidades de detecção e quantificação são características que fornecem informações fundamentais a respeito da performance do procedimento analítico adotado (CURRIE, 1968 e 1999).

Estes limites para os elementos presentes nas plantas foram calculados aplicando-se as equações (4.1) e (4.2) (CURRIE, 1968):

$$
\begin{gathered}
\mathrm{L}_{\mathrm{D}}=2,71+4,65 \mu \mathrm{B}^{1 / 2} \\
\mathrm{~L}_{\mathrm{Q}}=50\left\{1+[1+\mu \mathrm{B} / 12,5]^{1 / 2}\right\}
\end{gathered}
$$

onde $\mu \mathrm{B}$ refere-se ao branco analítico, que em observações de radioatividade corresponde à radiação de fundo. Uma vez obtidos os valores de $L_{D}$ e $L_{Q}$ em termos de contagens calcularam-se as taxas de contagens. Os valores dos limites em termos de concentração foram calculados utilizando-se a relação 3.22 .

\subsection{Tratamento estatístico dos resultados}

4.8.1 Análise hierárquica de agrupamentos

A análise de agrupamento hierárquico é uma técnica estatística multivariada que identifica grupos de amostras com o objetivo de enfatizar suas semelhanças e padrões naturais. Os pontos correspondentes às amostras são localizados no espaço n-dimensional 
e, a cada passo, os pares de pontos mais próximos são reunidos em um agrupamento até que haja a formação de um único grupo.

Existem várias maneiras de se calcular distâncias entre dois pontos no espaço, sendo a mais usual delas, e a utilizada neste trabalho, a distância euclidiana quadrática $\left(\mathrm{x}_{\mathrm{ab}}{ }^{2}\right)$, dada por:

$$
x_{a b}^{2}=\sum_{j=1}^{n}\left(d_{a j}-d_{b j}\right)^{2}
$$

A partir do cálculo das distâncias, são obtidos os índices de similaridade, $\mathrm{S}_{\mathrm{ij}}$, segundo a seguinte expressão:

$$
S_{i j}=1-\frac{d_{i j}}{d_{\max }}
$$

onde $\mathrm{d}_{\mathrm{ij}}$ é a distância entre os pontos i e j e $\mathrm{d}_{\text {máx }}$ é a distância máxima entre qualquer par de pontos. A representação da análise hierárquica de agrupamentos é feita por meio de dendrogramas, que reúnem amostras e variáveis em função da semelhança de suas propriedades. No eixo vertical dos dendrogramas são apresentadas as amostras ou as variáveis e no eixo horizontal, os índices de similaridade. (MOITA NETO \& MOITA, 1998).

Para obtenção do dendrograma neste trabalho, foi utilizada a versão 6.0 do programa STATISTICA. 


\section{RESULTADOS E DISCUSSÃO}

No presente capítulo estão apresentados e discutidos os resultados obtidos nos materiais certificados de referência, seguidos dos resultados das análises de folhas, extratos medicinais e de solos. São apresentados também os limites de detecção e determinação obtidos para uma amostra de folha e de solo.

\subsection{Resultados das análises dos materiais de referência certificados}

Os materiais de referência certificados foram analisados para o controle da qualidade dos resultados analíticos com relação à precisão e exatidão. Nas TAB. 5.1 a 5.3 estão os resultados das análises dos materiais de referência certificados NIST-1515 Apple Leaves, NIST-1573a Tomato Leaves e INCT-TL-1 Tea Leaves, respectivamente. As médias aritméticas dos resultados dos elementos com seus respectivos desvios padrão relativos e erros relativos, bem como os valores de seus certificados, são apresentados nestas tabelas. Os resultados individuais das concentrações de elementos das análises de três materiais de referência encontram-se no Apêndice 1.

No caso do material de referência INCT-TL-1 Tea Leaves, este foi analisado para avaliar principalmente a exatidão e a precisão dos resultados das determinações de Br, Cs, La e Sc, uma vez que nos materiais Apple Leaves e Tomato Leaves estes elementos não possuem valores certificados, ou seja, apresentam apenas valores informativos.

Analisando os resultados das TAB. 5.1 a 5.3 verifica-se que as porcentagens de erro relativo dos resultados foram inferiores a 15\% para a maioria dos elementos nos três 
materiais de referência, o que confirma a exatidão dos resultados obtidos pelo procedimento analítico empregado nas análises de plantas. A única exceção foi o elemento Se no material Tomato Leaves (TAB. 5.2)

TABELA 5.1 - Médias das concentrações de elementos obtidas no material de referência NIST-1515 Apple Leaves, em $\mu \mathrm{g} \mathrm{g}^{-1}$ (a menos que esteja indicado)

\begin{tabular}{lccccc}
\hline \multirow{2}{*}{ Elemento } & \multicolumn{4}{c}{ Este trabalho } & Valor do certificado \\
\cline { 2 - 4 } & $\mathrm{n}$ & $\mathrm{X} \pm \mathrm{DP}$ & $\mathrm{DPR}(\%)$ & $\operatorname{Er}(\%)$ & $($ NIST, 1993) \\
\hline $\mathrm{As}$ & 4 & $0,036 \pm 0,006$ & 16,6 & 5,2 & $0,038 \pm 0,007$ \\
$\mathrm{Br}$ & 4 & $2,13 \pm 0,01$ & 0,5 & - & $(1,8) *$ \\
$\mathrm{Ca}(\%)$ & 4 & $1,548 \pm 0,039$ & 2,5 & 2,4 & $1,526 \pm 0,015$ \\
$\mathrm{Cl}$ & 4 & $495 \pm 25$ & 5,1 & 14,5 & $579 \pm 23$ \\
$\mathrm{Co}$ & 5 & $0,107 \pm 0,003$ & 2,8 & - & $(0,09)$ \\
$\mathrm{Cr}$ & 5 & $0,85 \pm 0,02$ & 2,4 & - & $(0,3)$ \\
$\mathrm{Fe}$ & 4 & $81,7 \pm 1,7$ & 2,1 & 1,2 & $83 \pm 5$ \\
$\mathrm{~K}(\%)$ & 4 & $1,62 \pm 0,01$ & 0,6 & 0,6 & $1,61 \pm 0,02$ \\
$\mathrm{La}$ & 5 & $20,2 \pm 0,1$ & 0,5 & - & $(20)$ \\
$\mathrm{Mg}(\%)$ & 3 & $0,246 \pm 0,027$ & 11 & 9,2 & $0,271 \pm 0,008$ \\
$\mathrm{Mn}$ & 3 & $50,0 \pm 1,1$ & 2,2 & 7,4 & $54 \pm 3$ \\
$\mathrm{Rb}$ & 4 & $9,8 \pm 0,2$ & 2,0 & 3,9 & $10,2 \pm 1,5$ \\
$\mathrm{Sb}$ & 4 & $0,017 \pm 0,003$ & 17,6 & - & $(0,014)$ \\
$\mathrm{Sc}$ & 5 & $0,031 \pm 0,003$ & 1,0 & - & $(0,03)$ \\
$\mathrm{Se}$ & 3 & $0,055 \pm 0,014$ & 25,4 & 10 & $0,050 \pm 0,009$ \\
$\mathrm{Zn}$ & 3 & $12,7 \pm 0,2$ & 1,6 & 1,6 & $12,5 \pm 0,3$ \\
\hline
\end{tabular}

$\mathrm{n}$ = número de determinações; $\mathrm{X}$ = valor médio; $\mathrm{DP}$ = desvio padrão; DPR = desvio padrão relativo; $\mathrm{Er}=$ erro relativo percentual; * valores informativos são apresentados entre parênteses.

Com relação à precisão dos resultados pode-se verificar que com exceção os elementos As e Sb no material Apple Leaves e de Se nos três materiais de referência analisados (TAB. 5.1 a 5.3) os resultados foram obtidos com uma boa precisão, tendo os desvios padrão relativos sido inferiores a 15\%. 
TABELA 5.2 - Médias das concentrações de elementos obtidas no material de referência NIST-1573a Tomato Leaves, em $\mu \mathrm{g} \mathrm{g}^{-1}$ (a menos que esteja indicado)

\begin{tabular}{lccccc}
\hline \multirow{2}{*}{ Elemento } & \multicolumn{4}{c}{ Este trabalho } & Valor do certificado \\
\cline { 2 - 4 } & $\mathrm{n}$ & $\mathrm{X} \pm \mathrm{DP}$ & $\mathrm{DPR}(\%)$ & $\operatorname{Er}(\%)$ & $(1300) *$ \\
\hline $\mathrm{Br}$ & 3 & $1089 \pm 2$ & 0,2 & - & $5,05 \pm 0,09$ \\
$\mathrm{Ca}(\%)$ & 4 & $5,08 \pm 0,18$ & 3,5 & 0,6 & $(6600)$ \\
$\mathrm{Cl}\left(\mathrm{mg} \mathrm{g}^{-1}\right)$ & 4 & $5850 \pm 210$ & 3,6 & - & $0,57 \pm 0,02$ \\
$\mathrm{Co}$ & 3 & $0,60 \pm 0,01$ & 1,7 & 5,3 & $1,99 \pm 0,06$ \\
$\mathrm{Cr}$ & 4 & $2,03 \pm 0,03$ & 1,5 & 2,0 & $(0,053)$ \\
$\mathrm{Cs}$ & 4 & $0,054 \pm 0,003$ & 5,5 & - & $368 \pm 7$ \\
$\mathrm{Fe}$ & 4 & $358 \pm 8$ & 2,2 & 2,7 & $2,70 \pm 0,05$ \\
$\mathrm{~K}(\%)$ & 5 & $2,66 \pm 0,21$ & 7,9 & 1,5 & $(2,3)$ \\
$\mathrm{La}$ & 4 & $2,16 \pm 0,02$ & 1,0 & - & $(1,2)$ \\
$\mathrm{Mg}(\%)$ & 4 & $1,15 \pm 0,06$ & 5,2 & - & $246 \pm 8$ \\
$\mathrm{Mn}$ & 4 & $229 \pm 5$ & 2,2 & 4,1 & $136 \pm 4$ \\
$\mathrm{Na}$ & 5 & $141 \pm 12$ & 8,5 & 3,7 & $14,89 \pm 0,27$ \\
$\mathrm{Rb}$ & 4 & $14,5 \pm 0,3$ & 2,1 & 2,6 & $0,063 \pm 0,06$ \\
$\mathrm{Sb}$ & 2 & $0,072 \pm 0,011$ & 15 & 14 & $(0,1)$ \\
$\mathrm{Sc}$ & 4 & $0,104 \pm 0,001$ & 1,0 & - & $0,054 \pm 0,003$ \\
$\mathrm{Se}$ & 2 & $0,093 \pm 0,018$ & 19,4 & 72 & $30,9 \pm 0,7$ \\
$\mathrm{Zn}$ & 4 & $30,5 \pm 0,5$ & 1,6 & 1,3 & \\
\hline
\end{tabular}

$\mathrm{n}$ = número de determinações; $\mathrm{X}$ = valor médio; $\mathrm{DP}$ = desvio padrão; $\mathrm{DPR}=$ desvio padrão relativo; $\mathrm{Er}=$ erro relativo; * valores informativos são apresentados entre parênteses.

A falta de reprodutibilidade e/ou exatidão dos resultados obtidos para As, Sb e Se pode ser atribuída às baixas concentrações desses elementos nas amostras. Os três elementos foram encontrados em concentrações da ordem de $\mathrm{ng} \mathrm{g}^{-1}$, o que pode tornar sua distribuição não homogênea na matriz, dificultando a quantificação destes elementos. 
TABELA 5.3 - Média das concentrações de elementos obtidas no material de referência INCT-TL-1 Tea Leaves, em $\mu \mathrm{g} \mathrm{g}^{-1}$ (a menos que esteja indicado)

\begin{tabular}{lccccc}
\hline \multirow{2}{*}{ Elemento } & \multicolumn{4}{c}{ Este trabalho } & Valor do certificado \\
\cline { 2 - 4 } & $\mathrm{n}$ & $\mathrm{X} \pm \mathrm{DP}$ & $\mathrm{DPR}(\%)$ & $\mathrm{Er}(\%)$ & (INCT-TL-1, 2002) \\
\hline As $\left(\mathrm{ng} \mathrm{g}^{-1}\right)$ & 1 & $99,4 \pm 9,5^{*}$ & - & 6,2 & $106 \pm 21$ \\
$\mathrm{Br}$ & 2 & $12,8 \pm 0,1$ & 0,8 & 4,1 & $12,3 \pm 1,0$ \\
$\mathrm{Ca}(\%)$ & 2 & $0,55 \pm 0,01$ & 1,8 & 5,5 & $0,582 \pm 0,052$ \\
$\mathrm{Co}\left(\mathrm{ng} \mathrm{g}^{-1}\right)$ & 2 & $401 \pm 7$ & 1,7 & 3,6 & $387 \pm 42$ \\
$\mathrm{Cr}$ & 2 & $1,90 \pm 0,03$ & 1,6 & 0,5 & $1,91 \pm 0,22$ \\
$\mathrm{Cs}$ & 2 & $3,89 \pm 0,04$ & 1,0 & 7,8 & $3,61 \pm 0,37$ \\
$\mathrm{Fe}$ & 2 & $508 \pm 5$ & 1,0 & - & $(432)$ \\
$\mathrm{K}(\%)$ & 3 & $1,73 \pm 0,01$ & 0,6 & 1,8 & $1,70 \pm 0,12$ \\
$\mathrm{La}$ & 2 & $0,96 \pm 0,01$ & 1,0 & 4,0 & $1,00 \pm 0,07$ \\
$\mathrm{Na}$ & 2 & $22,8 \pm 0,2$ & 0,9 & 7,7 & $24,7 \pm 3,2$ \\
$\mathrm{Rb}$ & 2 & $79,8 \pm 0,9$ & 1,1 & 2,1 & $81,5 \pm 6,5$ \\
$\mathrm{Sb}\left(\mathrm{ng} \mathrm{g}{ }^{-1}\right)$ & 2 & $77,8 \pm 2,7$ & 3,5 & - & $(50)$ \\
$\mathrm{Sc}$ & 2 & $263 \pm 2$ & 0,8 & 1,1 & $266 \pm 24$ \\
$\mathrm{Se}$ & 2 & $0,069 \pm 0,013$ & 18,8 & - & $(0,076)$ \\
$\mathrm{Zn}$ & 2 & $35,4 \pm 0,4$ & 1,1 & 2,0 & $34,7 \pm 2,7$ \\
\hline
\end{tabular}

$\mathrm{n}$ = número de determinações; $\mathrm{X}$ = valor médio; $\mathrm{DP}$ = desvio padrão; $\mathrm{DPR}$ = desvio padrão relativo;

$\mathrm{Er}=$ erro relativo; * incerteza calculada considerando erros nas medições das taxas de contagens da amostra e padrão; ** valores informativos são apresentados entre parênteses.

A qualidade dos resultados com relação à exatidão e a precisão obtidos nas análises de solos foi garantida pela análise dos materiais geológicos de referência certificados Soil-7, da International Atomic Energy Agency (IAEA, 2000), e rocha W1 da United States Geological Survey (GLADNEY et al., 1983). Nas TAB. 5.4 e 5.5 encontramse as médias das concentrações dos elementos obtidas nas análises destes materiais de referência. Os resultados individuais destas análises estão apresentados no Apêndice 1.

Com exceção dos resultados obtidos para Nd e U no material USGS W1, ambos os materiais de referência geológicos apresentaram resultados com desvios padrão relativos inferiores a 9,2\% para os elementos determinados, atestando a precisão dos resultados obtidos nas análises de solo (TAB. 5.4 e 5.5). As porcentagens de erros relativos 
obtidas em ambos os materiais de referência foram inferiores a 15\%, exceto nos casos dos elementos Zn e U no material W1, o que indica boa exatidão dos resultados obtidos nas análises destes elementos.

TABELA 5.4 - Médias das concentrações de elementos no material de referência IAEA Soil-7, dadas em $\mu_{\mathrm{g} \mathrm{g}^{-1}}$ (a menos que esteja indicado).

\begin{tabular}{|c|c|c|c|c|c|}
\hline \multirow{2}{*}{ Elemento } & \multicolumn{4}{|c|}{ Este trabalho } & \multirow{2}{*}{$\begin{array}{l}\text { Valor do Certificado } \\
\text { (IAEA, 2000) }\end{array}$} \\
\hline & $\mathrm{N}$ & $\mathrm{X} \pm \mathrm{DP}$ & DPR (\%) & $\operatorname{Er}(\%)$ & \\
\hline Ca (\%) & 4 & $17,1 \pm 0,6$ & 3,5 & - & $16,3(15,7-17,4)^{*}$ \\
\hline $\mathrm{Ce}$ & 4 & $63,4 \pm 0,5$ & 0,8 & 3,9 & $61(50-63)$ \\
\hline $\mathrm{Eu}$ & 4 & $1,00 \pm 0,03$ & 3,0 & 0,0 & $1,0(0,9-1,3)$ \\
\hline $\mathrm{Fe}(\%)$ & 4 & $2,52 \pm 0,04$ & 1,6 & - & $2,57(2,52-2,63)^{*}$ \\
\hline $\mathrm{Hf}$ & 4 & $5,00 \pm 0,05$ & 1,0 & 2,0 & $5,1(4,8-5,5)$ \\
\hline $\mathrm{La}$ & 4 & $26,3 \pm 0,4$ & 1,5 & 6,1 & $28(27-29)$ \\
\hline $\mathrm{Lu}$ & 4 & $0,35 \pm 0,01$ & 2,9 & - & $0,3(0,1-0,4)^{*}$ \\
\hline $\mathrm{Nd}$ & 4 & $28,3 \pm 2,6$ & 9,2 & 5,7 & $30(22-34)$ \\
\hline $\mathrm{Rb}$ & 4 & $49,7 \pm 1,4$ & 2,8 & 2,5 & $51(47-56)$ \\
\hline Sc & 4 & $8,43 \pm 0,07$ & 0,8 & 1,6 & $8,3(6,9-9,0)$ \\
\hline $\mathrm{Sm}$ & 4 & $4,85 \pm 0,02$ & 0,4 & 4,9 & $5,1(4,8-5,5)$ \\
\hline $\mathrm{Tb}$ & 4 & $0,64 \pm 0,04$ & 6,2 & 6,6 & $0,6(0,5-0,9)$ \\
\hline Th & 4 & $8,09 \pm 0,33$ & 4,1 & 1,3 & $8,2(6,5-8,7)$ \\
\hline $\mathrm{U}$ & 4 & $2,13 \pm 0,09$ & 4,2 & 18 & $2,6(2,2-3,3)$ \\
\hline $\mathrm{Yb}$ & 4 & $2,18 \pm 0,04$ & 1,8 & 9,2 & $2,4(1,9-2,6)$ \\
\hline $\mathrm{Zn}$ & 4 & $104 \pm 2$ & 1,9 & 0,3 & $104(101-113)$ \\
\hline
\end{tabular}

$\mathrm{n}$ = número de determinações; $\mathrm{X}=$ valor médio; $\mathrm{DP}=$ desvio padrão; DPR = desvio padrão relativo; $\mathrm{Er}=$ erro relativo; $*$ indicam valores informativos.

O desvio padrão relativo obtido na determinação do elemento $\mathrm{Nd}$ foi de $19 \%$ no material W1 (TAB. 5.5) e de 9,2\% no Soil-7 (TAB. 5.4). A baixa reprodutibilidade dos resultados para $\mathrm{Nd}$ se deve às baixas taxas de contagens obtidas para os fotopicos de ${ }^{147} \mathrm{Nd}$ devido a baixa secção de choque do isótopo alvo para nêutrons térmicos, de 1,45 barns, considerando a velocidade média dos nêutrons de $2200 \mathrm{~m} \mathrm{~s}^{-1}$ (IAEA, 1990). Além disso, devido às interferências na região de baixa energia do espectro de raios gama o pico de 
91,1 keV, o de maior intensidade emitido pelo radioisótopo ${ }^{147} \mathrm{Nd}$, não pôde ser utilizado nos cálculos de concentração deste elemento. O fotopico utilizado nos cálculos foi o de $531 \mathrm{keV}$, que por apresentar baixas taxas de contagens contribuiu para a baixa reprodutibilidade dos resultados obtidos para o elemento $\mathrm{Nd}$.

TABELA 5.5 - Médias das concentrações de elementos no material de referência USGS $\mathrm{W} 1$, dadas em $\mu \mathrm{g} \mathrm{g}^{-1}$ (a menos que esteja indicado).

\begin{tabular}{lccccc}
\hline \multirow{2}{*}{ Elemento } & \multicolumn{4}{c}{ Este trabalho } & $\begin{array}{c}\text { Valor de consenso } \\
\text { (Gladney et al., 1983) }\end{array}$ \\
\cline { 2 - 4 } & $\mathrm{n}$ & $\mathrm{X} \pm \mathrm{DP}$ & $\mathrm{DPR}(\%)$ & $\operatorname{Er}(\%)$ & $7,82 \pm 0,12$ \\
\hline $\mathrm{Ca}(\%)$ & 4 & $7,91 \pm 0,48$ & 6,1 & 1,2 & $23 \pm 2$ \\
$\mathrm{Ce}$ & 4 & $24,2 \pm 0,3$ & 1,2 & 5,2 & $1,11 \pm 0,09$ \\
$\mathrm{Eu}$ & 4 & $1,10 \pm 0,04$ & 3,6 & 0,9 & $7,79 \pm 0,16$ \\
$\mathrm{Fe} \mathrm{( \% )}$ & 4 & $7,77 \pm 0,11$ & 1,4 & 0,3 & $2,6 \pm 0,3$ \\
$\mathrm{Hf}$ & 4 & $2,59 \pm 0,05$ & 1,9 & 0,4 & $10,9 \pm 1,3$ \\
$\mathrm{La}$ & 4 & $9,97 \pm 0,26$ & 2,6 & 8,5 & $340 \pm 40$ \\
$\mathrm{Lu}\left(\mathrm{ng} \mathrm{g}^{-1}\right)$ & 4 & $303 \pm 7$ & 2,3 & 11 & $15 \pm 3$ \\
$\mathrm{Nd}$ & 4 & $16 \pm 3$ & 19 & 6,6 & $21,4 \pm 0,3$ \\
$\mathrm{Rb}$ & 4 & $22,7 \pm 1,8$ & 7,9 & 6,1 & $35 \pm 2$ \\
$\mathrm{Sc}$ & 4 & $34,7 \pm 0,3$ & 0,8 & 0,9 & $3,5 \pm 0,3$ \\
$\mathrm{Sm}$ & 4 & $3,18 \pm 0,04$ & 1,3 & 9,1 & $0,65 \pm 0,07$ \\
$\mathrm{~Tb}$ & 4 & $0,72 \pm 0,06$ & 8,3 & 11 & $2,4 \pm 0,4$ \\
$\mathrm{Th}$ & 4 & $2,31 \pm 0,04$ & 1,7 & 3,8 & $0,57 \pm 0,07$ \\
$\mathrm{U}$ & 4 & $0,50 \pm 0,10$ & 20 & 12 & $2,12 \pm 0,18$ \\
$\mathrm{Yb}$ & 4 & $2,03 \pm 0,07$ & 3,4 & 4,2 & $84 \pm 6$ \\
$\mathrm{Zn}$ & 4 & $103,0 \pm 2,3$ & 1,9 & 23 & \\
\hline
\end{tabular}

$\mathrm{n}$ = número de determinações; $\mathrm{X}=$ valor médio; $\mathrm{DP}=$ desvio padrão; $\mathrm{DPR}=$ desvio padrão relativo; Er $=$ erro relativo

O radioisótopo utilizado na determinação da concentração do elemento U foi o ${ }^{239} \mathrm{~Np}$, cujo tempo de meia-vida é de 2,36 dias. A primeira medição da atividade gama nos materiais geológicos de referência foi realizada após aproximadamente 7 dias de decaimento, quando a atividade do radioisótopo ${ }^{239} \mathrm{~Np}$ já era baixa. Medições com tempos de decaimento mais curtos poderiam contribuir para a obtenção de resultados mais exatos para concentração de $\mathrm{U}$, entretanto a alta atividade do radioisótopo ${ }^{24} \mathrm{Na}$ impediu a 
realização destas medidas para um tempo de decaimento menor que de 7 dias. Uma outra alternativa para a determinação do $U$ seria a irradiação das amostras com nêutrons epitérmicos.

As interferências no fotopico $1115,6 \mathrm{keV}$ do ${ }^{65} \mathrm{Zn}$ ocasionadas pelos picos dos radioisótopos ${ }^{46} \mathrm{Sc}(1120,6 \mathrm{keV}),{ }^{152} \mathrm{Eu}(1112,1 \mathrm{keV})$ e ${ }^{160} \mathrm{~Tb}(1115,1 \mathrm{keV})($ IAEA, 1990), foram responsáveis pelo erro relativo percentual de $23 \%$ obtido para os resultados da determinação de Zn no material W1. Os teores de Eu e Tb foram similares em ambos os materiais geológicos de referência, entretanto, a concentração de Sc é cerca de cinco vezes maior no material W1 que no material Soil-7 cujo erro relativo percentual obtido na determinação do Zn foi de apenas de 0,3\%.

Para avaliar a qualidade analítica dos resultados obtidos nas análises dos materiais de referência, foram calculados os valores de diferença padronizada ou Z scores ou índices Z (BODE, 1996). O Z score é um tratamento que permite avaliar a exatidão dos resultados obtidos na análise do material de referência em relação aos seus valores certificados.

Valores de $|\mathrm{Z}|>3$ informam a presença de não-confomidades no procedimento analítico adotado e indicam que ações corretivas devem ser tomadas para que a qualidade dos resultados obtidos seja garantida. Valores de $|Z|<3$ indicam que os resultados estão dentro da faixa de concentração dos valores dos certificados, a um nível de confiança de $99 \%$.

Os valores de Z score foram calculados por meio da seguinte relação: (BODE, 1996)

$$
Z_{\text {score }}=\left(\mathrm{C}_{\mathrm{i}}-\mathrm{C}_{\text {ref } \mathrm{i}}\right) /\left(\sigma_{\mathrm{i}}^{2}+\sigma_{\text {ref i }}^{2}\right)^{1 / 2}
$$


onde $C_{i}=$ concentração do elemento i obtida

$\mathrm{C}_{\text {ref i }}=$ valor do certificado para concentração do elemento i

$\sigma_{\mathrm{i}}=$ incerteza da concentração obtida do elemento i

$\sigma_{\text {ref } i}=$ incerteza do valor do certificado para concentração do elemento i

O certificado do material de referência Soil-7 fornece apenas o intervalo de confiança de $95 \%$ da média. Neste caso, a incerteza $\sigma_{\text {ref i }}$ foi calculada com auxílio da seguinte relação (BEIGUELMAN, 2002):

$$
\mathrm{IC}=\mathrm{X} \pm\left(\mathrm{t}_{\mathrm{c}} \sigma_{\text {ref i }} / \mathrm{n}^{1 / 2}\right)
$$

onde, $\quad$ IC $=$ intervalo de confiança

$\mathrm{X}=$ valor médio do intervalo de confiança

$\mathrm{t}_{\mathrm{c}}=$ valor de $\mathrm{t}$ student ( $\mathrm{t}$ crítico)

$\sigma_{\text {ref } \mathrm{i}}=$ incerteza do valor certificado para concentração do elemento i

$\mathrm{n}=$ número de determinações

Os resultados de Z score obtidos para os materiais de referência Apple Leaves, Tomato Leaves e Tea Leaves, representadas respectivamente pelas FIG. 5.1 a 5.3, mostram que todos os elementos apresentaram $|\mathrm{Z}|<3$, indicando que os resultados estão dentro da faixa das concentrações dos valores dos certificados, a um nível de confiança de 99\%. Estes resultados garantem a qualidade dos resultados obtidos nas análises de plantas (folhas e extratos) realizadas neste estudo. 


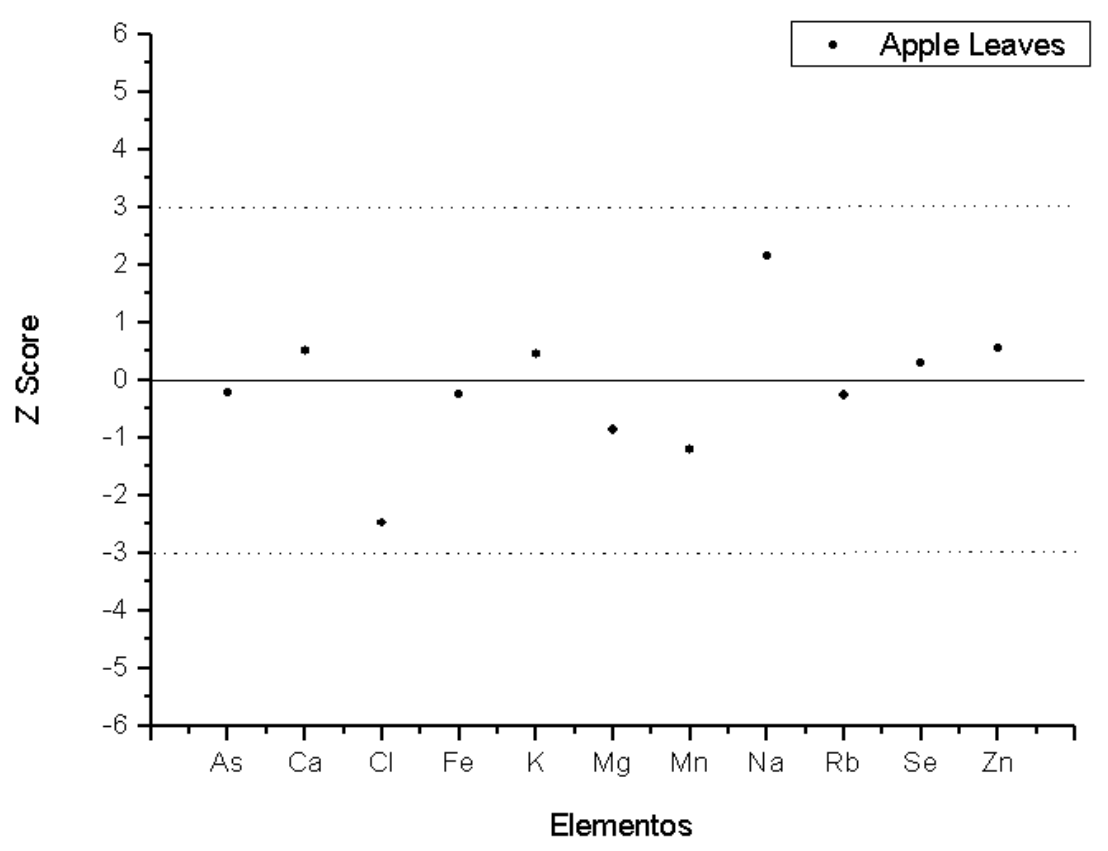

FIGURA 5.1 - Valores de Z score obtidos para os elementos determinados no material de referência NIST-1515 Apple Leaves.

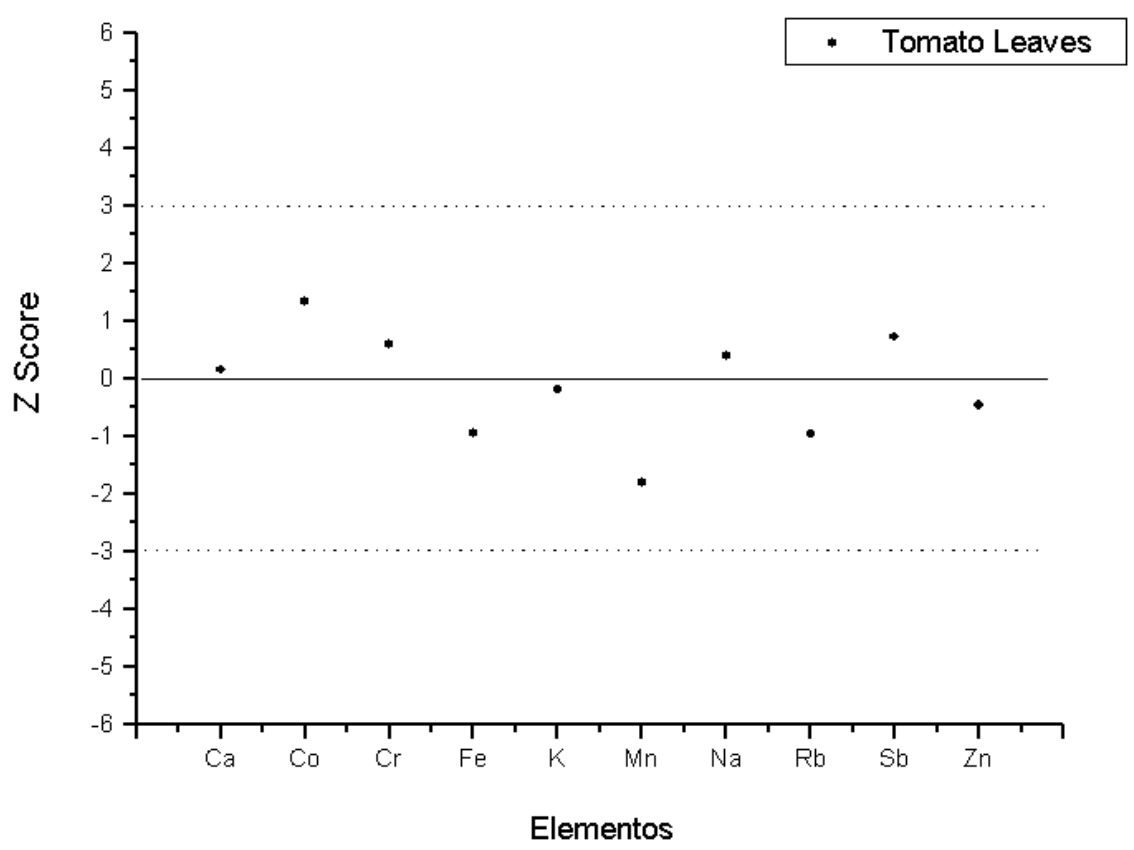

FIGURA 5.2 - Valores de Z score obtidos para os elementos determinados no material de referência NIST-1573a Tomato Leaves. 


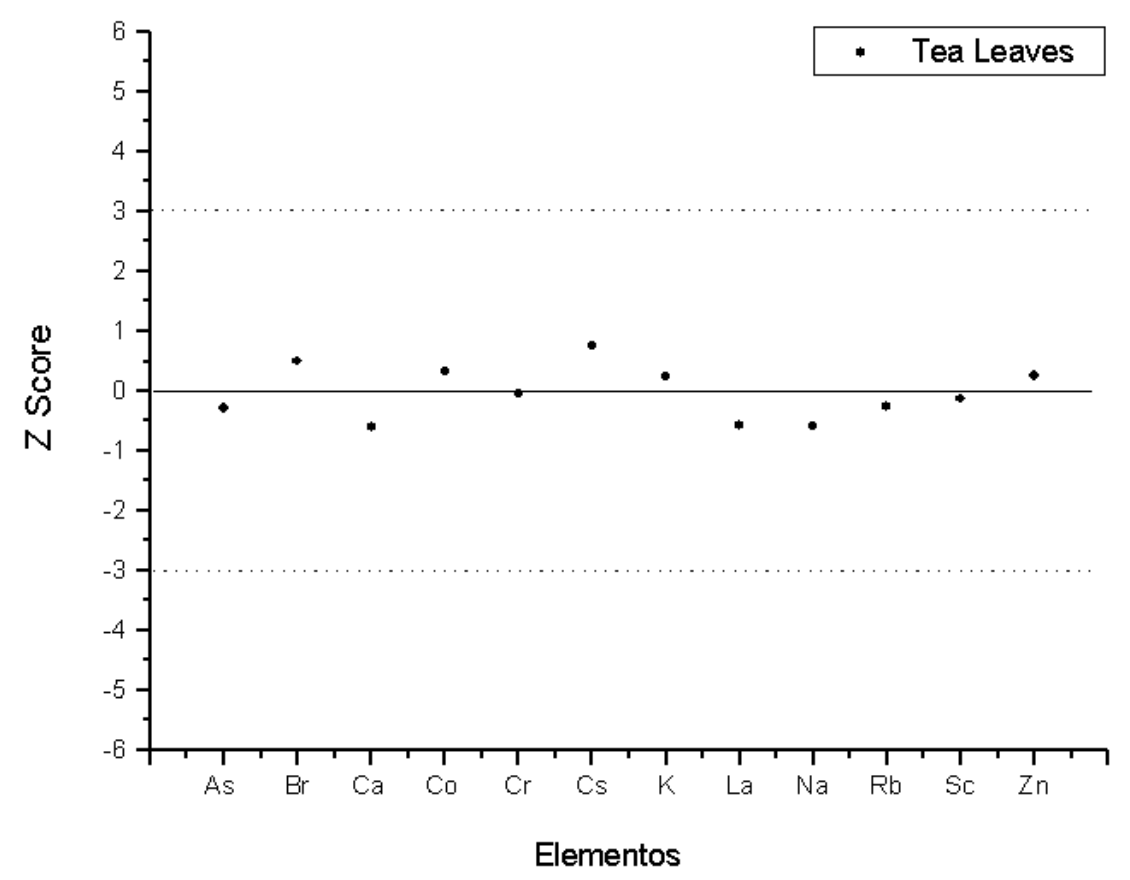

FIGURA 5.3 - Valores de Z score obtidos para os elementos determinados no material de referência INCT-TL-1 Tea Leaves.

Conforme se pode observar nas FIG.5.4 e 5.5, também no caso dos materiais geológicos de referência, os valores de $\mathrm{Z}$ score foram de $|\mathrm{Z}|<3$. Isto indica que os resultados estão dentro da faixa das concentrações dos valores dos certificados a um nível de confiança de 99\%, garantindo a qualidade dos resultados obtidos nas análises de solo deste estudo.

Os resultados obtidos neste trabalho para $\mathrm{Br}$, Co, Cr, La, Sb e Sc no Apple Leaves, Br, Cl, Cs, La, Mg e Sc no Tomato Leaves, Fe, Sb e Se no Tea Leaves e Ca, Fe e Lu no Soil-7 constituem uma contribuição à certificação desses elementos nesses materiais de referência, uma vez que para estes casos não há valores certificados ou existem apenas valores informativos. 


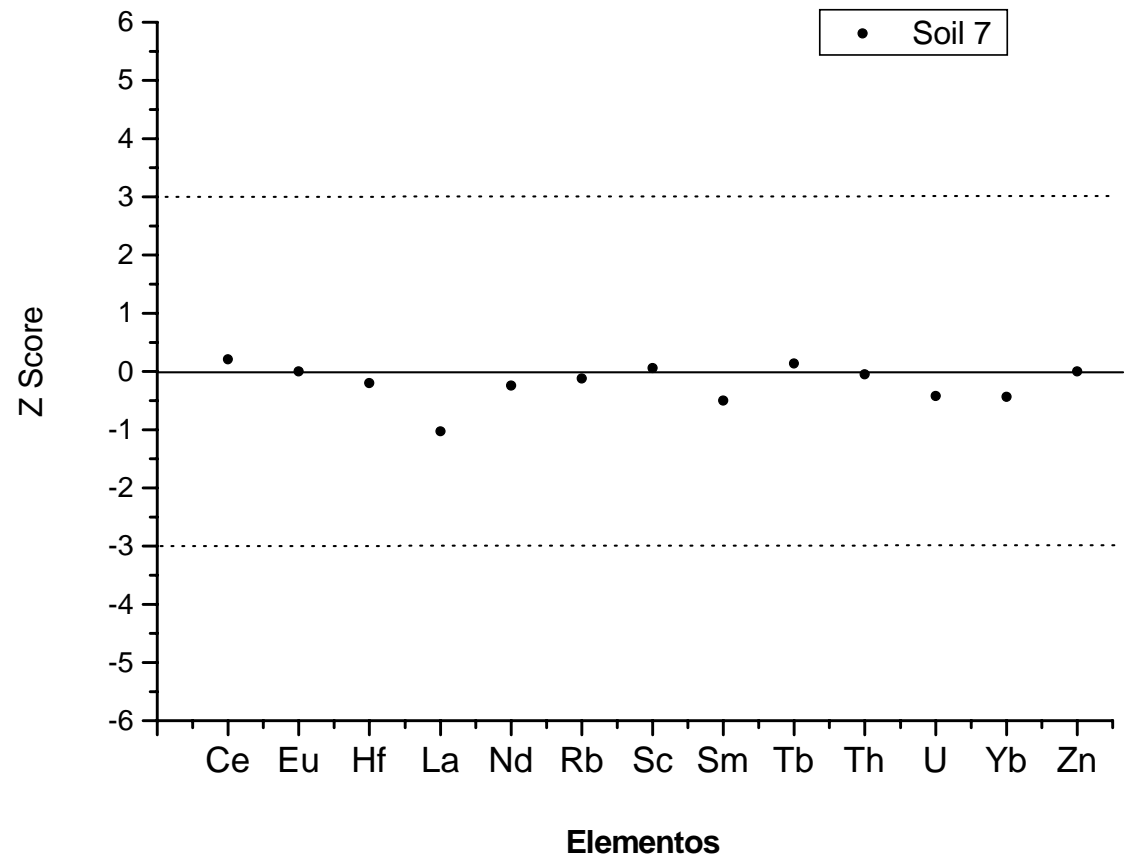

FIGURA 5.4 - Valores de Z score obtidos para os elementos determinados no material de de referência Soil 7 da IAEA.

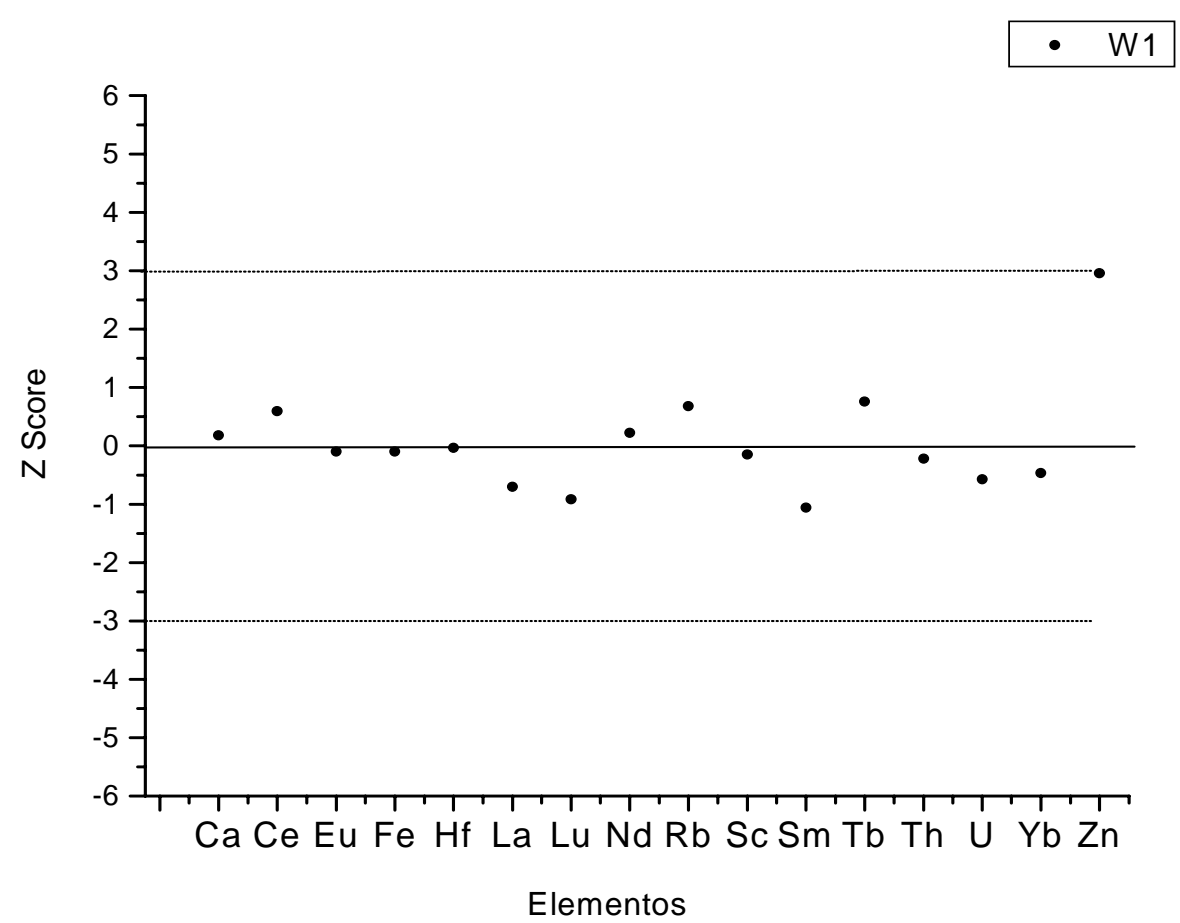

FIGURA 5.5 - Valores de Z score obtidos para os elementos determinados no material de referência W1 da USGS. 
5.2 Resultados das análises das folhas das plantas medicinais

Foram determinadas as concentrações dos elementos $\mathrm{As}, \mathrm{Br}, \mathrm{Ca}, \mathrm{Cl}, \mathrm{Co}, \mathrm{Cr}$, Cs, Fe, K, La, Mg, Mn, Na, Rb, Sb, Sc, Se e Zn presentes nas amostras de folhas de plantas medicinais nativas e cultivadas, das espécies C. sylvestris, C. obliqua e C. decandra, coletadas em diferentes pontos da Mata Atlântica. Um dos locais de coleta foi a Reserva do Morro Grande e o outro o Instituto de Química da Universidade de São Paulo. As médias aritméticas, os desvios padrão, e os desvios padrão relativos dos resultados obtidos nas análises realizadas em replicatas estão apresentadas na TAB.5.6. Os resultados individuais destas análises encontram-se no Apêndice 2.

O elemento $\mathrm{K}$ nas folhas foi encontrado em nível de porcentagem, os elementos Ca, Cl, Mg e Na na ordem de $\mathrm{mg} \mathrm{g}^{-1}, \mathrm{Br}, \mathrm{Fe}, \mathrm{Mn}, \mathrm{Rb}$ e Zn na ordem de $\mu \mathrm{g}^{-1}$ e os elementos As, Co, Cr, Cs, La, Sb, Sc e Se em teores mais baixos, da ordem de ng $\mathrm{g}^{-1}$.

Elementos tóxicos como $\mathrm{Cd}, \mathrm{Cu}$ e $\mathrm{Hg}$ não foram detectados nas amostras de folhas analisadas. Já o Sb, detectado em todas as amostras, e As e Se detectados em algumas amostras estavam presentes em concentrações muito baixas. Os limites de detecção, bem como os limites de quantificação dos elementos estão apresentados no item 5.5 deste capítulo.

Como pode ser observado na TAB. 5.6 a maioria dos resultados foi obtida com grande precisão, tendo os desvios padrão relativos sido inferiores a 10\%. Os elementos As, Se e Sb estão presentes em folhas em concentrações muito próximas ou inferiores aos seus limites de determinação, o que significa que a quantificação destes elementos não pôde ser feita com um nível de confiança adequado por este procedimento de análise por ativação com nêutrons. 
TABELA 5.6 - Médias das concentrações de elementos nas amostras de folhas de plantas medicinais.

\begin{tabular}{|c|c|c|c|c|c|c|c|c|c|c|c|c|}
\hline \multirow[b]{2}{*}{ Elementos } & \multicolumn{3}{|c|}{$\mathrm{J} 1$} & \multicolumn{3}{|c|}{$\mathrm{J} 2$} & \multicolumn{3}{|c|}{ J3 } & \multicolumn{3}{|c|}{$\mathrm{J} 4$} \\
\hline & $\mathrm{N}$ & $\mathrm{X} \pm \mathrm{DP}$ & $\begin{array}{c}\text { DPR } \\
(\%)\end{array}$ & $\mathrm{n}$ & $\mathrm{X} \pm \mathrm{DP}$ & $\begin{array}{c}\text { DPR } \\
(\%)\end{array}$ & $\mathrm{n}$ & $\mathrm{X} \pm \mathrm{DP}$ & $\begin{array}{c}\text { DPR } \\
(\%)\end{array}$ & $\mathrm{n}$ & $\mathrm{X} \pm \mathrm{DP}$ & $\begin{array}{c}\text { DPR } \\
(\%)\end{array}$ \\
\hline As (ng g $\left.{ }^{-1}\right)$ & 3 & $75 \pm 10$ & 13 & & ND & & & ND & & 1 & $10,1 \pm 1,8$ & \\
\hline $\operatorname{Br}\left(\mu g^{-1}\right)$ & 2 & $18,17 \pm 0,04$ & 0,2 & 3 & $4,86 \pm 0,02$ & 0,4 & 2 & $3,77 \pm 0,01$ & 0,3 & 2 & $3,60 \pm 0,01$ & 0,3 \\
\hline Ca $\left(\mathrm{mg} \mathrm{g}^{-1}\right)$ & 3 & $9,5 \pm 0,2$ & 2,1 & 4 & $2,23 \pm 0,07$ & 3,1 & 3 & $5,6 \pm 0,1$ & 1,8 & 2 & $4,8 \pm 0,1$ & 2,1 \\
\hline $\mathrm{Cl}\left(\mathrm{mg} \mathrm{g}^{-1}\right)$ & 3 & $3,9 \pm 0,1$ & 2.6 & 3 & $0,44 \pm 0,02$ & 4,5 & 3 & $1,88 \pm 0,08$ & 4,3 & 3 & $1,48 \pm 0,06$ & 4,1 \\
\hline Co (ng g $\left.g^{-1}\right)$ & 3 & $167 \pm 3$ & 1,8 & 4 & $76,5 \pm 2,4$ & 3,1 & 3 & $187 \pm 4$ & 2,1 & 3 & $65,4 \pm 1,4$ & 2,1 \\
\hline $\mathrm{Cr}\left(\mathrm{ng} \mathrm{g}^{-1}\right)$ & 3 & $452 \pm 15$ & 3,3 & 3 & $51,1 \pm 11,0$ & 22 & 3 & $64,0 \pm 11,0$ & 17 & 3 & $114 \pm 12$ & 10 \\
\hline Cs $\left(\operatorname{ng~g~}^{-1}\right)$ & 3 & $101 \pm 4$ & 4,0 & 4 & $148 \pm 4$ & 2,7 & 3 & $113 \pm 2$ & 1,8 & 3 & $79,6 \pm 3,2$ & 4,0 \\
\hline $\mathrm{Fe}\left(\mu \mathrm{g} \mathrm{g}^{-1}\right)$ & 3 & $162 \pm 2$ & 1,2 & 4 & $56,3 \pm 1,1$ & 2,0 & 3 & $72,7 \pm 1,3$ & 1,8 & 3 & $86,4 \pm 1,5$ & 1,7 \\
\hline K (\%) & 3 & $1,80 \pm 0,01$ & 0,1 & 4 & $1,49 \pm 0,03$ & 2,0 & 3 & $1,90 \pm 0,14$ & 7,4 & 3 & $1,49 \pm 0,07$ & 4,7 \\
\hline La (ng g $\left.{ }^{-1}\right)$ & 3 & $188 \pm 4$ & 2,1 & 4 & $36,8 \pm 1,5$ & 4,1 & 3 & $80,0 \pm 1,7$ & 2,1 & 3 & $59,4 \pm 1,3$ & 2,2 \\
\hline $\operatorname{Mg}\left(\mathrm{mg} \mathrm{g}^{-1}\right)$ & 1 & $4,4 \pm 0,6$ & & 3 & $2,3 \pm 0,1$ & 4,3 & 3 & $2,3 \pm 0,2$ & 8,7 & 3 & $2,2 \pm 0,3$ & 13,6 \\
\hline $\operatorname{Mn}\left(\mu g g^{-1}\right)$ & 3 & $693 \pm 21$ & 3,0 & 2 & $193 \pm 4$ & 2,1 & 3 & $508 \pm 15$ & 3,0 & 3 & $342 \pm 7$ & 2,0 \\
\hline $\mathrm{Na}\left(\mathrm{mg} \mathrm{g}^{-1}\right)$ & 3 & $1,413 \pm 0,002$ & 0,1 & 4 & $0,014 \pm 0,001$ & 0,7 & 3 & $0,25 \pm 0,02$ & 8,0 & 3 & $0,041 \pm 0,002$ & 4,5 \\
\hline $\mathrm{Rb}\left(\mu \mathrm{g} \mathrm{g}^{-1}\right)$ & 3 & $32,0 \pm 0,3$ & 0,9 & 4 & $145 \pm 2$ & 1,4 & 3 & $98,4 \pm 0,8$ & 0,8 & 3 & $79,0 \pm 0,8$ & 1,0 \\
\hline $\mathrm{Sb}\left(\mathrm{ng} \mathrm{g}^{-1}\right)$ & 3 & $129 \pm 4$ & 3,1 & 4 & $11,3 \pm 1,1$ & 9,7 & 3 & $9,4 \pm 1,5$ & 16 & 3 & $16,9 \pm 1,5$ & 8,9 \\
\hline Sc $\left(\right.$ ng g $\left.^{-1}\right)$ & 3 & $22,9 \pm 0,2$ & 0,9 & 4 & $4,8 \pm 0,2$ & 4,2 & 3 & $5,79 \pm 0,12$ & 2,1 & 3 & $10,2 \pm 0,1$ & 1,0 \\
\hline Se $\left(n g g^{-1}\right)$ & 3 & $87,1 \pm 14,5$ & 16,6 & & ND & & & ND & & & ND & \\
\hline $\mathrm{Zn}\left(\mu \mathrm{g} \mathrm{g}^{-1}\right)$ & 3 & $59,3 \pm 0,3$ & 0,5 & 4 & $29,2 \pm 0,2$ & 0,7 & 3 & $28,8 \pm 0,2$ & 0,7 & 3 & $17,3 \pm 0,1$ & 0,6 \\
\hline
\end{tabular}

$\mathrm{X}=$ média aritmética dos resultados; $\mathrm{n}$ = número de determinações; $\mathrm{DP}=$ desvio padrão; $\mathrm{DPR}$ = desvio padrão relativo; ND = Não Detectado;

* no caso de uma única determinação o DP refere-se à incerteza calculada considerando erros nas medições das taxas de contagens da amostra e padrão

J1 - Amostra cultivada de C.sylvestris coletada no Instituto de Química da USP J3 - Amostra nativa de C. decandra coletada na Reserva do Morro Grande

J2 - Amostra nativa de C. obliqua coletada na Reserva do Morro Grande

J4 - Amostra nativa de C. sylvestris coletada na Reserva do Morro Grande

TABELA 5.6 - Médias das concentrações de elementos nas amostras de folhas de plantas medicinais (Continuação) 


\begin{tabular}{|c|c|c|c|c|c|c|c|c|c|}
\hline \multirow{2}{*}{ Elementos } & \multicolumn{3}{|c|}{$\mathrm{J} 5$} & \multicolumn{3}{|c|}{$\mathrm{J} 6$} & \multicolumn{3}{|c|}{ J7 } \\
\hline & $\mathrm{n}$ & $\mathrm{X} \pm \mathrm{DP}$ & DPR (\%) & $\mathrm{n}$ & $\mathrm{X} \pm \mathrm{DP}$ & DPR (\%) & $\mathrm{n}$ & $\mathrm{X} \pm \mathrm{DP}$ & DPR (\%) \\
\hline As (ng g $\left.{ }^{-1}\right)$ & & ND & & & ND & & 3 & $37,6 \pm 4,2$ & 11,2 \\
\hline $\mathrm{Br}\left(\mu \mathrm{g} \mathrm{g}^{-1}\right)$ & 2 & $13,88 \pm 0,03$ & 0,2 & 3 & $16,93 \pm 0,03$ & 0,8 & 3 & $14,90 \pm 0,03$ & 0,2 \\
\hline $\mathrm{Ca}\left(\mathrm{mg} \mathrm{g}^{-1}\right)$ & 3 & $6,0 \pm 0,1$ & 1,7 & 3 & $3,99 \pm 0,08$ & 2,0 & 3 & $8,28 \pm 0,1$ & 1,2 \\
\hline $\mathrm{Cl}\left(\mathrm{mg} \mathrm{g}^{-1}\right)$ & 3 & $0,85 \pm 0,06$ & 7,1 & 3 & $1,31 \pm 0,07$ & 5,3 & 3 & $1,32 \pm 0,06$ & 4,5 \\
\hline Co (ng g $\left.{ }^{-1}\right)$ & 3 & $87,8 \pm 2,0$ & 2,3 & 3 & $169 \pm 3$ & 1,8 & 4 & $128 \pm 3$ & 2,3 \\
\hline $\mathrm{Cr}\left(\operatorname{ng~g}^{-1}\right)$ & 3 & $130 \pm 10$ & 7,7 & 3 & $271 \pm 13$ & 4,8 & 4 & $266 \pm 14$ & 5,2 \\
\hline Cs (ng g $\left.{ }^{-1}\right)$ & 3 & $358 \pm 4$ & 1,1 & 3 & $272 \pm 3$ & 1,1 & 4 & $48,8 \pm 2,3$ & 4,7 \\
\hline $\mathrm{Fe}\left(\mu \mathrm{g} \mathrm{g}^{-1}\right)$ & 3 & $99,7 \pm 1,2$ & 1,2 & 3 & $175 \pm 2$ & 1,1 & 3 & $161 \pm 2$ & 1,2 \\
\hline K (\%) & 3 & $1,28 \pm 0,02$ & 1,6 & 4 & $1,37 \pm 0,01$ & 0,7 & 4 & $1,47 \pm 0,1$ & 6,8 \\
\hline La $\left(\operatorname{ng~g}^{-1}\right)$ & 3 & $163 \pm 3$ & 1,8 & 3 & $265 \pm 5$ & 1,9 & 4 & $242 \pm 2$ & 0,8 \\
\hline $\operatorname{Mg}\left(\mathrm{mg} \mathrm{g}^{-1}\right)$ & 1 & $3,2 \pm 0,8$ & & 1 & $1,59 \pm 0,9$ & & 1 & $3,0 \pm 0,3$ & \\
\hline $\operatorname{Mn}\left(\mu g g^{-1}\right)$ & 3 & $765 \pm 20$ & 2,6 & 3 & $665 \pm 14$ & 2,1 & 3 & $806 \pm 21$ & 2,6 \\
\hline $\mathrm{Na}\left(\mathrm{mg} \mathrm{g}^{-1}\right)$ & 3 & $3,15 \pm 0,01$ & 0,3 & 4 & $5,63 \pm 0,01$ & 0,2 & 3 & $0,0306 \pm 0,0001$ & 0,3 \\
\hline $\mathrm{Rb}\left(\mu \mathrm{g} \mathrm{g}^{-1}\right)$ & 3 & $98,7 \pm 0,9$ & 0,9 & 3 & $67,5 \pm 0,6$ & 0,9 & 3 & $60,5 \pm 0,5$ & 0,8 \\
\hline $\mathrm{Sb}\left(\mathrm{ng} \mathrm{g}^{-1}\right)$ & 3 & $49,6 \pm 1,9$ & 3,8 & 3 & $39,9 \pm 3,2$ & 8,0 & 4 & $35,9 \pm 1,4$ & 3,7 \\
\hline Sc $\left(\operatorname{ng~g~}^{-1}\right)$ & 3 & $16,0 \pm 0,2$ & 1,3 & 4 & $33,5 \pm 0,5$ & 1,5 & 4 & $29,5 \pm 0,2$ & 0,7 \\
\hline Se $\left(n g g^{-1}\right)$ & 2 & $24,5 \pm 9,0$ & 37 & 4 & $49,4 \pm 11,8$ & 24 & 2 & $35 \pm 10$ & 29 \\
\hline $\mathrm{Zn}\left(\mu \mathrm{g} \mathrm{g}^{-1}\right)$ & 3 & $37,7 \pm 0,2$ & 0,5 & 3 & $78,4 \pm 0,4$ & 0,5 & 3 & $45,2 \pm 0,2$ & 0,4 \\
\hline
\end{tabular}

$\mathrm{X}=$ média aritmética dos resultados; $\mathrm{n}=$ número de determinações; $\mathrm{DP}$ = desvio padrão; $\mathrm{DPR}$ = desvio padrão relativo; ND = Não Detectado; J5 - Amostra nativa de C. sylvestris coletada na Reserva do Morro Grande.

J6 - Amostra cultivada de C. sylvestris coletada na Reserva do Morro Grande.

J7 - Amostra nativa de C. obliqua coletada na Reserva do Morro Grande. 
Nas amostras nativas de C. obliqua (J2) e de C. decandra (J3) coletadas na Reserva do Morro Grande, o elemento Cr estava presente nas mais baixas concentrações de modo que para estas amostras, os valores de desvios padrão relativos de seus resultados foram também superiores a $15 \%$.

A precisão dos resultados obtidos para o elemento $\mathrm{Mg}$ nas amostras de $C$. sylvestris coletada no IQUSP (J1), de C. sylvestris (J5 e J6) e C. obliqua (J7) da Reserva do Morro Grande, não pôde ser avaliada porque nestas amostras o Mg foi detectado em apenas uma das determinações realizadas. A dificuldade na determinação de Mg se deve às elevadas concentrações de Mn também presentes nas amostras mencionadas. O pico de absorção total em $846 \mathrm{keV}$ devido à atividade de ${ }^{56} \mathrm{Mn}$ provoca interferência no pico de $843 \mathrm{keV}$ do ${ }^{27} \mathrm{Mg}$ utilizado nos cálculos de concentração do Mg. O pico de $1014 \mathrm{keV}$ do ${ }^{27} \mathrm{Mg}$ é baixa intensidade e nem sempre foi detectado no espectro de raios gama.

Para melhor visualização das diferenças nas concentrações dos elementos presente nas folhas de plantas pertencentes a uma mesma espécie porém provenientes de diferentes localidades, foram elaborados os gráficos (FIG. 5.6 a FIG. 5.8) com os resultados obtidos para as amostras de C. sylvestris cultivadas em duas localidades distintas: o IQUSP e a Reserva do Morro Grande.

A primeira destas figuras (FIG.5.6) mostra os elementos mais abundantes (macroelementos) nas folhas, ou seja, dos elementos $\mathrm{Ca}, \mathrm{Cl}, \mathrm{K}, \mathrm{Mg}$ e $\mathrm{Mn}$, cujas concentrações variaram de 0,67 a 18,0 $\mathrm{mg} \mathrm{g}^{-1}$. 


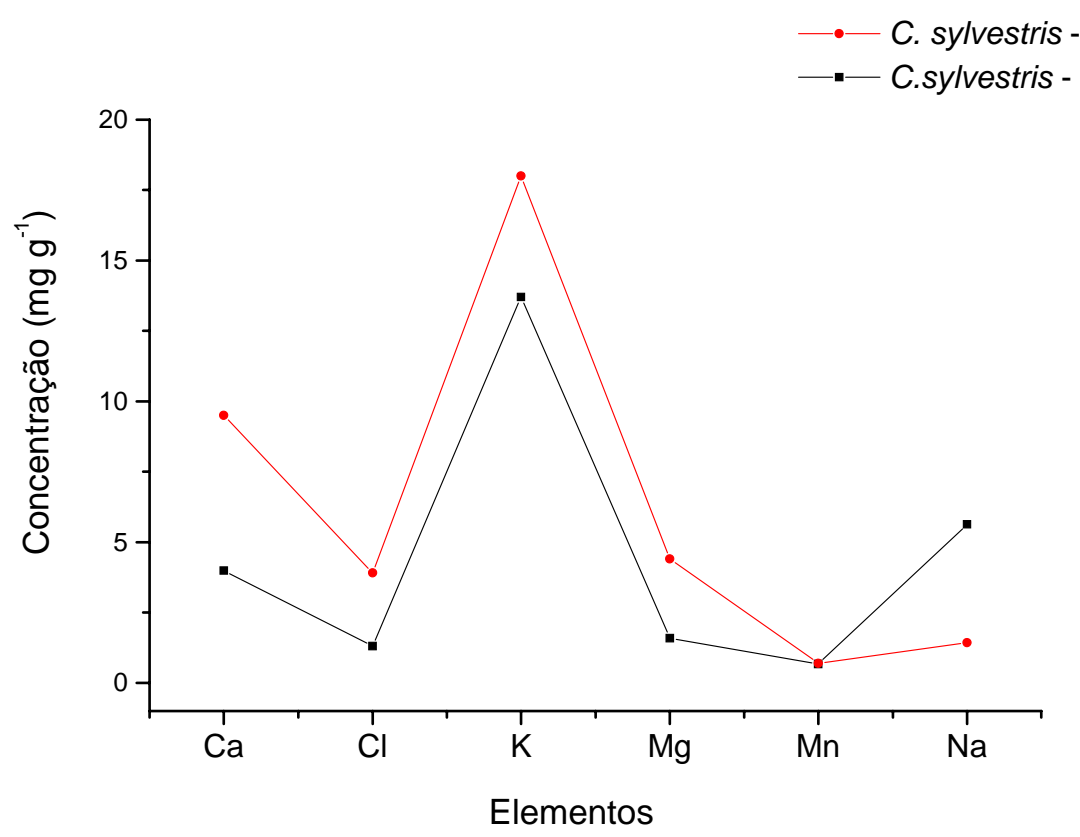

FIGURA 5.6 - Concentrações de macroelementos nas folhas de C. sylvestris cultivadas em regiões distintas da Mata Atlântica.

Na FIG. 5.7 encontram-se os resultados obtidos para $\mathrm{Br}, \mathrm{Fe}$, $\mathrm{Rb}$ e $\mathrm{Zn}$ (microelementos) nas folhas de C. sylvestris, cujas concentrações variaram de 16,9 a 175 $\mu \mathrm{g}^{-1}$.
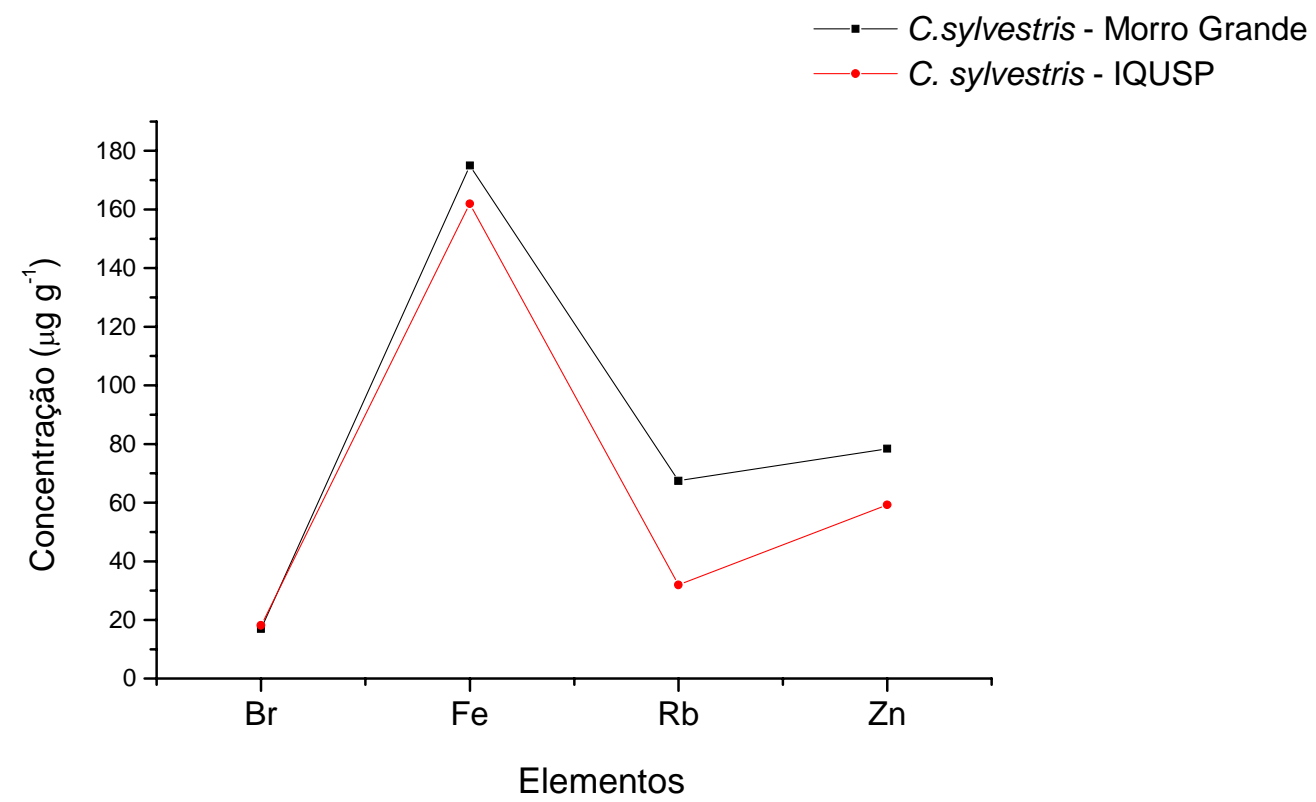

FIGURA 5.7 - Concentrações de microelementos nas folhas de C. sylvestris cultivadas em regiões distintas da Mata Atlântica. 
Os resultados obtidos para os elementos presentes nas folhas de C. sylvestris em baixas concentrações (elementos traço), As, Co, Cr, Cs, La, Sb, Sc e Se, estão apresentadas na FIG. 5.8. As concentrações destes elementos variaram de 22,9 a 452 ng $g^{-1}$.
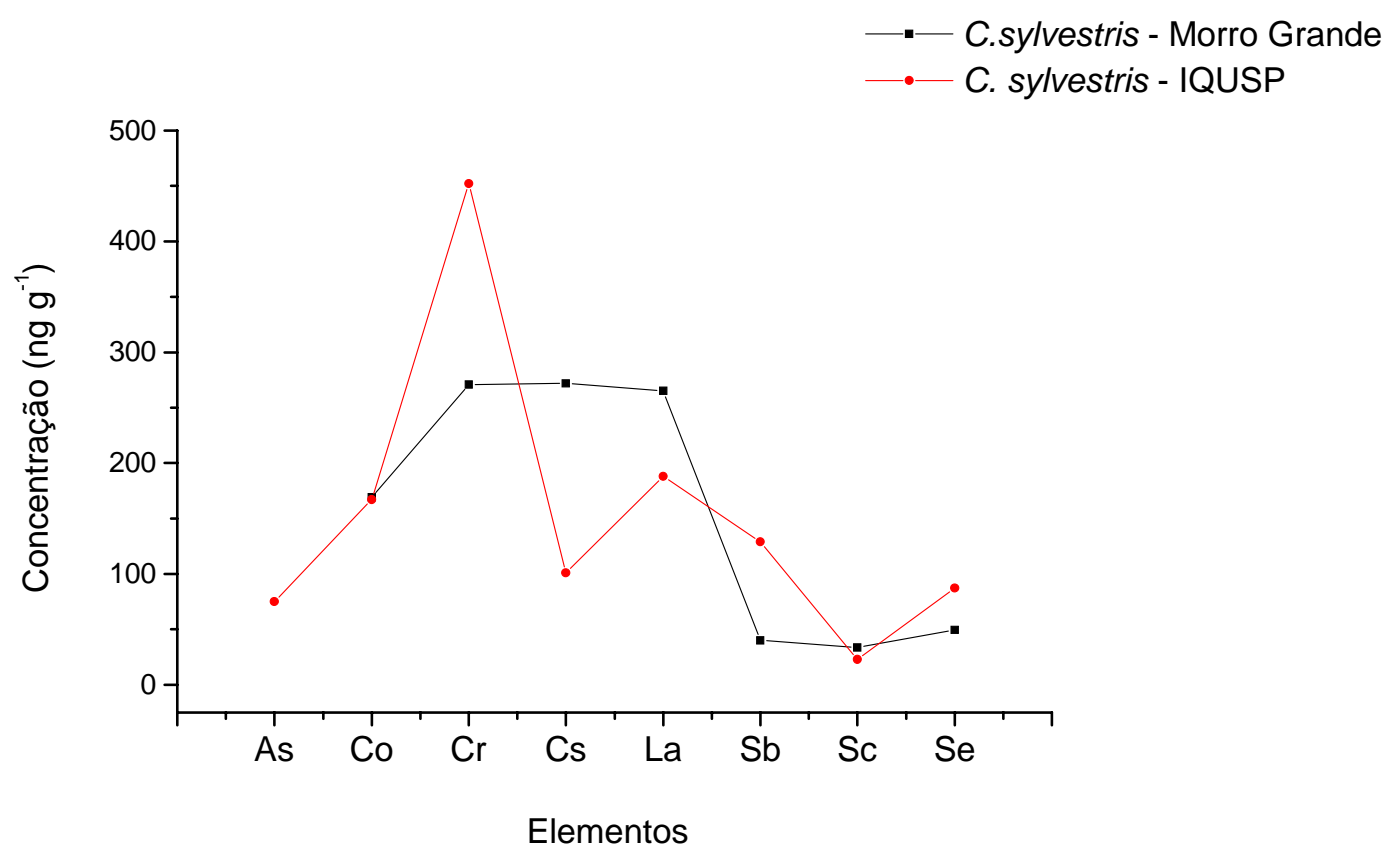

FIGURA 5.8 - Concentrações de elementos traço nas folhas de C. sylvestris cultivadas em regiões distintas da Mata Atlântica.

Pode-se observar nas FIG. 5.6 a 5.8 que as folhas de C. sylvestris cultivadas no IQUSP apresentaram concentrações mais elevadas dos elementos $\mathrm{Ca}, \mathrm{Cl}, \mathrm{Mn}, \mathrm{K}, \mathrm{Cr}$ e Se, bem como dos elementos tóxicos As e Sb. As folhas de C. sylvestris cultivadas na Reserva do Morro Grande por sua vez apresentaram concentrações de Na, Fe, Rb, Zn, Cs e Sc mais elevadas em relação à amostra do IQUSP.

Por outro lado, analisando os resultados obtidos para as três diferentes espécies de Casearia nativas de uma mesma região (Reserva do Morro Grande) (FIG.5.9), verificou-se que, para a maioria dos elementos, não houve uma grande diferença entre as concentrações obtidas nas folhas das três espécies $C$. sylvestris, $C$. decandra e C. obliqua. 
As exceções foram o elemento As detectado apenas em C. sylvestris e os elementos Cl, Co, La e Na que foram encontrados em concentrações mais altas nas folhas de $C$. decandra.

Segundo MENEZES (2004), as repostas farmacológica obtidas em modelos experimentais de úlcera gástrica para estas três espécies de plantas medicinais foram de 71,88\% para C. sylvestris, de 46,27\% para C. obliqua e de 48,02\% para C. decandra. Uma vez que as folhas de Casearia sylvestris apresentaram concentrações ligeiramente mais elevadas de Cr, Fe, Sb e Sc, além do As, em relação às demais espécies, isto indica que a biossíntese de compostos responsáveis pela atividade farmacológica destas plantas pode estar relacionada com a presença destes constituintes inorgânicos em suas folhas.

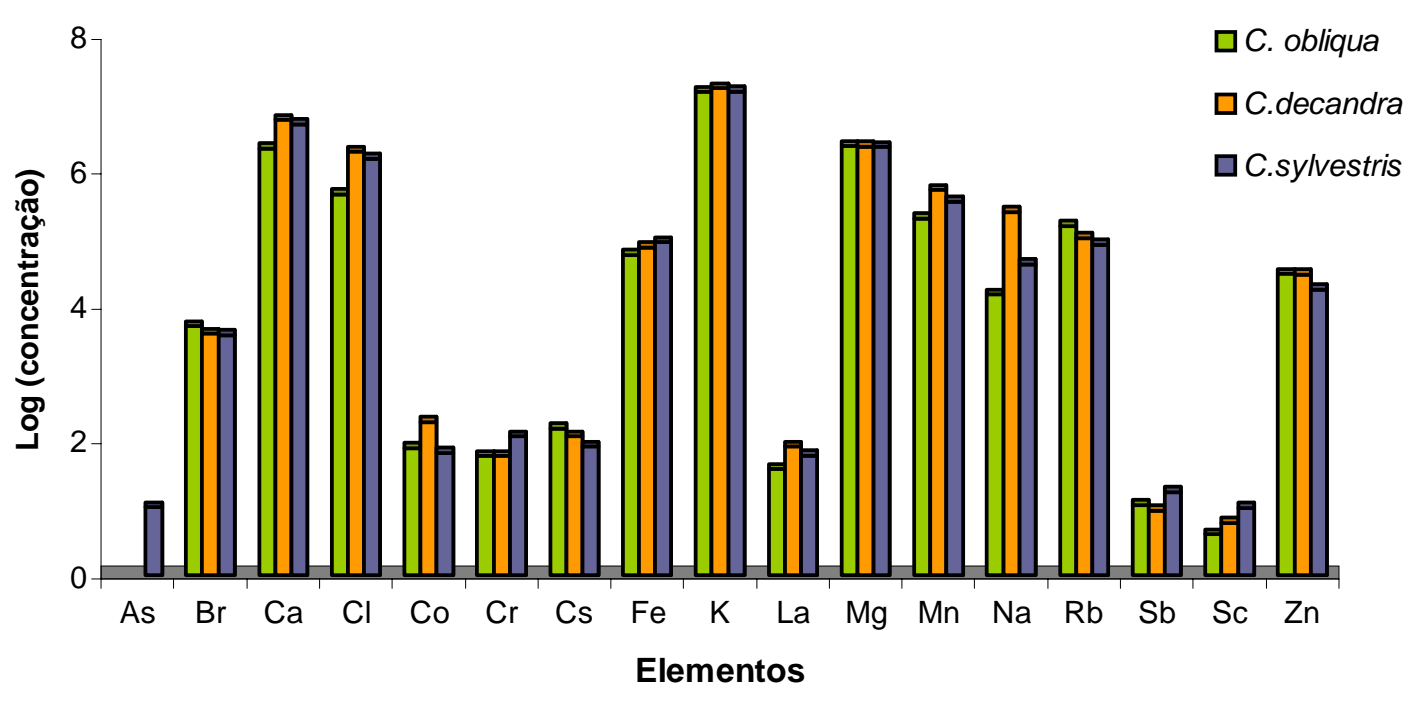

FIGURA 5.9 - Concentrações de elementos em folhas de três espécies de Casearia nativas provenientes de um mesmo local de coleta (Reserva do Morro Grande). Concentrações em ng g g $^{-1}$

A análise hierárquica de agrupamentos, ou análise de clusters, foi realizada com base nos dados apresentados na TAB.5.6. Foi aplicado o método de Ward de ligação, ou método da mínima variância, e a distância euclidiana quadrática foi utilizada como medida da distância entre os grupos. Os missing values para as concentrações dos elementos As e Se que não foram determinados em algumas amostras foram substituídos 
por seus respectivos limites de detecção. O dendrograma obtido para verificar a semelhança entre as sete amostras de folhas, encontra-se apresentado na FIG.5.10.

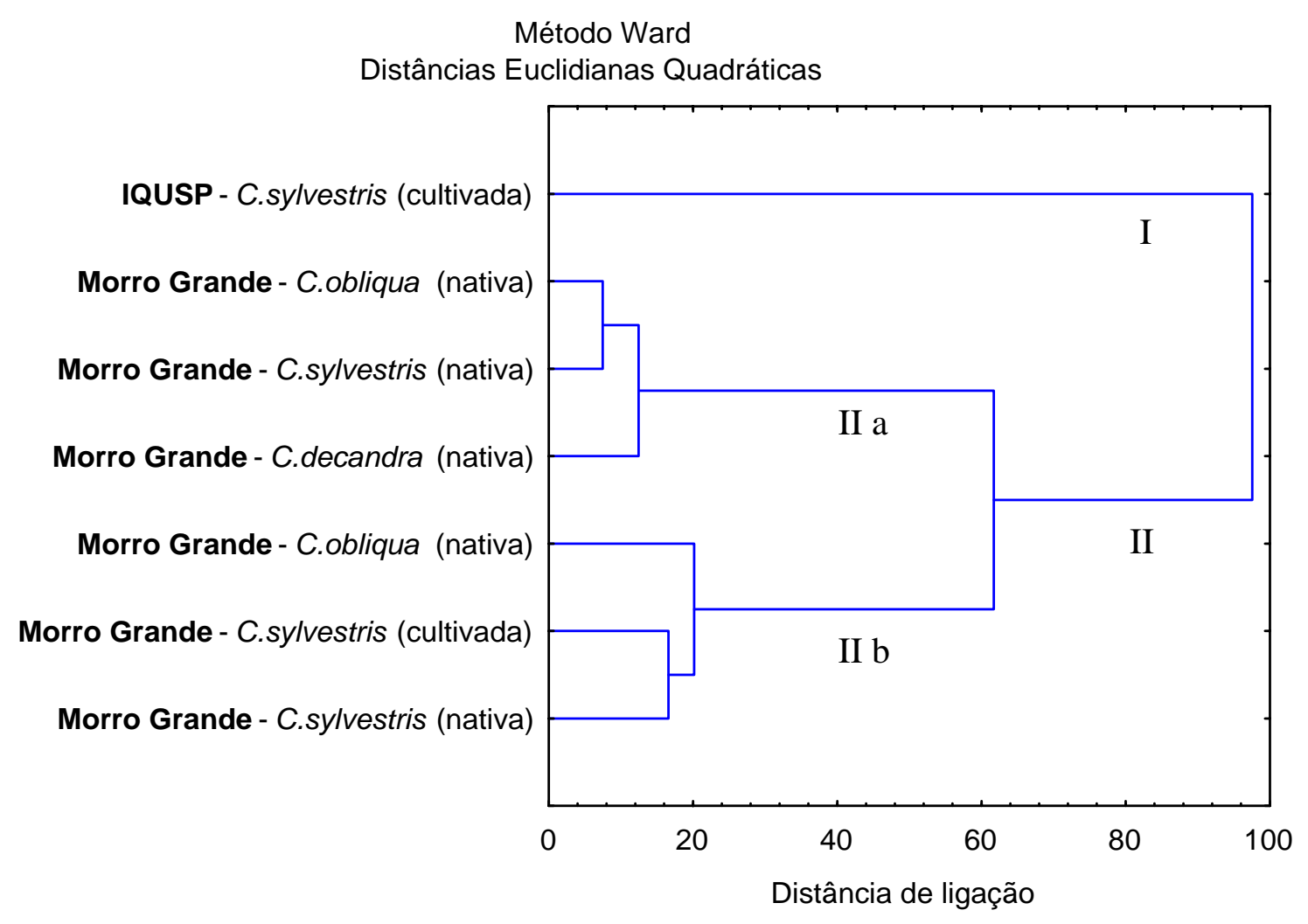

FIGURA 5.10 - Dendrograma obtido na análise de clusters utilizando o método Ward de ligação.

Observa-se no dendrograma da FIG.5.10 a formação de dois grupos bastante distintos de amostras: I e II. A amostra de C. sylvestris coletada no IQUSP forma um grupo distinto (I) do formado pelas amostras provenientes da Reserva do Morro Grande (II). Este resultado indica que o local em que as plantas foram cultivadas influenciou na composição de elementos das suas folhas.

Como pode ser observado na FIG.5.10, o grupo II é formado por dois subgrupos IIa e IIb distintos. O subgrupo IIa é formado por amostras de C. obliqua, $C$. decandra, C. sylvestris provenientes da Reserva do Morro Grande, coletadas no mês de 
Novembro de 2001. O subgrupo IIb é formado pelas amostras de folhas coletadas em Julho de 2002. Estes resultados mostram que ainda que as plantas medicinais tenham sido cultivadas em uma mesma região da Mata Atlântica, a Reserva do Morro Grande, as concentrações de seus constituintes inorgânicos podem ter sido influenciadas pelos períodos distintos de coleta destas plantas.

5.3 Resultados das análises dos extratos das plantas medicinais

Os resultados obtidos nas análises dos extratos etanólicos das plantas medicinais C. decandra, C. obliqua e C. sylvestris encontram-se na TAB. 5.7. Os elementos $\mathrm{Ca}, \mathrm{Cl}, \mathrm{K}$ e Mg, foram obtidos nestes extratos em concentrações da ordem de mg g ${ }^{-1}, \mathrm{Br}, \mathrm{Cr}, \mathrm{Fe}, \mathrm{Mn}, \mathrm{Na}, \mathrm{Rb}$ e Zn aos níveis de $\mu \mathrm{g} \mathrm{g}^{-1}$ e As, Co, Cs, La, Sb, Sc e Se da ordem de ng g ${ }^{-1}$. Os resultados individuais destas análises encontram-se no Apêndice 3.

Todos os elementos encontrados nas folhas das três espécies de Casearia também foram determinados nos seus respectivos extratos. A TAB. 5.7 mostra que os elementos $\mathrm{K}$, Ca e Mg encontrados em altas concentrações nas folhas também estão presentes em altas concentrações nos extratos.

Os desvios padrão relativos dos resultados obtidos para a maioria dos elementos foram inferiores a 9,2\% comprovando a precisão dos resultados obtidos. Os elementos As, La, Mg, Sc e Se foram determinados em concentrações muito baixas da ordem de ng $\mathrm{g}^{-1}$, e para estes elementos os desvios padrão relativos foram superiores a 10\%. Em algumas amostras, estes elementos foram detectados em apenas uma das análises realizadas. No caso dos extratos, um fator que também contribuiu para a baixa reprodutibilidade dos resultados foi consistência viscosa das amostras. Após o processo de liofilização os extratos tornaram-se ainda mais rígidos, o que dificultou a homogeneização destas amostras. 
TABELA 5.7 - Médias das concentrações de elementos nos extratos de Casearia.

\begin{tabular}{|c|c|c|c|c|c|c|c|c|c|}
\hline \multirow{2}{*}{ Elementos } & \multicolumn{3}{|c|}{ E2 } & \multicolumn{3}{|c|}{ E3 } & \multicolumn{3}{|c|}{ E4 } \\
\hline & $\mathrm{n}$ & $\mathrm{X} \pm \mathrm{DP}$ & $\begin{array}{c}\text { DPR } \\
(\%)\end{array}$ & $\mathrm{N}$ & $\mathrm{X} \pm \mathrm{DP}$ & $\begin{array}{c}\begin{array}{c}\text { DPR } \\
(\%)\end{array} \\
\end{array}$ & $\mathrm{n}$ & $\mathrm{X} \pm \mathrm{DP}$ & $\begin{array}{c}\text { DPR } \\
(\%)\end{array}$ \\
\hline As $\left(n g g^{-1}\right)$ & & ND & & 2 & $18,4 \pm 3,7$ & 20 & 1 & $34,9 \pm 6,5$ & \\
\hline $\operatorname{Br}\left(\mu g^{-1}\right)$ & 3 & $23,88 \pm 0,06$ & 0,03 & 3 & $8,74 \pm 0,03$ & 0,3 & 3 & $15,70 \pm 0,05$ & 0,3 \\
\hline $\mathrm{Ca}\left(\mathrm{mg} \mathrm{g}^{-1}\right)$ & 2 & $3,92 \pm 0,16$ & 4,1 & 2 & $5,5 \pm 0,1$ & 1,8 & 2 & $13,1 \pm 1,2$ & 9,2 \\
\hline $\mathrm{Cl}\left(\mathrm{mg} \mathrm{g}^{-1}\right)$ & 3 & $3,15 \pm 0,08$ & 2,5 & 4 & $5,5 \pm 0,1$ & 1,8 & 4 & $7,2 \pm 0,2$ & 2,8 \\
\hline $\mathrm{Co}\left(\mathrm{ng} \mathrm{g}^{-1}\right)$ & 3 & $43,3 \pm 1,5$ & 3,5 & 3 & $58,0 \pm 1,7$ & 2,9 & 3 & $71,0 \pm 1,9$ & 2,7 \\
\hline $\mathrm{Cr}\left(\mu \mathrm{g} \mathrm{g}^{-1}\right)$ & 3 & $0,11 \pm 0,01$ & 9,1 & 3 & $0,90 \pm 0,02$ & 2,2 & 3 & $1,36 \pm 0,02$ & 1,5 \\
\hline $\mathrm{Cs}\left(\mathrm{ng} \mathrm{g}^{-1}\right)$ & 3 & $120 \pm 3$ & 2,5 & 3 & $59,8 \pm 2,5$ & 4,2 & 3 & $59,1 \pm 2,8$ & 4,7 \\
\hline $\mathrm{Fe}\left(\mu \mathrm{g} \mathrm{g}^{-1}\right)$ & 3 & $8,6 \pm 0,5$ & 5,8 & 3 & $14,4 \pm 0,6$ & 4,2 & 3 & $16,4 \pm 0,7$ & 4,3 \\
\hline K (\%) & 3 & $1,26 \pm 0,07$ & 5,5 & 3 & $0,97 \pm 0,04$ & 4,1 & 3 & $1,06 \pm 0,03$ & 2,8 \\
\hline $\mathrm{La}\left(\mathrm{ng} \mathrm{g}^{-1}\right)$ & 3 & $4,4 \pm 0,9$ & 20 & 3 & $6,01 \pm 0,9$ & 15 & 3 & $9,18 \pm 1,7$ & 19 \\
\hline $\mathrm{Mg}\left(\mathrm{mg} \mathrm{g}^{-1}\right)$ & 2 & $0,64 \pm 0,09$ & 14 & 1 & $0,44 \pm 0,23$ & & 1 & $1,15 \pm 0,38$ & \\
\hline $\operatorname{Mn}\left(\mu \mathrm{g} \mathrm{g}^{-1}\right)$ & 3 & $26,6 \pm 0,5$ & 1,9 & 4 & $10,5 \pm 0,4$ & 3,8 & 4 & $17,1 \pm 0,4$ & 2,3 \\
\hline $\mathrm{Na}\left(\mu \mathrm{g} \mathrm{g}^{-1}\right)$ & 3 & $98,6 \pm 3,7$ & 3,8 & 3 & $249 \pm 1$ & 0,4 & 3 & $634 \pm 16$ & 2,5 \\
\hline $\mathrm{Rb}\left(\mu \mathrm{g}^{-1}\right)$ & 3 & $110 \pm 1$ & 1,0 & 3 & $50,5 \pm 0,4$ & 0,8 & 3 & $57,8 \pm 0,6$ & 1,0 \\
\hline $\mathrm{Sb}\left(\mathrm{ng} \mathrm{g}^{-1}\right)$ & 3 & $211 \pm 3$ & 1,4 & 3 & $168 \pm 4$ & 2,4 & 3 & $165 \pm 3$ & 1,8 \\
\hline $\mathrm{Sc}\left(\mathrm{ng} \mathrm{g}^{-1}\right)$ & 3 & $0,85 \pm 0,10$ & 12 & 3 & $1,0 \pm 0,1$ & 10 & 3 & $1,6 \pm 0,1$ & 6,3 \\
\hline $\operatorname{Se}\left(n g g^{-1}\right)$ & 1 & $32,2 \pm 13$ & & & ND & & 1 & $42 \pm 11$ & \\
\hline $\mathrm{Zn}\left(\mu \mathrm{g} \mathrm{g}^{-1}\right)$ & 3 & $12,1 \pm 0,1$ & 1,0 & 3 & $25,4 \pm 0,2$ & 0,8 & 3 & $31,0 \pm 0,2$ & 0,6 \\
\hline
\end{tabular}

$\mathrm{n}$ = número de determinações; $\mathrm{DP}$ = desvio padrão; DPR = desvio padrão relativo; Er = erro relativo percentual; ND = não detectado.

E2 - Extrato de C. obliqua coletada na Reserva do Morro Grande

E3 - Extrato de C. decandra coletada na Reserva do Morro Grande

E4 - Extrato de C. sylvestris coletada na Reserva do Morro Grande

Nas FIG. 5.11 a 5.13 são apresentadas as concentrações dos macroelementos, microelementos e elementos traço presentes nos extratos das três espécies do gênero Casearia (C. sylvestris, C. decandra e C. obliqua) nativas de uma mesma região (Reserva do Morro Grande). As composições dos extratos das três espécies foram, para a maioria dos elementos, bastante semelhantes. Contudo, a FIG. 5.11 mostra que com relação aos macroelementos, o extrato de C. sylvestris apresentou as mais elevadas concentrações de $\mathrm{Ca}, \mathrm{Cl}, \mathrm{Mg}$ e $\mathrm{Na}$, enquanto o extrato de $\mathrm{C}$. obliqua destacou-se por apresentar as mais altas concentrações de K e Mn. A planta de C. obliqua a partir da qual foi preparado seu extrato 
havia se desenvolvido em ambiente com sol, enquanto que C. sylvestris e C. obliqua haviam crescido à sombra. Neste caso, as condições ambientais de iluminação também podem ter influenciado as concentrações destes elementos nas plantas.

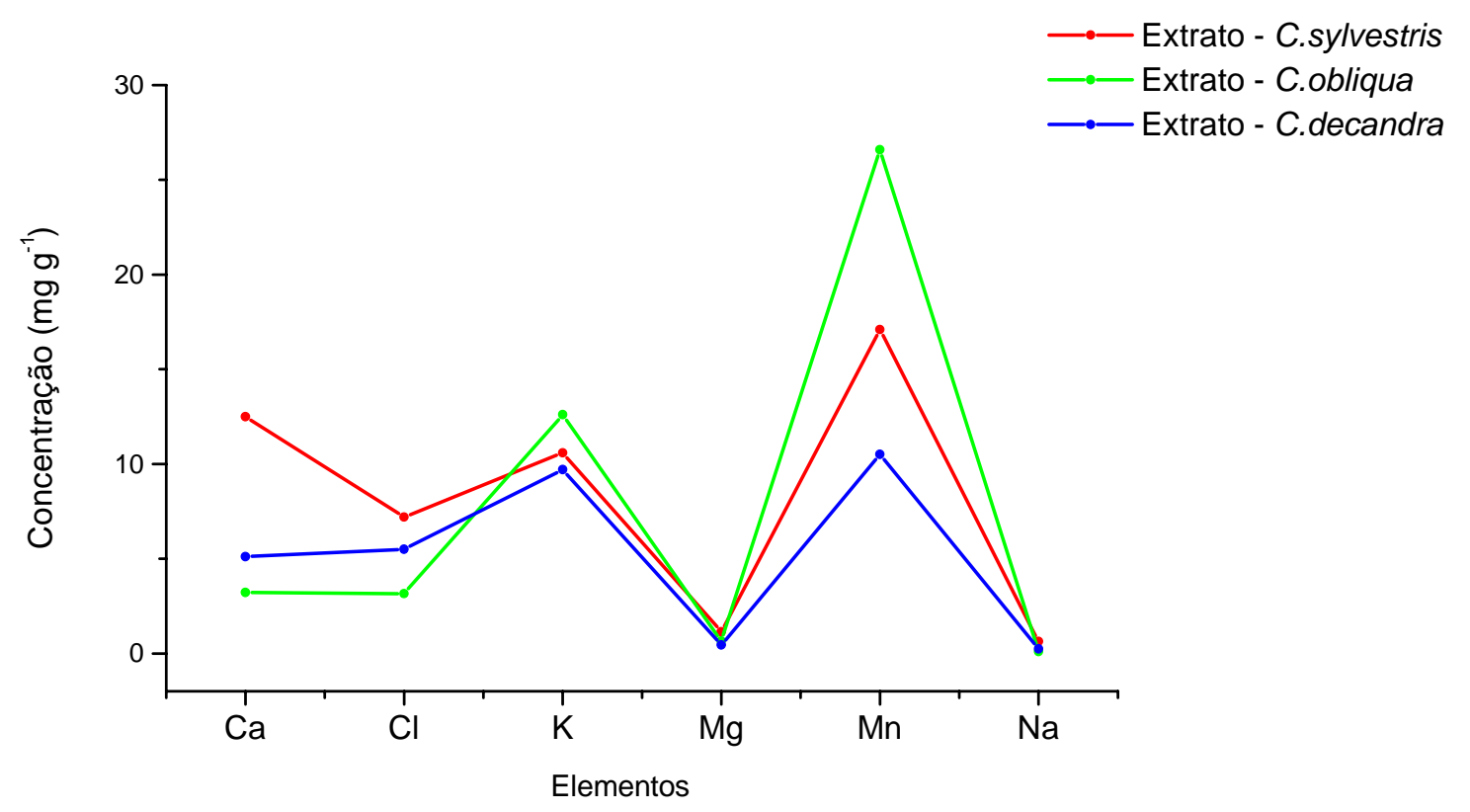

FIGURA 5.11 - Concentrações de macroelementos nos extratos de diferentes espécies de Casearia cultivadas na Reserva do Morro Grande.

Dentre os microelementos, a comparação dos resultados apresentados na FIG. 5.12 mostra que $\mathrm{Br}$ e $\mathrm{Rb}$ foram encontrados em concentrações mais elevadas no extrato de C. obliqua, enquanto que para $\mathrm{Cr}, \mathrm{Fe}$ e $\mathrm{Zn}$ as mais altas concentrações ou da mesma ordem de grandeza foram determinados no extrato de C. sylvestris.

Os resultados obtidos para os elementos traço apresentados na FIG.5.13 mostram que as mais altas concentrações de Cs e Sb foram obtidas para o extrato de $C$. obliqua enquanto que extrato de $C$. sylvestris apresentou as mais elevadas concentrações de As, Co, Se, La e Sc. O extrato de C. decandra foi o que apresentou as mais baixas concentrações de K, Mg, Mn, Br e Rb. 


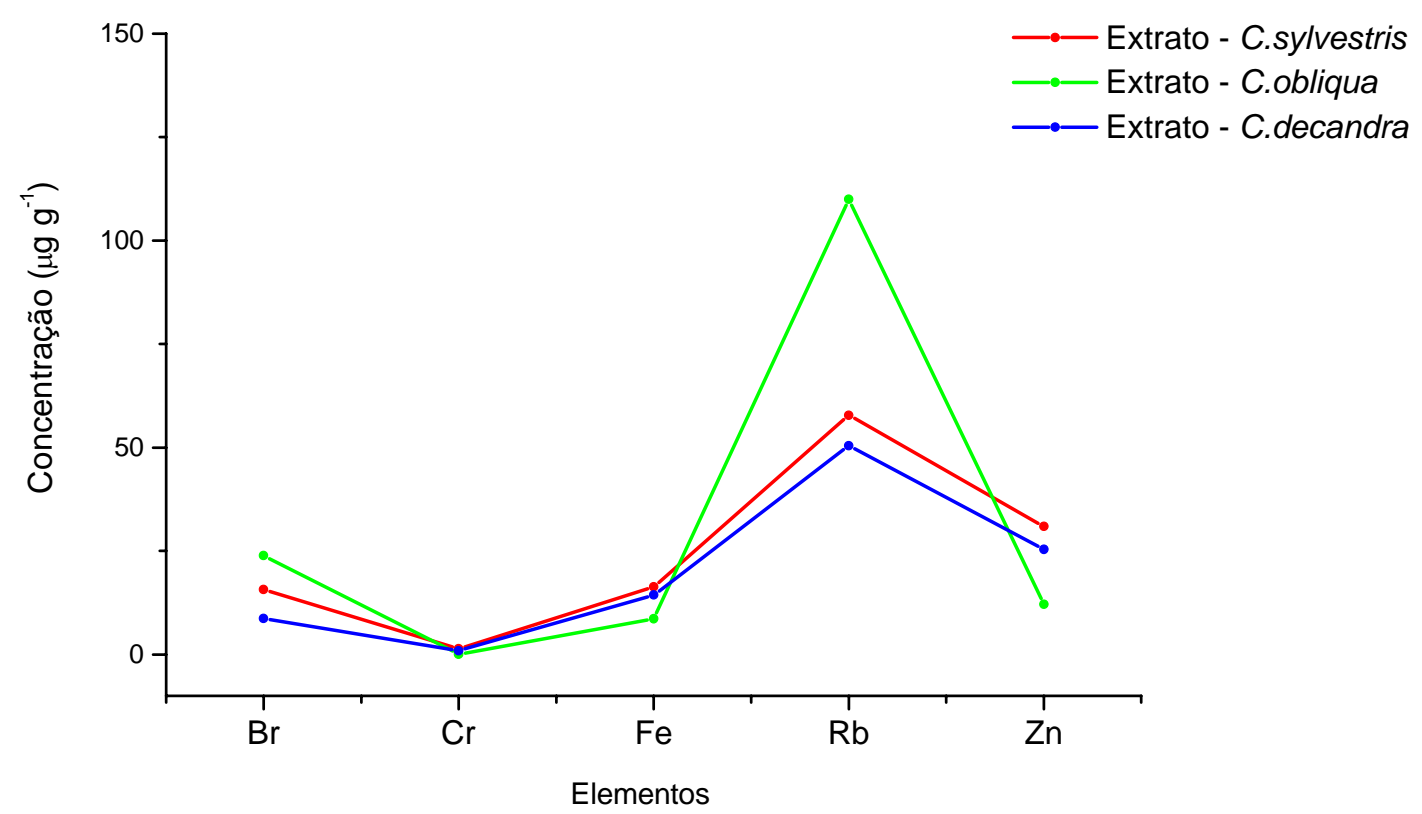

FIGURA 5.12 - Concentrações de microelementos nos extratos de diferentes espécies de Casearia cultivadas na Reserva do Morro Grande.

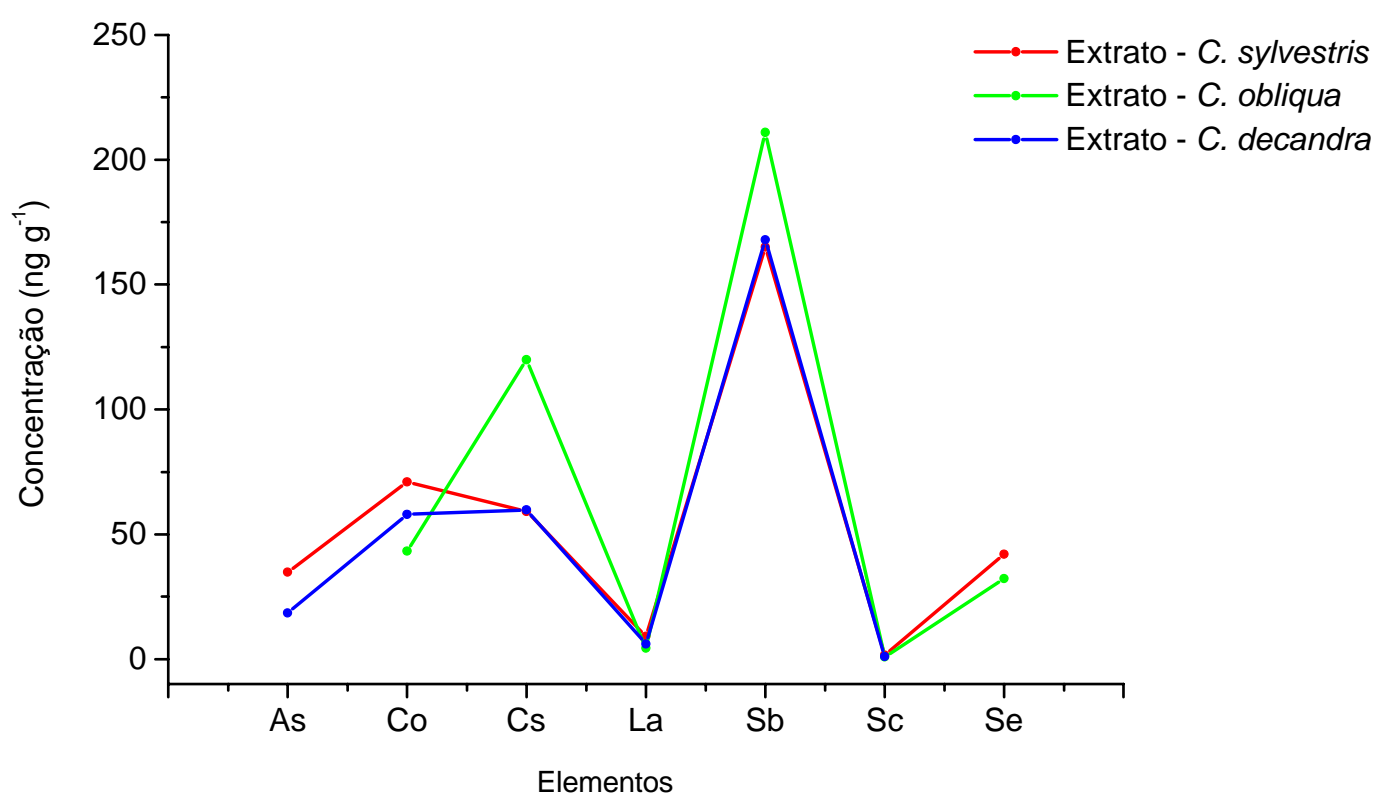

FIGURA 5.13 - Concentrações de elementos traço nos extratos de diferentes espécies de Casearia cultivadas na Reserva do Morro Grande. 
5.3.1 Comparação entre as concentrações de elementos obtidos nas folhas e nos extratos

Para uma análise dos resultados obtidos nas análises de folhas de Casearia e em seus respectivos extratos foram elaborados os gráficos das FIG. 5.14 a 5.16.

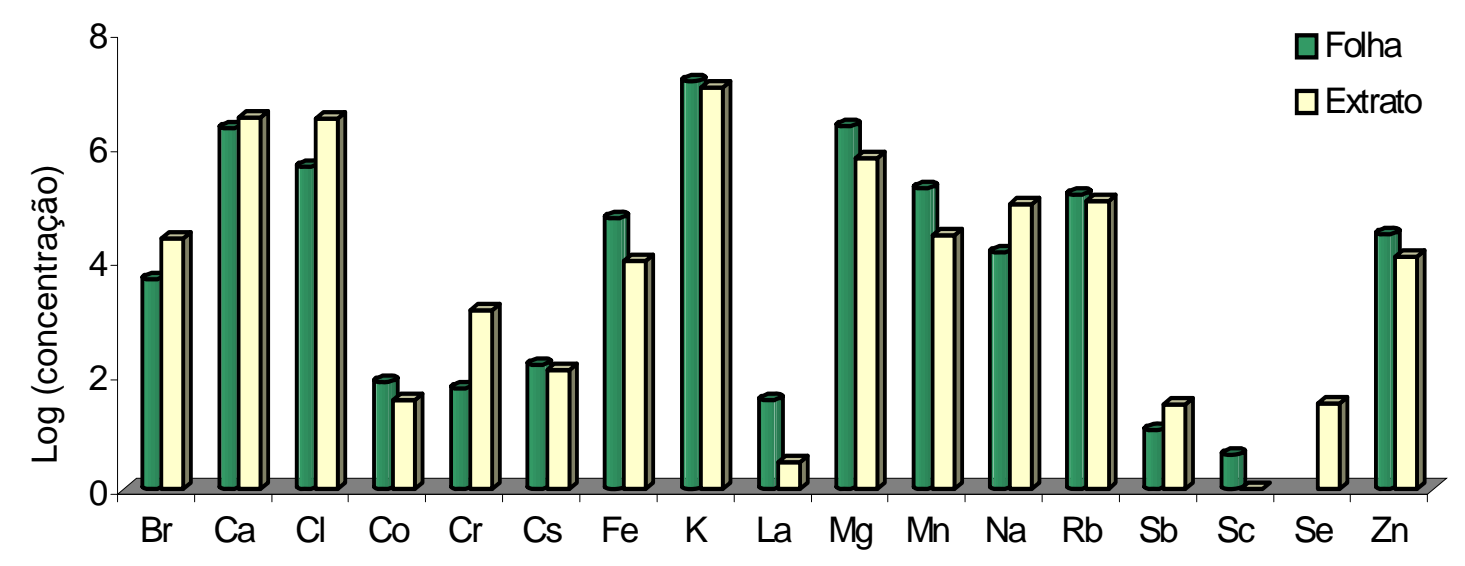

FIGURA 5.14 - Concentrações dos elementos determinados nas folhas (J2) e no extrato (E2) de C. decandra. Concentrações em ng g $\mathrm{g}^{-1}$.

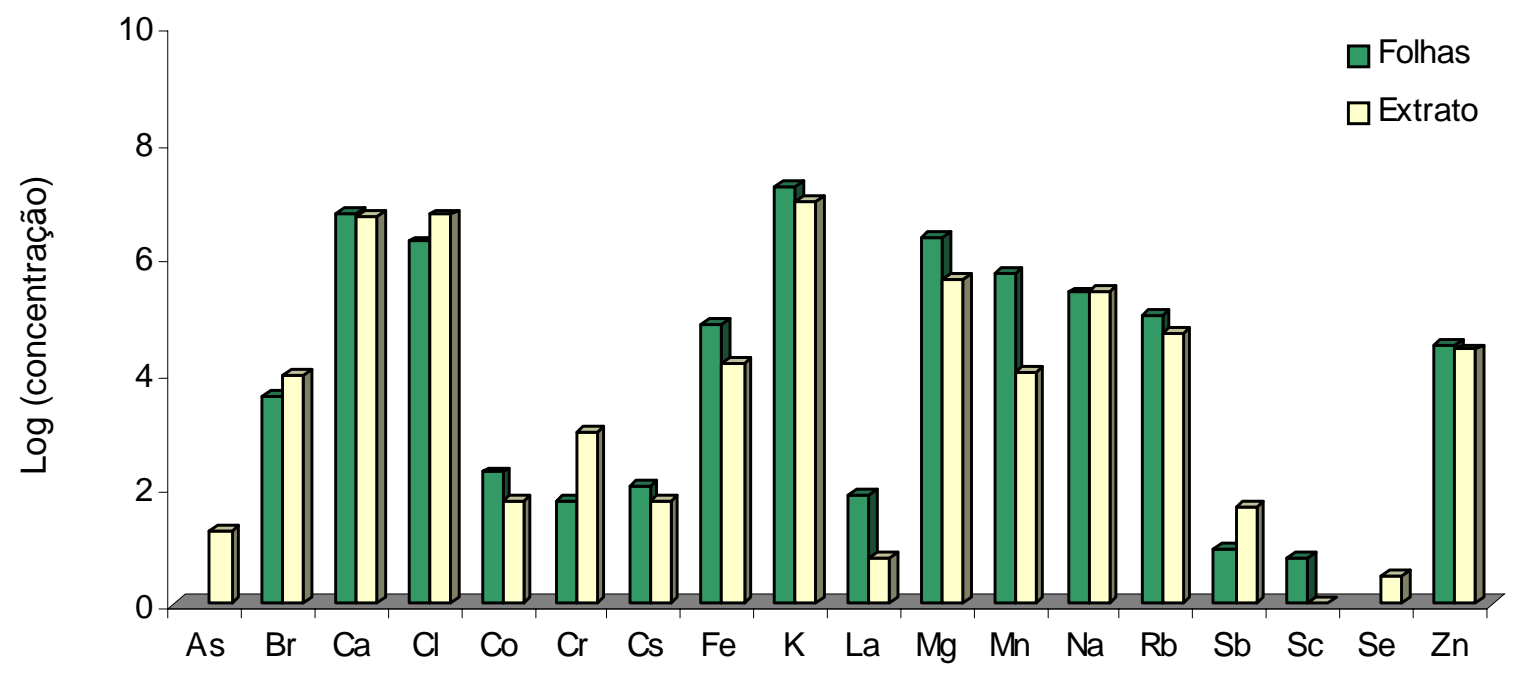

FIGURA 5.15 - Concentrações dos elementos determinados nas folhas (J3) e no extrato (E3) de C. obliqua. Concentrações em ng g ${ }^{-1}$. 


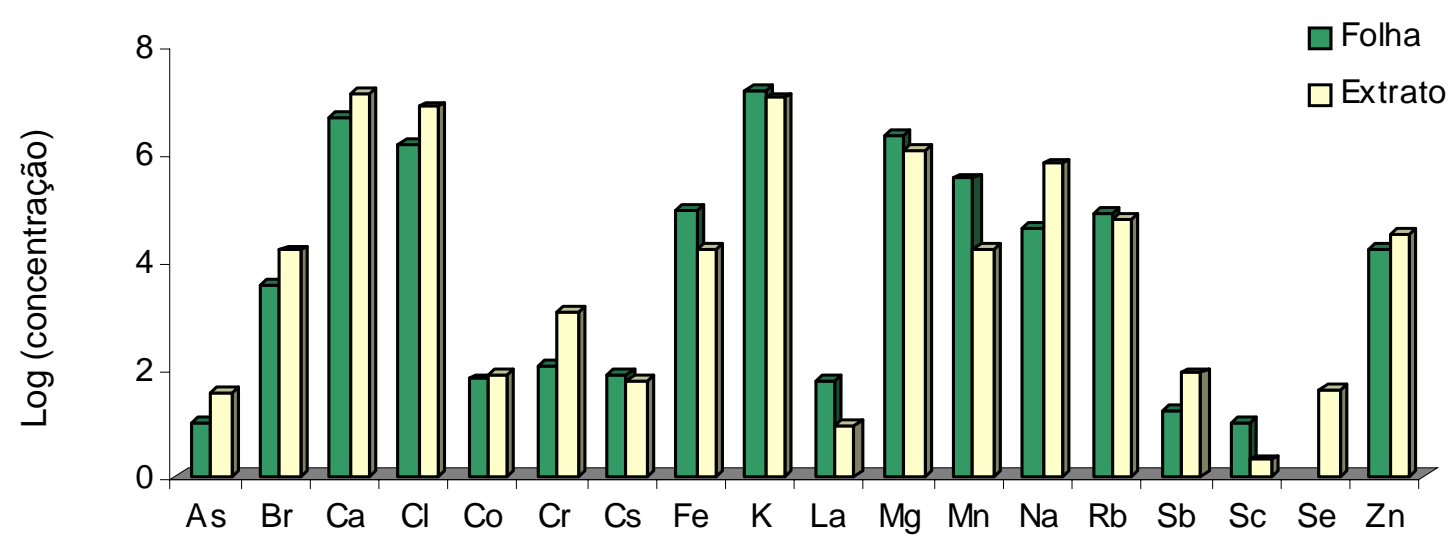

FIGURA 5.16 - Concentrações dos elementos determinados nas folhas (J4) e no extrato (E4) de C. sylvestris. Concentrações em ng g ${ }^{-1}$.

Conforme mostram os resultados das FIG. 5.14 a 5.16, todos os elementos encontrados nas folhas foram também detectados nos seus respectivos extratos, indicando que houve transferência dos componentes inorgânicos das folhas para a solução etanólica.

As concentrações da maioria dos elementos encontrados nos extratos foram da mesma ordem de grandeza ou mais altas que as das folhas, indicando que a extração proporciona a preconcentração destes elementos. As únicas exceções foram Fe, La, Mg, Mn e Sc cujos teores mais elevados foram obtidos nas folhas, o que indica que houve baixa extratibilidade destes elementos para a solução etanólica. 
5.4 Resultados das análises dos solos

Foram determinadas as concentrações dos elementos Ca, Ce, Eu, Fe, Hf, La, $\mathrm{Lu}, \mathrm{Nd}, \mathrm{Rb}, \mathrm{Sc}, \mathrm{Sm}, \mathrm{Tb}, \mathrm{Th}, \mathrm{U}$ e Zn nas amostras de solo coletadas em diferentes localidades da Mata Atlântica, juntos às plantas C. sylvestris, C. decandra e C. obliqua. Os resultados obtidos nestas análises estão apresentados na TAB. 5.8. Os resultados individuais destas análises encontram-se no Apêndice 4.

As concentrações dos elementos Ca e Fe foram determinadas em níveis de porcentagens, dos elementos Hf, La, Nd, Rb, Sc, Sm, Th, U, Yb e Zn da ordem de $\mu \mathrm{g} \mathrm{g}^{-1}$ e dos elementos Ce, Eu, Lu e Tb da ordem de ng g ${ }^{-1}$.

A TAB. 5.8 mostra que os resultados obtidos apresentaram uma boa precisão para todos os elementos analisados, com desvios padrão relativos inferiores a 8,1\%. A boa reprodutibilidade obtida na maioria dos elementos analisados indica a homogeneidade das amostras de solo preparadas para os elementos analisados.

Os resultados das determinações de $\mathrm{pH}$ das amostras de solo também se encontram na TAB. 5.8. Os valores de $\mathrm{pH}$ apresentados correspondem a uma média de três determinações. Estes resultados de $\mathrm{pH}$ indicam que os solos em que as plantas foram cultivadas eram ácidos, com valores de pH que variaram de 3,29 a 4,48. Segundo NYE (1981), os solos coletados próximos às raízes das plantas são comumente ácidos devido à liberação de íons $\mathrm{H}^{+}$pelas células radiculares em troca da absorção de $\mathrm{K}^{+}$e $\mathrm{Ca}^{2+}$, com o intuito de manter o equilíbrio de cargas nas células. 
TABELA 5.8 - Médias das concentrações de elementos e medidas de pH nas amostras de solo.

\begin{tabular}{|c|c|c|c|c|c|c|c|c|c|c|c|c|c|c|c|c|c|c|}
\hline \multirow[b]{2}{*}{ Elemento } & \multicolumn{3}{|c|}{$\mathrm{K} 1$} & \multicolumn{3}{|c|}{$\mathrm{K} 2$} & \multicolumn{3}{|c|}{ K3 } & \multicolumn{3}{|c|}{$\mathrm{K} 4$} & \multicolumn{3}{|c|}{ K56 } & \multicolumn{3}{|c|}{ K7 } \\
\hline & $\mathrm{N}$ & $\mathrm{X} \pm \mathrm{DP}$ & $\begin{array}{l}\text { DPR } \\
(\%)\end{array}$ & $\mathrm{n}$ & $\mathrm{X} \pm \mathrm{DP}$ & $\begin{array}{l}\text { DPR } \\
(\%)\end{array}$ & $\mathrm{n}$ & $X \pm D P$ & $\begin{array}{l}\text { DPR } \\
(\%)\end{array}$ & $\mathrm{n}$ & $X \pm D P$ & $\begin{array}{l}\text { DPR } \\
(\%)\end{array}$ & $\mathrm{n}$ & $\mathrm{X} \pm \mathrm{DP}$ & $\begin{array}{l}\text { DPR } \\
(\%)\end{array}$ & $\mathrm{n}$ & $X \pm D P$ & $\begin{array}{c}\text { DP } \\
\text { R } \\
(\%)\end{array}$ \\
\hline $\mathrm{Ca}(\%)$ & 3 & $1,03 \pm 0,04$ & 3,9 & 2 & $0,46 \pm 0,02$ & 4,3 & 3 & $0,75 \pm 0,02$ & 2,0 & 3 & $0,52 \pm 0,01$ & 2,7 & 3 & $0,80 \pm 0,02$ & 2,1 & 2 & $0,51 \pm 0,02$ & 3,9 \\
\hline $\mathrm{Ce}\left(\mathrm{ng} \mathrm{g}^{-1}\right)$ & 3 & $184 \pm 1$ & 0,5 & 2 & $120 \pm 1$ & 0,7 & 3 & $120 \pm 1$ & 0,6 & 3 & $122 \pm 1$ & 0,5 & 3 & $105 \pm 1$ & 0,5 & 2 & $151 \pm 2$ & 0,7 \\
\hline $\mathrm{Eu}\left(\mathrm{ng} \mathrm{g}^{-1}\right)$ & 3 & $2470 \pm 80$ & 3,2 & 3 & $422 \pm 12$ & 2,8 & 2 & $444 \pm 12$ & 2,7 & 3 & $545 \pm 14$ & 2,6 & 3 & $377 \pm 10$ & 2,7 & 2 & $356 \pm 14$ & 3,9 \\
\hline $\mathrm{Fe}(\%)$ & 3 & $4,91 \pm 0,08$ & 1,6 & 2 & $1,96 \pm 0,03$ & 1,5 & 4 & $2,20 \pm 0,03$ & 1,4 & 3 & $1,75 \pm 0,03$ & 1,7 & 3 & $1,51 \pm 0,02$ & 1,3 & 2 & $1,37 \pm 0,02$ & 1,5 \\
\hline $\mathrm{Hf}\left(\mu \mathrm{g} \mathrm{g}^{-1}\right)$ & 3 & $13,1 \pm 0,1$ & 0,8 & 2 & $10,86 \pm 0,08$ & 0,7 & 3 & $9,70 \pm 0,06$ & 0,6 & 3 & $9,10 \pm 0,08$ & 0,9 & 3 & $12,5 \pm 0,1$ & 0,8 & 2 & $8,89 \pm 0,07$ & 0,8 \\
\hline La $\left(\mathrm{ng} \mathrm{g}^{-1}\right)$ & 3 & $91,0 \pm 0,5$ & 0,5 & 2 & $36,5 \pm 0,6$ & 1,6 & 3 & $41,0 \pm 0,3$ & 0,7 & 3 & $48,9 \pm 0,2$ & 0,4 & 3 & $28,0 \pm 0,2$ & 0,7 & 2 & $44,0 \pm 0,3$ & 0,7 \\
\hline Lu $\left(\mathrm{ng} \mathrm{g}^{-1}\right)$ & 3 & $331 \pm 5$ & 1,5 & 2 & $228 \pm 3$ & 1,3 & 3 & $142 \pm 2$ & 1,4 & 3 & $143 \pm 2$ & 1,4 & 3 & $196 \pm 2$ & 1,0 & 2 & $240 \pm 3$ & 1,3 \\
\hline $\mathrm{Nd}\left(\mu \mathrm{g} \mathrm{g}^{-1}\right)$ & 3 & $67,5 \pm 3,9$ & 5,8 & 2 & $23,95 \pm 1,76$ & 7,3 & 3 & $18,43 \pm 1,05$ & 5,7 & 3 & $30,7 \pm 2,5$ & 8,1 & 3 & $21,0 \pm 1,8$ & 8,6 & 2 & $24,2 \pm 1,7$ & 7,0 \\
\hline $\mathrm{Rb}\left(\mu \mathrm{g} \mathrm{g}^{-1}\right)$ & 3 & $15,3 \pm 1,1$ & 7,2 & 3 & $23,2 \pm 0,8$ & 3,4 & 4 & $14,1 \pm 0,5$ & 3,5 & 3 & $37,2 \pm 1,7$ & 4,6 & 3 & $17,7 \pm 0,8$ & 4,3 & 2 & $17,6 \pm 1,0$ & 5,7 \\
\hline $\mathrm{SC}\left(\mu \mathrm{g} \mathrm{g}^{-1}\right)$ & 3 & $14,5 \pm 0,1$ & 0,7 & 3 & $3,73 \pm 0,03$ & 0,8 & 4 & $4,45 \pm 0,03$ & 0,7 & 3 & $3,78 \pm 0,03$ & 0,8 & 3 & $3,09 \pm 0,02$ & 0,6 & 2 & $3,37 \pm 0,03$ & 0,9 \\
\hline $\operatorname{Sm}\left(\mu \mathrm{g} \mathrm{g}^{-1}\right)$ & 3 & $11,45 \pm 0,02$ & 0,2 & 2 & $3,60 \pm 0,02$ & 0,6 & 3 & $2,867 \pm 0,004$ & 0,1 & 3 & $3,973 \pm 0,004$ & 0,1 & 3 & $2,325 \pm 0,003$ & 0,1 & 2 & $3,172 \pm 0,004$ & 0,1 \\
\hline $\mathrm{Tb}\left(\mathrm{ng} \mathrm{g}^{-1}\right)$ & 3 & $1170 \pm 50$ & 4,3 & 3 & $329 \pm 18$ & 5,5 & 2 & $313 \pm 18$ & 5,8 & 3 & $397 \pm 18$ & 4,5 & 3 & $274 \pm 14$ & 5,1 & 2 & $331 \pm 21$ & 6,3 \\
\hline Th $\left(\mu \mathrm{g} \mathrm{g}^{-1}\right)$ & 3 & $21,9 \pm 0,2$ & 0,9 & 2 & $37,1 \pm 0,2$ & 0,5 & 3 & $37,7 \pm 0,2$ & 0,5 & 3 & $34,8 \pm 0,1$ & 0,3 & 3 & $15,9 \pm 0,1$ & 0,6 & 2 & $36,2 \pm 0,3$ & 0,8 \\
\hline$U\left(\mu g^{-1}\right)$ & 3 & $4,18 \pm 0,09$ & 2,2 & 2 & $4,30 \pm 0,05$ & 1,2 & 3 & $6,35 \pm 0,05$ & 0,8 & 3 & $6,21 \pm 0,05$ & 0,8 & 3 & $3,61 \pm 0,04$ & 1,1 & 2 & $3,91 \pm 0,06$ & 1,5 \\
\hline $\mathrm{Yb}\left(\mu \mathrm{g} \mathrm{g}^{-1}\right)$ & 3 & $2,24 \pm 0,05$ & 2,2 & 2 & $1,26 \pm 0,01$ & 0,8 & 3 & $0,84 \pm 0,02$ & 2,4 & 3 & $0,87 \pm 0,01$ & 1,1 & 3 & $1,21 \pm 0,01$ & 0,8 & 2 & $1,23 \pm 0,01$ & 0,8 \\
\hline $\mathrm{Zn}\left(\mu \mathrm{g} \mathrm{g}^{-1}\right)$ & 3 & $44,6 \pm 1,2$ & 2,7 & 2 & $32,5 \pm 0,7$ & 2,2 & 4 & $29,0 \pm 0,6$ & 2,1 & 3 & $39,2 \pm 0,5$ & 0,1 & 3 & $34,8 \pm 0,6$ & 1,7 & 2 & $36,6 \pm 0,8$ & 2,2 \\
\hline $\mathrm{pH}$ & & 4,48 & & & 3,38 & & & 3,48 & & & 3,85 & & & 3,95 & & & 3,29 & \\
\hline
\end{tabular}

$\mathrm{n}$ = número de determinações; $\mathrm{DP}=$ desvio padrão; DPR = desvio padrão relativo; $\mathrm{Er}=$ erro relativo percentual; ND = não detectado

K1 - Amostra de solo coletada no IQUSP, junto à $C$. sylvestris cultivada no local $\quad$ K4 - Amostra de solo coletada no Morro Grande, junto à $C$. sylvestris nativa do local.

K2 - Amostra de solo coletada no Morro Grande, junto à C. obliqua nativa do local. K56 - Amostra de solo coletada no Morro Grande, junto à C. sylvestris cultivada no local.

K3 - Amostra de solo coletada no Morro Grande, junto à C. decandra nativa do local. K7 - Amostra de solo coletada no Morro Grande, junto à C. obliqua nativa do local. 
A amostra de solo K1 coletada no IQUSP destaca-se por apresentar as mais elevadas concentrações de $\mathrm{Ca}$, Fe, $\mathrm{Zn}$ e elementos de terras raras, além do pH mais alto em relação às amostras coletadas na Reserva do Morro Grande.

O dendrograma da FIG. 5.17, elaborado com base nos dados da TAB. 5.8, confirma a grande dissimilaridade da amostra de solo coletada no IQUSP (grupo I) em relação e às amostras coletadas na Reserva do Morro Grande, reunidas no grupo II do dendrograma.

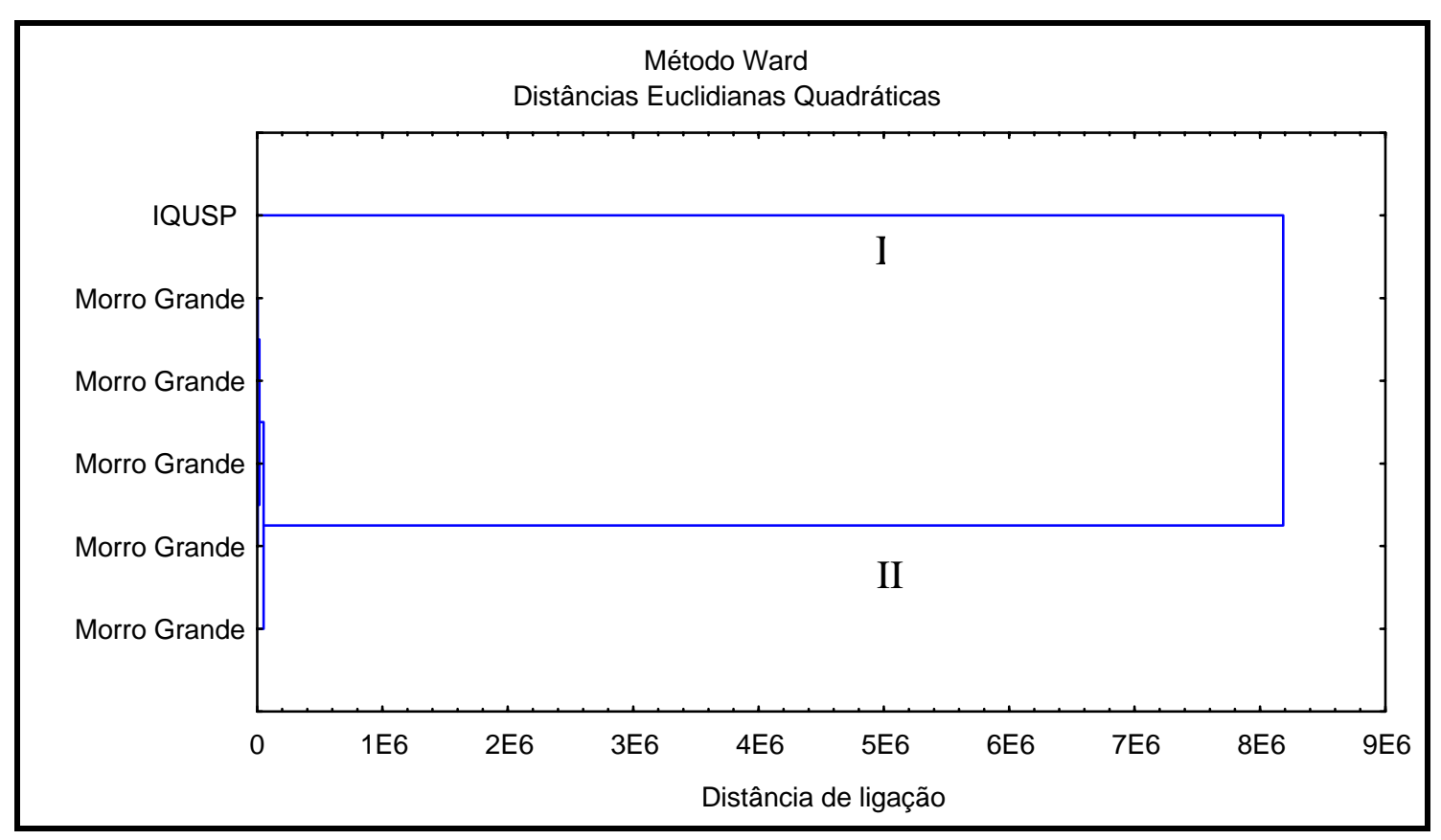

FIGURA 5.17 - Dendrograma obtido na análise de clusters utilizando o método Ward de ligação.

Para melhor visualização das dissimilaridades entre as amostras de solo contidas no grupo II, foi construído um novo dendrograma retirando-se da análise de agrupamentos os resultados obtidos para a amostra do IQUSP (K1). 


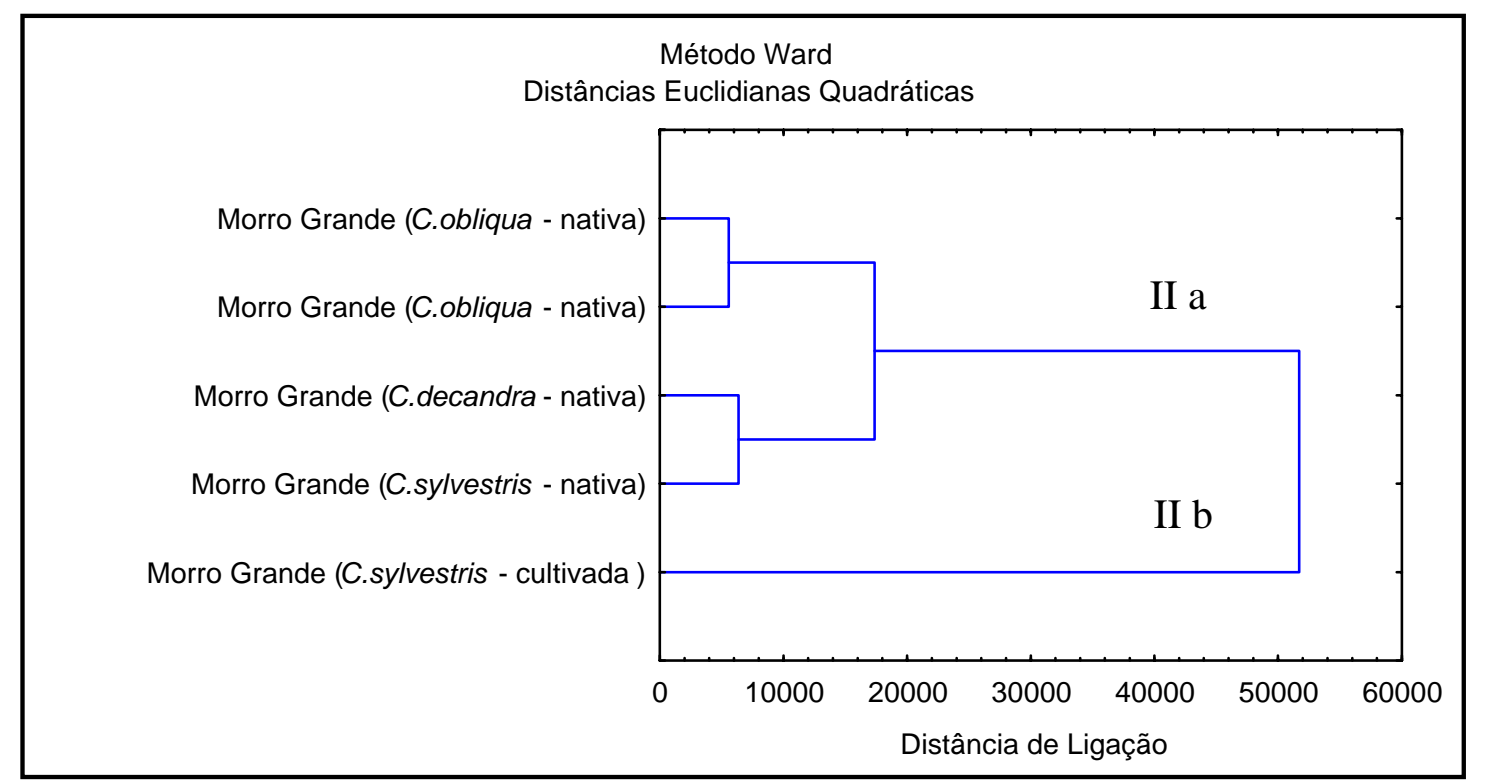

FIGURA 5.18 - Dendrograma obtido na análise de clusters utilizando o método Ward de ligação, retirando os dados obtidos para a amostra do IQUSP.

O dendrograma da FIG. 5.18 mostra que as amostras de solo da Reserva do Morro Grande coletadas junto às amostras nativas de plantas do gênero Casearia formam o subgrupo IIa, enquanto que o grupo IIb é formado pela amostra de solo coletada junto à Casearia sylvestris que foi cultivada na Reserva do Morro Grande. Isto indica que o solo em que a $C$. sylvestris foi cultivada apresenta características que a diferenciam dos solos coletados junto às plantas nativas da Reserva do Morro Grande.

\subsubsection{Coeficiente de Absorção Biológico}

A capacidade de uma espécie de planta absorver nutrientes retirados do solo foi avaliada calculando-se o coeficiente de absorção biológico (BAC), também conhecido como índice de bioacumulação. O valor do BAC é obtido pela razão entre a concentração do elemento na planta $\left(C_{p}\right)$ e a concentração do mesmo elemento no solo $\left(C_{s}\right)($ KABATAPENDIAS \& PENDIAS, 1984). 
Foram calculados os valores de BAC dos elementos Ca, Fe, La, Rb, Sc e Zn determinados tanto nas folhas quanto nos solos. Os resultados obtidos para as amostras de folhas e solos da Reserva do Morro Grande foram utilizados para comparar os valores de BAC das três diferentes espécies de Casearia. Estes valores de BAC obtidos foram representados nos gráficos de A a C da FIG. 5.19.

Segundo KABATA-PENDIAS \& PENDIAS (1984), alguns elementos como o Cd, B, Cs e Rb, são facilmente absorvidos e acumulados nas plantas, enquanto que outros como Fe, são de difícil absorção e acumulação. Comparando os valores de BAC obtidos para as três espécies de Casearia observa-se que para Ca, Fe e Zn estes valores foram em geral bastante próximos nas três amostras analisadas. Além disso, as três espécies apresentaram valores elevados de BAC para o elemento $\mathrm{Rb}$ e, no caso do $\mathrm{Fe}$, o valor do BAC foi próximo de zero, e estes resultados são concordantes com aqueles obtidos por outros pesquisadores (HOKURA e col., 2000 ; DE FRANÇA, 2005).

A FIG. 5.19 mostra ainda que os perfis de acumulação dos elementos nas espécies C. decandra (A) e C. obliqua (B) foram bastante semelhantes entre si. Em relação a estas duas espécies, a C. sylvestris (C) apresentou um perfil de acumulação diferente, tendo um valor de BAC para Rb mais baixo e para Sc mais elevado.

Conforme mencionado anteriormente, MENEZES (2004) comprovou que a resposta farmacológica da Casearia sylvestris a úlceras gástricas é significativamente maior em relação às respostas da Casearia obliqua e da Casearia decandra. Os resultados apresentados na FIG. 5.19 confirmam que a C. sylvestris apresenta uma característica de absorção e acumulação de elementos retirados do solo que a diferencia das demais espécies. 


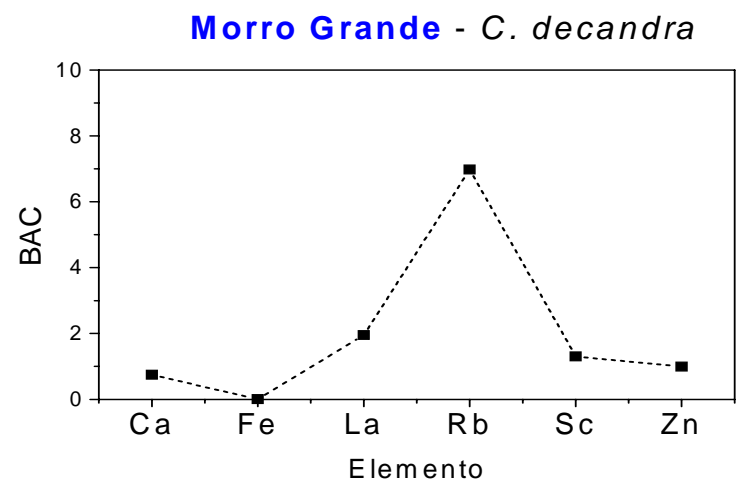

B

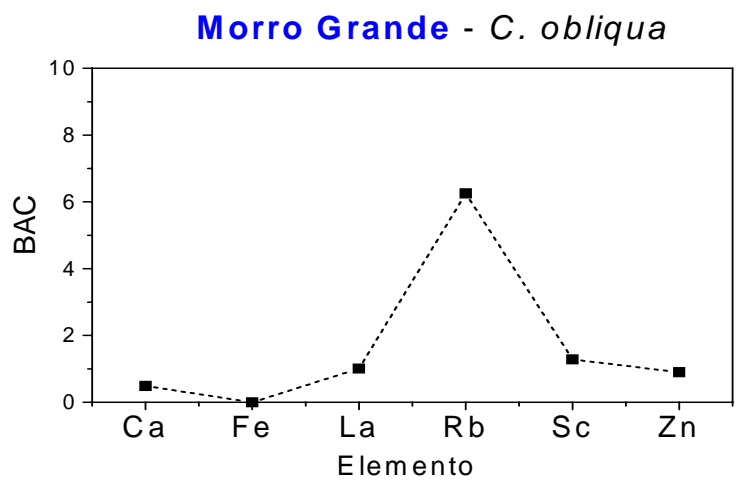

C

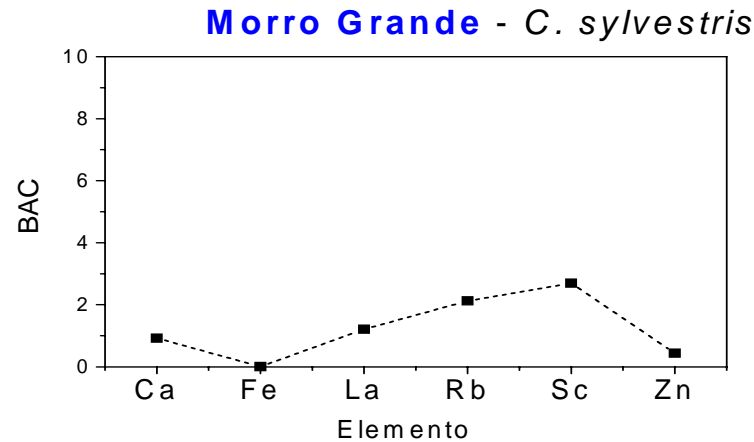

FIGURA 5.19 - Coeficientes de Absorção Biológica (BAC) para as espécies do gênero Casearia analisadas neste trabalho. 
5.5 Resultados de limite de detecção e determinação dos elementos

Os valores de limite de detecção $\left(\mathrm{L}_{\mathrm{D}}\right)$ e de determinação $\left(\mathrm{L}_{\mathrm{Q}}\right)$ obtidos para os elementos analisados respectivamente em uma amostra de folha e uma de solo estão nas TAB. 5.9 e 5.10, respectivamente. No caso da folha a amostra analisada foi a J1 e no caso do solo a amostra K2. Os limites de detecção e determinação obtidos em ambos os tipos de matrizes variaram de $\mu \mathrm{g} \mathrm{g}^{-1}$ a ng g ${ }^{-1}$ comprovando a sensibilidade da metodologia de INAA utilizada neste trabalho.

TABELA 5.9 - Limites de detecção $\left(\mathrm{L}_{\mathrm{D}}\right)$ e determinação $\left(\mathrm{L}_{\mathrm{Q}}\right)$ dos elementos obtidos na análise de folha de Casearia (amostra J1).

\begin{tabular}{ccccc}
\hline Elemento & $\begin{array}{c}\text { Radioisótopo } \\
\text { medido }\end{array}$ & $\begin{array}{c}\text { Energia do pico } \\
\text { utilizado }(\mathrm{keV})\end{array}$ & $\mathrm{L}_{\mathrm{D}}$ & $\mathrm{L}_{\mathrm{Q}}$ \\
\hline $\mathrm{Al}\left(\mu \mathrm{g} \mathrm{g}^{-1}\right)$ & ${ }^{28} \mathrm{Al}$ & 1778,99 & 429,7 & $-*$ \\
$\mathrm{As}\left(\mathrm{ng} \mathrm{g}^{-1}\right)$ & ${ }^{76} \mathrm{As}$ & 559,10 & 10,4 & 36,4 \\
$\mathrm{Br}\left(\mathrm{ng} \mathrm{g}^{-1}\right)$ & ${ }^{82} \mathrm{Br}$ & 776,52 & 19,9 & 60,7 \\
$\mathrm{Ca}\left(\mu \mathrm{g} \mathrm{g}^{-1}\right)$ & ${ }^{47} \mathrm{Ca}$ & 1297,09 & 67,8 & 215,7 \\
$\mathrm{Cd}\left(\mu \mathrm{g} \mathrm{g}^{-1}\right)$ & ${ }^{115} \mathrm{Cd}$ & 336,26 & 185,9 & 568,7 \\
$\mathrm{Cl}\left(\mu \mathrm{g} \mathrm{g}^{-1}\right)$ & ${ }^{38} \mathrm{Cl}$ & 1642,69 & 53,1 & 257,6 \\
$\mathrm{Co}\left(\mathrm{ng} \mathrm{g}^{-1}\right)$ & ${ }^{60} \mathrm{Co}$ & 1332,50 & 2,1 & 6,9 \\
$\mathrm{Cr}\left(\mathrm{ng} \mathrm{g}^{-1}\right)$ & ${ }^{51} \mathrm{Cr}$ & 320,08 & 28,2 & 87,1 \\
$\mathrm{Cs}\left(\mathrm{ng} \mathrm{g}^{-1}\right)$ & ${ }^{134} \mathrm{Cs}$ & 795,85 & 7,4 & 22,8 \\
$\mathrm{Cu}\left(\mu \mathrm{g} \mathrm{g}^{-1}\right)$ & ${ }^{66} \mathrm{Cu}$ & 1039,20 & 326,9 & - \\
$\mathrm{Fe}\left(\mu \mathrm{g} \mathrm{g}^{-1}\right)$ & ${ }^{59} \mathrm{Fe}$ & 1291,60 & 2,5 & 7,8 \\
$\mathrm{~K}\left(\mu \mathrm{g} \mathrm{g}^{-1}\right)$ & ${ }^{42} \mathrm{~K}$ & 1524,58 & 11,7 & 35,9 \\
$\mathrm{La}\left(\mathrm{ng} \mathrm{g}^{-1}\right)$ & ${ }^{140} \mathrm{La}$ & 1596,21 & 4,4 & 13,6 \\
$\mathrm{Mg}\left(\mu \mathrm{g} \mathrm{g}^{-1}\right)$ & ${ }^{27} \mathrm{Mg}$ & 1014,43 & 438 & 1567 \\
$\mathrm{Mn}\left(\mu \mathrm{g} \mathrm{g}^{-1}\right)$ & ${ }^{56} \mathrm{Mn}$ & 846,76 & 2,8 & 8,47 \\
$\mathrm{Na}\left(\mu \mathrm{g} \mathrm{g}^{-1}\right)$ & ${ }^{24} \mathrm{Na}$ & 1368,60 & 0,10 & 0,32 \\
$\mathrm{Rb}\left(\mu \mathrm{g} \mathrm{g}^{-1}\right)$ & ${ }^{86} \mathrm{Rb}$ & 1076,60 & 0,12 & 0,37 \\
$\mathrm{Sb}\left(\mathrm{ng} \mathrm{g}^{-1}\right)$ & ${ }^{122} \mathrm{Sb}$ & 564,24 & 5,0 & 15,2 \\
$\mathrm{Sc}\left(\mathrm{ng} \mathrm{g}^{-1}\right)$ & ${ }^{46} \mathrm{Sc}$ & 889,28 & 0,33 & 1,04 \\
$\mathrm{Se}\left(\mathrm{ng} \mathrm{g}^{-1}\right)$ & ${ }^{75} \mathrm{Se}$ & 264,66 & 31,7 & 97,8 \\
$\mathrm{~V}\left(\mu \mathrm{g} \mathrm{g}^{-1}\right)$ & ${ }^{52} \mathrm{~V}$ & 1434,08 & & - \\
$\mathrm{Zn}\left(\mu \mathrm{g} \mathrm{g}^{-1}\right)$ & ${ }^{65} \mathrm{Zn}$ & 115,55 & & \\
\hline
\end{tabular}

* - indica que não foi realizado o cálculo do limite. 
TABELA 5.10 - Limites de detecção e determinação dos elementos em matriz de solo (amostra K2).

\begin{tabular}{ccccc}
\hline Elemento & $\begin{array}{c}\text { Radioisótopo } \\
\text { medido }\end{array}$ & $\begin{array}{c}\text { Energia do pico } \\
\text { utilizado }(\mathrm{keV})\end{array}$ & $\mathrm{L}_{\mathrm{D}}$ & $\mathrm{L}_{\mathrm{Q}}$ \\
\hline $\mathrm{Ca}\left(\mu \mathrm{g} \mathrm{g}^{-1}\right)$ & ${ }^{47} \mathrm{Ca}$ & 1297,09 & 768,2 & 2350 \\
$\mathrm{Ce}\left(\mu \mathrm{g} \mathrm{g}^{-1}\right)$ & ${ }^{141} \mathrm{Ce}$ & 145,44 & 0,35 & 1,08 \\
$\mathrm{Eu}\left(\mathrm{ng} \mathrm{g}^{-1}\right)$ & ${ }^{152} \mathrm{Eu}$ & 1408,00 & 35,2 & 110,8 \\
$\mathrm{Fe}\left(\mu \mathrm{g} \mathrm{g}^{-1}\right)$ & ${ }^{59} \mathrm{Fe}$ & 1291,60 & 74,0 & 228,6 \\
$\mathrm{Hf}\left(\mathrm{ng} \mathrm{g}^{-1}\right)$ & ${ }^{181} \mathrm{Hf}$ & 208,36 & 102,4 & 314,0 \\
$\mathrm{La}\left(\mathrm{ng} \mathrm{g}^{-1}\right)$ & ${ }^{140} \mathrm{La}$ & 1596,21 & 40,2 & 124,4 \\
$\mathrm{Lu}\left(\mathrm{ng} \mathrm{g}^{-1}\right)$ & ${ }^{177} \mathrm{Lu}$ & 208,36 & 25,0 & 76,5 \\
$\mathrm{Nd}\left(\mathrm{ng} \mathrm{g}^{-1}\right)$ & ${ }^{147} \mathrm{Nd}$ & 531,01 & 13871 & 42569 \\
$\mathrm{Rb}\left(\mu \mathrm{g} \mathrm{g}^{-1}\right)$ & ${ }^{86} \mathrm{Rb}$ & 1076,60 & 2,7 & 8,53 \\
$\mathrm{Sc}\left(\mathrm{ng} \mathrm{g}^{-1}\right)$ & ${ }^{46} \mathrm{Sc}$ & 889,28 & 14,7 & 45,6 \\
$\mathrm{Sm}\left(\mathrm{ng} \mathrm{g}^{-1}\right)$ & ${ }^{153} \mathrm{Sm}$ & 103,18 & 7,6 & 23,1 \\
$\mathrm{~Tb}\left(\mathrm{ng} \mathrm{g}^{-1}\right)$ & ${ }^{160} \mathrm{~Tb}$ & 879,38 & 115,1 & 353,6 \\
$\mathrm{Th}\left(\mathrm{ng} \mathrm{g}^{-1}\right)$ & ${ }^{233} \mathrm{~Pa}$ & 312,01 & 91,2 & 279,1 \\
$\mathrm{U}\left(\mu \mathrm{g} \mathrm{g} \mathrm{g}^{-1}\right)$ & ${ }^{239} \mathrm{~Np}$ & 277,60 & 0,30 & 0,93 \\
$\mathrm{Yb}\left(\mathrm{ng} \mathrm{g}^{-1}\right)$ & ${ }^{175} \mathrm{Yb}$ & 396,33 & 96,7 & 296,1 \\
$\mathrm{Zn}\left(\mu \mathrm{g} \mathrm{g}^{-1}\right)$ & ${ }^{65} \mathrm{Zn}$ & 115,55 & 3,1 & 9,6 \\
\hline
\end{tabular}




\section{CONCLUSÕES}

Os resultados obtidos neste trabalho indicaram que a análise por ativação com nêutrons é uma técnica bastante sensível e adequada para a determinação dos elementos As, Br, Ca, Cl, Co, Cr, Cs, Fe, K, La, Mg, Mn, Na, Rb, Sc, e Zn em folhas e extratos de planta, bem como Ca, Ce, Eu, Fe, Hf, La, Lu, Nd, Rb, Sc, Sm, Tb, Th, U e Zn em amostras de solo. As análises dos materiais de referência indicaram que os procedimentos analíticos adotados permitem a determinação das concentrações destes elementos com boa precisão e exatidão.

Os resultados obtidos nas análises das folhas e dos solos foram reprodutíveis, indicando que as amostras estavam homogêneas, e que, portanto, o procedimento de tratamento dessas amostras foi adequado.

Os resultados obtidos para as folhas de diferentes espécies de Casearia permitiram concluir que as concentrações de elementos nessas plantas dependem da região em que foram cultivadas. A espécie C. sylvestris cultivada no IQUSP apresentou concentrações mais altas de diversos elementos se comparada às amostras de C. sylvestris cultivada na Reserva do Morro Grande. O solo coletado junto à $C$. sylvestris no IQUSP também apresentou concentrações de elementos e pH mais elevados em relação às amostras de solos coletadas na Reserva do Morro Grande. Este estudo mostrou também que as amostras de folhas das diferentes espécies de Casearia coletadas numa mesma região não apresentaram diferenças significativas na maioria de seus constituintes inorgânicos. No entanto, dentre as três espécies, a que apresentou a maior atividade farmacológica foi a C. sylvestris e nas folhas desta planta foram encontradas concentrações ligeiramente mais elevadas de As, $\mathrm{Cr}, \mathrm{Fe}, \mathrm{Sb}$ e Sc em relação às duas outras espécies. Isto indica que estes constituintes inorgânicos podem participar da biossíntese de compostos 
farmacologicamente ativos, responsáveis pelas propriedades curativas das plantas do gênero Casearia.

Os resultados dos coeficientes de absorção biológica para as três espécies de Casearia indicaram que C. sylvestris apresenta uma característica de acumulação de elementos diferente se comparada às espécies $C$. obliqua e $C$. decandra que apresentaram perfis de acumulação de elementos bastante semelhantes entre si.

A comparação entre as composições elementares das folhas e dos extratos de Casearia mostrou que para a maioria dos elementos as concentrações obtidas para as folhas foram da mesma ordem de grandeza daquelas obtidas nos extratos. Os elementos encontrados em altas concentrações nas folhas foram também os de maior concentração nos seus respectivos extratos.

Com relação aos elementos encontrados nas folhas e extratos de Casearia convém salientar que elementos com importantes funções biológicas no organismo humano foram determinados em altas concentrações, como o K, Ca e Mg. Elementos tóxicos como Cd, Cu e Hg não foram detectados nas folhas e nos extratos e os teores dos elementos As, Sb e Se encontrados em algumas das amostras analisadas foram baixos. 
APÊNDICE 1. Resultados individuais obtidos nas análises dos materiais de referência certificados.

TABELA 1 - Concentrações dos elementos obtidas nas análises do material de referência Apple Leaves (NIST 1515), em $\mu \mathrm{g} \mathrm{g}^{-1}$ (a menos que esteja indicado).

\begin{tabular}{ll}
\hline Elemento & Resultados individuais \\
\hline As & $0,028 \pm 0,008^{*} ; 0,044 \pm 0,005 ; 0,033 \pm 0,006 ; 0,037 \pm 0,004$ \\
Br & $2,1 \pm 0,01 ; 2,5 \pm 0,01 ; 1,7 \pm 0,01 ; 2,2 \pm 0,01$ \\
Ca (\%) & $1,61 \pm 0,02 ; 1,57 \pm 0,04 ; 1,52 \pm 0,02 ; 1,49 \pm 0,06$ \\
Cl & $485 \pm 21 ; 498 \pm 26 ; 479 \pm 21 ; 519 \pm 35$ \\
Co (ng g $\left.{ }^{-1}\right)$ & $109 \pm 3 ; 108 \pm 3 ; 106 \pm 3 ; 103 \pm 2 ; 109 \pm 4$ \\
Cr (ng g $\left.{ }^{-1}\right)$ & $984 \pm 21 ; 743 \pm 19 ; 748 \pm 22 ; 825 \pm 18 ; 928 \pm 24$ \\
Fe & $83,1 \pm 1,5 ; 83,4 \pm 2 ; 80,0 \pm 1,3 ; 80,4 \pm 2$ \\
K (\%) & $1,67 \pm 0,01 ; 1,54 \pm 0,01 ; 1,61 \pm 0,02 ; 1,66 \pm 0,01$ \\
La & $20,5 \pm 0,1 ; 19,0 \pm 0,1 ; 19,9 \pm 0,1 ; 19,2 \pm 0,1 ; 22,4 \pm 0,1$ \\
Mg (\%) & $0,24 \pm 0,03 ; 0,22 \pm 0,03 ; 0,28 \pm 0,03$ \\
Mn & $47,7 \pm 1,0 ; 51,5 \pm 1,3 ; 50,8 \pm 1,0$ \\
Rb & $10,1 \pm 0,2 ; 10,1 \pm 0,1 ; 9,6 \pm 0,2 ; 9,3 \pm 0,1$ \\
Sb (ng g $\left.{ }^{-1}\right)$ & $18,9 \pm 2,1 ; 17,7 \pm 2,8 ; 17,3 \pm 2,5 ; 14,9 \pm 3,3$ \\
Sc (ng g $\left.{ }^{-1}\right)$ & $30,8 \pm 0,2 ; 28,9 \pm 0,5 ; 31,5 \pm 0,3 ; 32,0 \pm 0,2 ; 30,6 \pm 0,3$ \\
\hline & $0,054 \pm 0,013 ; 0,051 \pm 0,015 ; 0,060 \pm 0,013$ \\
\hline Se & $13,9 \pm 0,3 ; 12,9 \pm 0,2 ; 11,4 \pm 0,1$ \\
\hline & \\
\hline
\end{tabular}

* Incerteza calculada considerando erros nas medições das taxas de contagens da amostra e do padrão 
TABELA 2 - Concentrações dos elementos obtidas nas análises do material de referência Tomato Leaves (NIST 1573a), em $\mu \mathrm{g} \mathrm{g}^{-1}$ (a menos que esteja indicado).

\begin{tabular}{|c|c|}
\hline Elemento & Resultados individuais \\
\hline $\mathrm{Br}$ & $1092 \pm 2^{*} ; 1089 \pm 2 ; 1086 \pm 2$ \\
\hline Ca (\%) & $5,53 \pm 0,23 ; 5,5 \pm 0,23 ; 4,5 \pm 0,1 ; 4,77 \pm 0,12$ \\
\hline $\mathrm{Cl}\left(\mathrm{mg} \mathrm{g}^{-1}\right)$ & $5,6 \pm 0,2 ; 5,8 \pm 0,2 ; 5,9 \pm 0,3 ; 6,1 \pm 0,1$ \\
\hline Co & $0,57 \pm 0,02 ; 0,63 \pm 0,01 ; 0,59 \pm 0,01$ \\
\hline $\mathrm{Cr}$ & $1,96 \pm 0,03 ; 2,00 \pm 0,03 ; 2,21 \pm 0,02 ; 1,95 \pm 0,04$ \\
\hline Cs $\left(\right.$ ng g $\left.^{-1}\right)$ & $53,7 \pm 3,3 ; 53,3 \pm 3,3 ; 56,0 \pm 2,0 ; 53,0 \pm 3,0$ \\
\hline $\mathrm{Fe}$ & $366 \pm 10 ; 361 \pm 10 ; 3,58 \pm 3 ; 3,46 \pm 4$ \\
\hline $\mathrm{K}(\%)$ & $2,95 \pm 0,10 ; 2,21 \pm 0,30 ; 2,91 \pm 0,17 ; 2,92 \pm 0,23 ; 2,31 \pm 0,17$ \\
\hline $\mathrm{La}$ & $2,16 \pm 0,02 ; 2,21 \pm 0,02 ; 2,10 \pm 0,01 ; 2,20 \pm 0,02$ \\
\hline $\operatorname{Mg}(\%)$ & $1,11 \pm 0,05 ; 1,26 \pm 0,05 ; 1,10 \pm 0,08 ; 1,14 \pm 0,05$ \\
\hline Mn & $206 \pm 2 ; 235 \pm 5 ; 231 \pm 6 ; 242 \pm 6$ \\
\hline $\mathrm{Na}$ & $151 \pm 12 ; 129 \pm 15 ; 143 \pm 10 ; 153 \pm 14 ; 131 \pm 7$ \\
\hline $\mathrm{Rb}$ & $15,3 \pm 0,2 ; 14,9 \pm 0,5 ; 13,9 \pm 0,3 ; 13,9 \pm 0,2$ \\
\hline $\mathrm{Sb}$ & $0,07 \pm 0,01 ; 0,07 \pm 0,01$ \\
\hline Sc $\left(\operatorname{ng~g}^{-1}\right)$ & $103 \pm 1 ; 102 \pm 1 ; 108 \pm 1 ; 103 \pm 1$ \\
\hline Se & $0,109 \pm 0,020 ; 0,055 \pm 0,015$ \\
\hline $\mathrm{Zn}$ & $30,8 \pm 0,6 ; 30,8 \pm 0,6 ; 29,3 \pm 0,2 ; 31,1 \pm 0,2$ \\
\hline
\end{tabular}

* Incerteza calculada considerando erros nas medições das taxas de contagens da amostra e do padrão 
TABELA 3 - Concentrações dos elementos obtidas nas análises do material de referência Tea Leaves (INCT-TL-1), em $\mu \mathrm{g} \mathrm{g}^{-1}$ (a menos que esteja indicado).

\begin{tabular}{ll}
\hline Elemento & Resultados individuais \\
\hline As $\left(\mathrm{ng} \mathrm{g}^{-1}\right)$ & $99,4 \pm 9,4^{*}$ \\
Br & $12,91 \pm 0,04 ; 12,60 \pm 0,07$ \\
Ca (\%) & $0,547 \pm 0,002 ; 0,578 \pm 0,005$ \\
Co (ng g & \\
Cr & $410 \pm 6 ; 392 \pm 8$ \\
Cs & $1,87 \pm 0,03 ; 1,92 \pm 0,03$ \\
Fe & $4,06 \pm 0,04 ; 3,73 \pm 0,03$ \\
K (\%) & $1,74 \pm 0,01 ; 1,73 \pm 0,01$ \\
La & $0,93 \pm 0,01 ; 0,99 \pm 0,01$ \\
Se $\left(\mathrm{ng} \mathrm{g}^{-1}\right)$ & $266 \pm 2 ; 259 \pm 1$ \\
Na & $24,5 \pm 0,3 ; 21,1 \pm 0,1$ \\
Rb & $81,5 \pm 0,9 ; 78,0 \pm 1,0$ \\
\hline
\end{tabular}

* Incerteza calculada considerando erros nas medições das taxas de contagens da amostra e do padrão 
TABELA 4 - Concentrações dos elementos obtidas nas análises do material de referência IAEA-SOIL-7 , em $\mu \mathrm{g} \mathrm{g}^{-1}$ (a menos que esteja indicado).

\begin{tabular}{|c|c|}
\hline Elemento & Resultados individuais \\
\hline Ca (\%) & $16,2 \pm 0,3^{*} ; 16,6 \pm 0,3 ; 16,7 \pm 0,1$ \\
\hline $\mathrm{Ce}$ & $63,3 \pm 0,5 ; 63,6 \pm 0,5 ; 62,5 \pm 0,5 ; 64,0 \pm 0,5$ \\
\hline $\mathrm{Eu}$ & $1,03 \pm 0,03 ; 0,98 \pm 0,03 ; 0,94 \pm 0,03 ; 1,04 \pm 0,04$ \\
\hline Fe (\%) & $2,52 \pm 0,03 ; 2,45 \pm 0,04 ; 2,56 \pm 0,07 ; 2,56 \pm 0,03$ \\
\hline Hf & $4,89 \pm 0,04 ; 5,09 \pm 0,05 ; 4,83 \pm 0,05 ; 5,18 \pm 0,05$ \\
\hline $\mathrm{La}$ & $27,9 \pm 0,8 ; 26,5 \pm 0,1 ; 24,5 \pm 0,2 ; 26,3 \pm 0,1$ \\
\hline $\mathrm{Lu}$ & $0,347 \pm 0,004 ; 0,352 \pm 0,003 ; 0,321 \pm 0,005 ; 0,382 \pm 0,009$ \\
\hline $\mathrm{Nd}$ & $25,4 \pm 1,8 ; 27,8 \pm 1,7 ; 29,9 \pm 3,8 ; 30,1 \pm 3,1$ \\
\hline $\mathrm{Rb}$ & $50,4 \pm 1,4 ; 46,6 \pm 1,5 ; 51,3 \pm 1,3 ; 50,3 \pm 1,3$ \\
\hline Sc & $8,8 \pm 0,1 ; 8,4 \pm 0,1 ; 7,8 \pm 0,1 ; 8,7 \pm 0,1$ \\
\hline Sm & $5,22 \pm 0,04 ; 4,78 \pm 0,01 ; 4,50 \pm 0,02 ; 4,88 \pm 0,01$ \\
\hline $\mathrm{Tb}$ & $0,64 \pm 0,03 ; 0,65 \pm 0,04 ; 0,62 \pm 0,03 ; 0,67 \pm 0,04$ \\
\hline Th & $7,82 \pm 0,05 ; 7,91 \pm 0,07 ; 8,36 \pm 0,06 ; 8,27 \pm 0,07$ \\
\hline $\mathrm{U}$ & $2,19 \pm 0,06 ; 2,46 \pm 0,06 ; 2,01 \pm 0,12$ \\
\hline $\mathrm{Yb}$ & $2,33 \pm 0,09 ; 2,23 \pm 0,02 ; 2,00 \pm 0,03 ; 2,38 \pm 0,05$ \\
\hline $\mathrm{Zn}$ & $104 \pm 1 ; 104 \pm 2 ; 109 \pm 2 ; 100 \pm 1$ \\
\hline
\end{tabular}

* Incerteza calculada considerando erros nas medições das taxas de contagens da amostra e do padrão 
TABELA 5 - Concentrações dos elementos obtidas nas análises do material de referência $\mathrm{W} 1$, em $\mu \mathrm{g} \mathrm{g}^{-1}$ (a menos que esteja indicado).

\begin{tabular}{|c|c|}
\hline Elemento & Resultados individuais \\
\hline Ca (\%) & $7,7 \pm 0,5^{*} ; 8,4 \pm 0,4 ; 7,8 \pm 0,5 ; 7,7 \pm 0,5$ \\
\hline $\mathrm{Ce}$ & $22,4 \pm 0,2 ; 23,9 \pm 0,2 ; 24,6 \pm 0,3 ; 25,7 \pm 0,3$ \\
\hline $\mathrm{Eu}$ & $1,14 \pm 0,03 ; 1,10 \pm 0,04 ; 1,04 \pm 0,03 ; 1,10 \pm 0,04$ \\
\hline Fe (\%) & $7,4 \pm 0,1 ; 7,89 \pm 0,11 ; 7,78 \pm 0,11 ; 7,99 \pm 0,11$ \\
\hline $\mathrm{Hf}$ & $2,52 \pm 0,05 ; 2,62 \pm 0,05 ; 2,62 \pm 0,06 ; 2,59 \pm 0,05$ \\
\hline $\mathrm{La}$ & $10,9 \pm 0,5 ; 10,0 \pm 0,1 ; 9,7 \pm 0,1 ; 9,3 \pm 0,1$ \\
\hline $\operatorname{Lu}\left(\mathrm{ng} \mathrm{g}^{-1}\right)$ & $322 \pm 4 ; 303 \pm 8 ; 292 \pm 8 ; 296 \pm 5$ \\
\hline $\mathrm{Nd}$ & $13,6 \pm 1,8 ; 17,6 \pm 3,4 ; 14,7 \pm 4,3 ; 18,1 \pm 3,9$ \\
\hline $\mathrm{Rb}$ & $25,2 \pm 1,7 ; 19,8 \pm 1,8 ; 24,0 \pm 1,5 ; 21,7 \pm 2,2$ \\
\hline Sc & $36,6 \pm 0,3 ; 35,0 \pm 0,3 ; 33,2 \pm 0,3 ; 34,1 \pm 0,3$ \\
\hline Sm & $3,41 \pm 0,03 ; 3,4 \pm 0,1 ; 3,0 \pm 0,1 ; 2,9 \pm 0,2$ \\
\hline $\mathrm{Tb}$ & $0,68 \pm 0,05 ; 0,69 \pm 0,06 ; 0,64 \pm 0,06$ \\
\hline Th & $2,23 \pm 0,04 ; 2,20 \pm 0,05 ; 2,43 \pm 0,04 ; 2,36 \pm 0,05$ \\
\hline $\mathrm{U}$ & $0,60 \pm 0,09 ; 0,50 \pm 0,10 ; 0,48 \pm 0,15 ; 0,41 \pm 0,14$ \\
\hline $\mathrm{Yb}$ & $2,19 \pm 0,03 ; 2,08 \pm 0,03 ; 1,87 \pm 0,04 ; 1,99 \pm 0,12$ \\
\hline Zn & $97,2 \pm 2,2 ; 112 \pm 2 ; 103 \pm 2 ; 110 \pm 3$ \\
\hline
\end{tabular}

\footnotetext{
* Incerteza calculada considerando erros nas medições das taxas de contagens da amostra e do padrão
} 
APÊNDICE 2. Resultados individuais obtidos nas análises das amostras de folha de $C$. sylvestris, C. decandra e C. obliqua nativas e cultivadas na Mata Atlântica..

TABELA 6 - Concentrações dos elementos obtidas nas análises das folhas de C. sylvestris cultivada no IQUSP (amostra J1).

\begin{tabular}{|c|c|}
\hline Elemento & Resultados individuais \\
\hline As $\left(\operatorname{ng~g}^{-1}\right)$ & $71 \pm 11^{*} ; 78 \pm 9 ; 76 \pm 9$ \\
\hline $\operatorname{Br}\left(\mu g^{-1}\right)$ & $18,12 \pm 0,03 ; 18,21 \pm 0,05$ \\
\hline $\mathrm{Ca}\left(\mathrm{mg} \mathrm{g}^{-1}\right)$ & $9,9 \pm 0,3 ; 9,5 \pm 0,2 ; 9,2 \pm 0,2$ \\
\hline $\mathrm{Cl}\left(\mathrm{mg} \mathrm{g}^{-1}\right)$ & $3,9 \pm 0,1 ; 3,9 \pm 0,2 ; 3,9 \pm 0,1$ \\
\hline Co $\left(\operatorname{ng~g}^{-1}\right)$ & $180 \pm 4 ; 166 \pm 3 ; 156 \pm 3$ \\
\hline $\operatorname{Cr}\left(\operatorname{ng~g}^{-1}\right)$ & $472 \pm 18 ; 445 \pm 12 ; 438 \pm 14$ \\
\hline Cs $\left(\operatorname{ng~g}^{-1}\right)$ & $101 \pm 5 ; 103 \pm 2 ; 99 \pm 3$ \\
\hline $\mathrm{Fe}\left(\mu \mathrm{g} \mathrm{g}^{-1}\right)$ & $167 \pm 3 ; 164 \pm 2 ; 154 \pm 2$ \\
\hline $\mathrm{K}(\%)$ & $19,98 \pm 0,07 ; 17,38 \pm 0,05 ; 16,7 \pm 0,1$ \\
\hline La $\left(\right.$ ng g $\left.^{-1}\right)$ & $192 \pm 5 ; 200 \pm 3 ; 171 \pm 3$ \\
\hline $\operatorname{Mg}\left(\mathrm{mg} \mathrm{g}^{-1}\right)$ & $4,4 \pm 0,6$ \\
\hline $\operatorname{Mn}\left(\mu g^{-1}\right)$ & $659 \pm 19 ; 766 \pm 28 ; 653 \pm 15$ \\
\hline $\mathrm{Na}\left(\mathrm{mg} \mathrm{g}^{-1}\right)$ & $1,396 \pm 0,002 ; 1,438 \pm 0,002 ; 1,404 \pm 0,003$ \\
\hline $\mathrm{Rb}\left(\mu \mathrm{g} \mathrm{g}^{-1}\right)$ & $33,0 \pm 0,4 ; 32,0 \pm 0,2 ; 31,1 \pm 0,3$ \\
\hline $\mathrm{Sb}\left(\mathrm{ng} \mathrm{g}^{-1}\right)$ & $128 \pm 6 ; 120 \pm 1 ; 138 \pm 3$ \\
\hline Sc $\left(\operatorname{ng~g}^{-1}\right)$ & $22,8 \pm 0,3 ; 22,7 \pm 0,2 ; 23,2 \pm 0,2$ \\
\hline Se $\left(\mathrm{ng} \mathrm{g}^{-1}\right)$ & $96 \pm 17 ; 77 \pm 12 ; 88 \pm 14$ \\
\hline $\mathrm{Zn}\left(\mu \mathrm{g} \mathrm{g}^{-1}\right)$ & $62,0 \pm 0,4 ; 59,3 \pm 0,3 ; 56,7 \pm 0,3$ \\
\hline
\end{tabular}

* Incerteza calculada considerando erros nas medições das taxas de contagens da amostra e do padrão 
TABELA 7 - Concentrações dos elementos obtidas nas análises das folhas de C. obliqua nativa da Reserva do Morro Grande (amostra J2), desenvolvida sob o sol.

\begin{tabular}{|c|c|}
\hline Elemento & Resultados individuais \\
\hline $\mathrm{Br}\left(\mu \mathrm{g} \mathrm{g}^{-1}\right)$ & $4,85 \pm 0,01^{*} ; 4,90 \pm 0,03 ; 4,84 \pm 0,01$ \\
\hline $\mathrm{Ca}\left(\mathrm{mg} \mathrm{g}^{-1}\right)$ & $2,19 \pm 0,04 ; 2,31 \pm 0,05 ; 2,24 \pm 0,03 ; 2,20 \pm 0,03$ \\
\hline $\mathrm{Cl}\left(\mathrm{mg} \mathrm{g}^{-1}\right)$ & $0,42 \pm 0,02 ; 0,43 \pm 0,02 ; 0,45 \pm 0,02$ \\
\hline Co $\left(\operatorname{ng~g~}^{-1}\right)$ & $72,2 \pm 2,3 ; 82,1 \pm 3,1 ; 73,9 \pm 1,8 ; 77,8 \pm 2,3$ \\
\hline $\mathrm{Cr}\left(\mathrm{ng} \mathrm{g}^{-1}\right)$ & $58 \pm 11 ; 37 \pm 9 ; 58 \pm 13$ \\
\hline Cs $\left(\right.$ ng g $\left.^{-1}\right)$ & $152 \pm 5 ; 142 \pm 5 ; 149 \pm 3 ; 150 \pm 4$ \\
\hline $\mathrm{Fe}\left(\mu \mathrm{g} \mathrm{g}^{-1}\right)$ & $55,5 \pm 1,4 ; 58,1 \pm 1,0 ; 56,5 \pm 1,0 ; 55,1 \pm 0,9$ \\
\hline $\mathrm{K}(\%)$ & $1,654 \pm 0,007 ; 1,393 \pm 0,003 ; 1,545 \pm 0,003 ; 1,361 \pm 0,05$ \\
\hline La $\left(\right.$ ng g $\left.^{-1}\right)$ & $38,2 \pm 2,2 ; 35,1 \pm 1,0 ; 36,5 \pm 1,2 ; 37,2 \pm 1,4$ \\
\hline $\operatorname{Mg}\left(\mathrm{mg} \mathrm{g}^{-1}\right)$ & $2,25 \pm 0,13 ; 2,12 \pm 0,08 ; 2,51 \pm 0,10$ \\
\hline $\operatorname{Mn}\left(\mu g^{-1}\right)$ & $197 \pm 4 ; 188 \pm 4$ \\
\hline $\mathrm{Na}\left(\mu \mathrm{g} \mathrm{g}^{-1}\right)$ & $13,79 \pm 0,04 ; 15,45 \pm 0,03 ; 13,92 \pm 0,03 ; 11,8 \pm 0,1$ \\
\hline $\mathrm{Rb}\left(\mu \mathrm{g} \mathrm{g}^{-1}\right)$ & $146 \pm 2 ; 147 \pm 1 ; 150 \pm 1 ; 136 \pm 2$ \\
\hline Sb $\left(\right.$ ng g $\left.^{-1}\right)$ & $10,4 \pm 1,0 ; 13,3 \pm 1,3 ; 12,4 \pm 1,0 ; 12,8 \pm 1,0$ \\
\hline Sc $\left(\right.$ ng g $\left.^{-1}\right)$ & $4,9 \pm 0,2 ; 4,9 \pm 0,1 ; 4,7 \pm 0,1 ; 4,8 \pm 0,2$ \\
\hline $\operatorname{Zn}\left(\mu \mathrm{g} \mathrm{g}^{-1}\right)$ & $29,7 \pm 0,3 ; 29,8 \pm 0,2 ; 30,2 \pm 0,2 ; 27,0 \pm 0,2$ \\
\hline
\end{tabular}

* Incerteza calculada considerando erros nas medições das taxas de contagens da amostra e do padrão 
TABELA 8 - Concentrações dos elementos obtidas nas análises das folhas de C. decandra nativa da Reserva do Morro Grande (amostra J3).

\begin{tabular}{|c|c|}
\hline Elemento & Resultados individuais \\
\hline $\mathrm{Br}\left(\mu \mathrm{g} \mathrm{g}^{-1}\right)$ & $3,55 \pm 0,01^{*} ; 4,00 \pm 0,01$ \\
\hline $\mathrm{Ca}\left(\mathrm{mg} \mathrm{g}^{-1}\right)$ & $5,63 \pm 0,14 ; 5,50 \pm 0,21 ; 5,62 \pm 0,07$ \\
\hline $\mathrm{Cl}\left(\mathrm{mg} \mathrm{g}^{-1}\right)$ & $1,87 \pm 0,09 ; 1,96 \pm 0,08 ; 1,83 \pm 0,05$ \\
\hline Co $\left(\operatorname{ng~g}^{-1}\right)$ & $189 \pm 4 ; 183 \pm 3 ; 190 \pm 3$ \\
\hline $\mathrm{Cr}\left(\mathrm{ng} \mathrm{g}^{-1}\right)$ & $55 \pm 12 ; 60 \pm 10 ; 77 \pm 10$ \\
\hline Cs $\left(\right.$ ng g $\left.^{-1}\right)$ & $109 \pm 4 ; 108 \pm 2 ; 117 \pm 2$ \\
\hline $\mathrm{Fe}\left(\mu \mathrm{g} \mathrm{g}^{-1}\right)$ & $72,1 \pm 1,4 ; 73,7 \pm 1,6 ; 72,3 \pm 0,8$ \\
\hline $\mathrm{K}\left(\mathrm{mg} \mathrm{g}^{-1}\right)$ & $21,5 \pm 1,4 ; 18,8 \pm 1,7 ; 16,8 \pm 0,9$ \\
\hline La $\left(\right.$ ng g $\left.^{-1}\right)$ & $77,9 \pm 2,0 ; 71,1 \pm 1,2 ; 92,4 \pm 1,7$ \\
\hline $\operatorname{Mg}\left(\mathrm{mg} \mathrm{g}^{-1}\right)$ & $2,34 \pm 0,22 ; 2,11 \pm 0,04 ; 2,34 \pm 0,25$ \\
\hline $\operatorname{Mn}\left(\mu g g^{-1}\right)$ & $513 \pm 19 ; 529 \pm 12 ; 481 \pm 12$ \\
\hline $\mathrm{Na}\left(\mu \mathrm{g} \mathrm{g}^{-1}\right)$ & $261 \pm 1 ; 254 \pm 27 ; 225 \pm 17$ \\
\hline $\mathrm{Rb}\left(\mu \mathrm{g} \mathrm{g}^{-1}\right)$ & $97,8 \pm 0,8 ; 100 \pm 1 ; 97,5 \pm 0,4$ \\
\hline Sb $\left(\right.$ ng g $\left.^{-1}\right)$ & $8,9 \pm 2,1 ; 9,9 \pm 2,0 ; 9,5 \pm 1,3$ \\
\hline Sc $\left(\right.$ ng g $\left.^{-1}\right)$ & $5,46 \pm 0,14 ; 5,72 \pm 0,13 ; 6,2 \pm 0,1$ \\
\hline $\mathrm{Zn}\left(\mu \mathrm{g} \mathrm{g}^{-1}\right)$ & $28,6 \pm 0,2 ; 29,1 \pm 0,3 ; 28,8 \pm 0,1$ \\
\hline
\end{tabular}

* Incerteza calculada considerando erros nas medições das taxas de contagens da amostra e do padrão 
TABELA 9 - Concentrações dos elementos obtidas nas análises das folhas de C. sylvestris nativa da Reserva do Morro Grande (amostra J4), desenvolvida à sombra.

\begin{tabular}{ll}
\hline Elemento & Resultados individuais \\
\hline As $\left(\mathrm{ng} \mathrm{g}^{-1}\right)$ & $10,1 \pm 1,8$ \\
Br $\left(\mu \mathrm{g} \mathrm{g}^{-1}\right)$ & $3,60 \pm 0,01 ; 3,58 \pm 0,01$ \\
Ca $\left(\mathrm{mg} \mathrm{g}^{-1}\right)$ & $4,91 \pm 0,14 ; 4,73 \pm 0,03$ \\
Cl $\left(\mathrm{mg} \mathrm{g}^{-1}\right)$ & $1,40 \pm 0,05 ; 1,47 \pm 0,07 ; 1,57 \pm 0,07$ \\
Co $\left(\mathrm{ng} \mathrm{g}^{-1}\right)$ & $66,9 \pm 1,7 ; 62,7 \pm 1,3 ; 66,7 \pm 1,0$ \\
Cr $\left(\mathrm{ng} \mathrm{g}^{-1}\right)$ & $112 \pm 13 ; 110 \pm 12 ; 121 \pm 10$ \\
Cs $\left(\mathrm{ng} \mathrm{g}^{-1}\right)$ & $74,7 \pm 3,6 ; 81,1 \pm 1,9 ; 83 \pm 2$ \\
Fe $\left(\mu \mathrm{g} \mathrm{g}^{-1}\right)$ & $86,4 \pm 1,3 ; 89,2 \pm 2,1 ; 83,5 \pm 1,0$ \\
K $\left(\mathrm{mg} \mathrm{g}^{-1}\right)$ & $15,00 \pm 0,03 ; 14,40 \pm 0,08 ; 15,20 \pm 0,03$ \\
La $\left(\mathrm{ng} \mathrm{g}^{-1}\right)$ & $62,4 \pm 1,8 ; 56,4 \pm 0,9 ; 59,3 \pm 1,0$ \\
Mg $\left(\mathrm{mg} \mathrm{g}^{-1}\right)$ & $2,2 \pm 0,4 ; 2,2 \pm 0,2 ; 2,2 \pm 0,4$ \\
Mn $\left(\mu \mathrm{g} \mathrm{g}^{-1}\right)$ & $353 \pm 8 ; 361 \pm 11 ; 341 \pm 8$ \\
Na $\left(\mu \mathrm{g} \mathrm{g}^{-1}\right)$ & $39,2 \pm 0,1 ; 40,5 \pm 0,3 ; 43,2 \pm 0,1$ \\
Rb $\left(\mu \mathrm{g} \mathrm{g}^{-1}\right)$ & $79,5 \pm 07 ; 82,9 \pm 0,7 ; 74,6 \pm 0,5$ \\
Sb $\left(\mathrm{ng} \mathrm{g}^{-1}\right)$ & $19,7 \pm 1,0 ; 13,8 \pm 4,2 ; 17,1 \pm 0,6$ \\
Sc $\left(\mathrm{ng} \mathrm{g}^{-1}\right)$ & $9,9 \pm 0,2 ; 10,2 \pm 0,1 ; 10,5 \pm 0,1$ \\
Zn $\left(\mu \mathrm{g} \mathrm{g}^{-1}\right)$ & $17,5 \pm 0,1 ; 17,9 \pm 0,2 ; 16,4 \pm 0,1$ \\
\hline
\end{tabular}

* Incerteza calculada considerando erros nas medições das taxas de contagens da amostra e do padrão 
TABELA 10 - Concentrações dos elementos obtidas nas análises das folhas de C. sylvestris nativa da Reserva do Morro Grande (amostra J5), desenvolvida sob sol.

\begin{tabular}{ll}
\hline Elemento & Resultados individuais \\
\hline Br $\left(\mu \mathrm{g} \mathrm{g}^{-1}\right)$ & $13,78 \pm 0,03^{*} ; 13,98 \pm 0,03$ \\
Ca $\left(\mathrm{mg} \mathrm{g}^{-1}\right)$ & $6,11 \pm 0,16 ; 6,10 \pm 0,13 ; 5,83 \pm 0,12$ \\
Cl $\left(\mathrm{mg} \mathrm{g}^{-1}\right)$ & $0,82 \pm 0,05 ; 0,86 \pm 0,06 ; 0,87 \pm 0,07$ \\
Co $\left(\mathrm{ng} \mathrm{g}^{-1}\right)$ & $87,8 \pm 2,1 ; 85,5 \pm 2,0 ; 90 \pm 2$ \\
Cr $\left(\mathrm{ng} \mathrm{g}^{-1}\right)$ & $129 \pm 12 ; 127 \pm 9 ; 133 \pm 9$ \\
Cs $\left(\mathrm{ng} \mathrm{g}^{-1}\right)$ & $346 \pm 4 ; 362 \pm 4 ; 366 \pm 3$ \\
Fe $\left(\mu \mathrm{g} \mathrm{g}^{-1}\right)$ & $98,1 \pm 1,6 ; 100 \pm 1 ; 101 \pm 1$ \\
K $\left(\mathrm{mg} \mathrm{g}^{-1}\right)$ & $13,2 \pm 0,1 ; 12,9 \pm 0,3 ; 12,4 \pm 0,1$ \\
La $\left(\mathrm{ng} \mathrm{g}^{-1}\right)$ & $165 \pm 4 ; 164 \pm 3 ; 160 \pm 3$ \\
Mg $\left(\mathrm{mg} \mathrm{g}^{-1}\right)$ & $3,2 \pm 0,8$ \\
Mn $\left(\mu \mathrm{g} \mathrm{g}^{-1}\right)$ & $758 \pm 16 ; 753 \pm 23 ; 783 \pm 19$ \\
Na $\left(\mathrm{mg} \mathrm{g}^{-1}\right)$ & $3,23 \pm 0,01 ; 3,21 \pm 0,01 ; 3,021 \pm 0,004$ \\
Rb $\left(\mu \mathrm{g} \mathrm{g}^{-1}\right)$ & $99,1 \pm 0,9 ; 100 \pm 1 ; 97 \pm 0,6$ \\
Sb $\left(\mathrm{ng} \mathrm{g}^{-1}\right)$ & $45,1 \pm 2,4 ; 52 \pm 2 ; 51,4 \pm 1,0$ \\
Sc $\left(\mathrm{ng} \mathrm{g}^{-1}\right)$ & $15,6 \pm 0,2 ; 15,6 \pm 0,2 ; 16,9 \pm 0,2$ \\
Se $\left(\mathrm{ng} \mathrm{g}^{-1}\right)$ & $17,6 \pm 7,6 ; 31 \pm 10$ \\
\hline
\end{tabular}

\footnotetext{
* Incerteza calculada considerando erros nas medições das taxas de contagens da amostra e do padrão
} 
TABELA 11 - Concentrações dos elementos obtidas nas análises das folhas de C. sylvestris cultivada na Reserva do Morro Grande (amostra J6).

\begin{tabular}{|c|c|}
\hline Elemento & Resultados individuais \\
\hline As $\left(\right.$ ng g $\left.^{-1}\right)$ & $1085 \pm 11^{*}$ \\
\hline $\mathrm{Br}\left(\mu \mathrm{g} \mathrm{g}^{-1}\right)$ & $19,13 \pm 0,04 ; 14,89 \pm 0,03 ; 16,78 \pm 0,05$ \\
\hline $\mathrm{Ca}\left(\mathrm{mg} \mathrm{g}^{-1}\right)$ & $3,52 \pm 0,08 ; 4,01 \pm 0,10$ \\
\hline $\mathrm{Cl}\left(\mathrm{mg} \mathrm{g}^{-1}\right)$ & $1,29 \pm 0,06 ; 1,4 \pm 0,07 ; 1,24 \pm 0,07$ \\
\hline Co $\left(\right.$ ng g $\left.^{-1}\right)$ & $165 \pm 3 ; 172 \pm 3 ; 173 \pm 3 ; 164 \pm 3$ \\
\hline $\operatorname{Cr}\left(\mathrm{ng} \mathrm{g}^{-1}\right)$ & $348 \pm 13 ; 256 \pm 12 ; 245 \pm 12 ; 282 \pm 14$ \\
\hline Cs $\left(\right.$ ng g $\left.^{-1}\right)$ & $284 \pm 3 ; 264 \pm 3 ; 269 \pm 4 ; 269 \pm 4$ \\
\hline $\mathrm{Fe}\left(\mu \mathrm{g} \mathrm{g}^{-1}\right)$ & $167 \pm 2 ; 180 \pm 2 ; 178 \pm 2$ \\
\hline $\mathrm{K}\left(\mathrm{mg} \mathrm{g}^{-1}\right)$ & $13,9 \pm 0,2 ; 13,5 \pm 1,0 ; 13,6 \pm 0,1 ; 13,4 \pm 0,1$ \\
\hline La $\left(\mathrm{ng} \mathrm{g}^{-1}\right)$ & $272 \pm 4 ; 260 \pm 4 ; 255 \pm 5$ \\
\hline $\operatorname{Mg}\left(\mathrm{mg} \mathrm{g}^{-1}\right)$ & $1,6 \pm 0,9$ \\
\hline $\operatorname{Mn}\left(\mu \mathrm{g} \mathrm{g}^{-1}\right)$ & $663 \pm 13 ; 667 \pm 13 ; 666 \pm 15$ \\
\hline $\mathrm{Na}\left(\mathrm{mg} \mathrm{g}^{-1}\right)$ & $5,86 \pm 0,01 ; 5,42 \pm 0,01 ; 5,38 \pm 0,01 ; 5,88 \pm 0,01$ \\
\hline $\mathrm{Rb}\left(\mu \mathrm{g} \mathrm{g}^{-1}\right)$ & $63,3 \pm 0,5 ; 70,8 \pm 0,6 ; 69,9 \pm 0,5$ \\
\hline $\mathrm{Sb}\left(\mu \mathrm{g} \mathrm{g}^{-1}\right)$ & $42,3 \pm 2,8 ; 40,3 \pm 2,7 ; 37,2 \pm 3,9$ \\
\hline Sc $\left(\right.$ ng g $\left.^{-1}\right)$ & $34,2 \pm 0,3 ; 32,1 \pm 0,2 ; 35,1 \pm 0,3$ \\
\hline Se $\left(\right.$ ng g $\left.^{-1}\right)$ & $56,2 \pm 10,3 ; 40,7 \pm 10,1 ; 52 \pm 13$ \\
\hline $\mathrm{Zn}\left(\mu \mathrm{g} \mathrm{g}^{-1}\right)$ & $69,2 \pm 0,3 ; 77,2 \pm 0,5$ \\
\hline
\end{tabular}

* Incerteza calculada considerando erros nas medições das taxas de contagens da amostra e do padrão 
TABELA 12 - Concentrações dos elementos obtidas nas análises das folhas de C. obliqua nativa da Reserva do Morro Grande (amostra J7), desenvolvida à sombra.

\begin{tabular}{|c|c|}
\hline Elemento & Resultados individuais \\
\hline As $\left(\operatorname{ng~g}^{-1}\right)$ & $39,3 \pm 4,3^{*} ; 39,4 \pm 3,2 ; 34,2 \pm 4,8$ \\
\hline $\mathrm{Br}\left(\mu \mathrm{g} \mathrm{g}^{-1}\right)$ & $16,38 \pm 0,02 ; 14,41 \pm 0,02 ; 13,92 \pm 0,03$ \\
\hline $\mathrm{Ca}\left(\mathrm{mg} \mathrm{g}^{-1}\right)$ & $8,19 \pm 0,04 ; 7,83 \pm 0,06 ; 8,81 \pm 0,08$ \\
\hline $\mathrm{Cl}\left(\mathrm{mg} \mathrm{g}^{-1}\right)$ & $1,29 \pm 0,08 ; 1,42 \pm 0,05 ; 1,26 \pm 0,04$ \\
\hline Co $\left(\operatorname{ng~g}^{-1}\right)$ & $131 \pm 3 ; 129 \pm 2 ; 120 \pm 3 ; 130 \pm 3$ \\
\hline $\operatorname{Cr}\left(\operatorname{ng~g}^{-1}\right)$ & $256 \pm 10 ; 268 \pm 9 ; 272 \pm 19 ; 267 \pm 15$ \\
\hline Cs $\left(\operatorname{ng~g}^{-1}\right)$ & $48,1 \pm 1,9 ; 50,3 \pm 2,0 ; 49,1 \pm 2,8 ; 47,9 \pm 2,2$ \\
\hline $\mathrm{Fe}\left(\mu \mathrm{g}^{-1}\right)$ & $160 \pm 1 ; 159 \pm 2 ; 165 \pm 2$ \\
\hline $\mathrm{K}\left(\mathrm{mg} \mathrm{g}^{-1}\right)$ & $15,21 \pm 0,04 ; 17,71 \pm 0,04 ; 13,12 \pm 0,05 ; 12,90 \pm 0,08$ \\
\hline La $\left(\right.$ ng g $\left.^{-1}\right)$ & $241 \pm 2 ; 252 \pm 2 ; 229 \pm 2 ; 246 \pm 2$ \\
\hline $\operatorname{Mg}\left(\mathrm{mg} \mathrm{g}^{-1}\right)$ & $2,71 \pm 0,14$ \\
\hline $\operatorname{Mn}\left(\mu \mathrm{g} \mathrm{g}^{-1}\right)$ & $806 \pm 21 ; 793 \pm 17 ; 818 \pm 24$ \\
\hline $\mathrm{Na}\left(\mu \mathrm{g} \mathrm{g}^{-1}\right)$ & $32,8 \pm 0,1 ; 30,1 \pm 0,1 ; 29,0 \pm 0,2$ \\
\hline $\mathrm{Rb}\left(\mu \mathrm{g} \mathrm{g}^{-1}\right)$ & $61,0 \pm 0,4 ; 58,9 \pm 0,5 ; 61,6 \pm 0,5$ \\
\hline $\mathrm{Sb}\left(\mathrm{ng} \mathrm{g}^{-1}\right)$ & $32,7 \pm 1,7 ; 38,0 \pm 0,8 ; 34,3 \pm 1,2 ; 38,4 \pm 1,6$ \\
\hline Sc $\left(\mathrm{ng} \mathrm{g}^{-1}\right)$ & $30,0 \pm 0,2 ; 30,4 \pm 0,2 ; 29,2 \pm 0,3 ; 28,5 \pm 0,2$ \\
\hline Se $\left(\operatorname{ng~g}^{-1}\right)$ & $31,8 \pm 9,9 ; 37,5 \pm 9,6$ \\
\hline $\mathrm{Zn}\left(\mu \mathrm{g} \mathrm{g}^{-1}\right)$ & $44,7 \pm 0,2 ; 45,1 \pm 0,2 ; 45,8 \pm 0,2$ \\
\hline
\end{tabular}

\footnotetext{
${ }^{*}$ Incerteza calculada considerando erros nas medições das taxas de contagens da amostra e do padrão
} 
APÊNDICE 3. Resultados individuais obtidos nas análises dos extratos de C. sylvestris, $C$. decandra e C. obliqua.

TABELA 13 - Concentrações dos elementos obtidas nas análises dos extratos de C. obliqua. (amostra E2).

\begin{tabular}{ll}
\hline Elemento & Resultados individuais \\
\hline $\mathrm{Br}\left(\mu \mathrm{g} \mathrm{g}^{-1}\right)$ & $24,93 \pm 0,07^{*} ; 23,75 \pm 0,07 ; 22,95 \pm 0,05$ \\
$\mathrm{Ca}\left(\mathrm{mg} \mathrm{g}^{-1}\right)$ & $3,22 \pm 0,04 ; 4,63 \pm 0,22$ \\
$\mathrm{Cl}\left(\mathrm{mg} \mathrm{g}^{-1}\right)$ & $3,11 \pm 0,05 ; 3,18 \pm 0,06 ; 3,51 \pm 0,11$ \\
$\mathrm{Co}\left(\mathrm{ng} \mathrm{g}^{-1}\right)$ & $37,5 \pm 1,2 ; 36,3 \pm 1,3 ; 56,1 \pm 1,8$ \\
$\mathrm{Cr}\left(\mathrm{ng} \mathrm{g}^{-1}\right)$ & $146 \pm 11 ; 103 \pm 18 ; 71,3 \pm 14,5$ \\
$\mathrm{Cs}\left(\mathrm{ng} \mathrm{g}^{-1}\right)$ & $122 \pm 3 ; 120 \pm 3 ; 119 \pm 4$ \\
$\mathrm{Fe}\left(\mu \mathrm{g} \mathrm{g}^{-1}\right)$ & $7,6 \pm 0,5 ; 11,8 \pm 0,5 ; 6,31 \pm 0,5$ \\
$\mathrm{~K}\left(\mathrm{mg} \mathrm{g}^{-1}\right)$ & $12,8 \pm 0,5 ; 13,8 \pm 0,5 ; 11,1 \pm 0,9$ \\
$\mathrm{La}\left(\mathrm{ng} \mathrm{g}^{-1}\right)$ & $1,1 \pm 0,7 ; 4,0 \pm 0,9 ; 8,2 \pm 1,1$ \\
$\mathrm{Mg}\left(\mathrm{mg} \mathrm{g}^{-1}\right)$ & $0,57 \pm 0,12 ; 0,71 \pm 0,06$ \\
$\mathrm{Mn}\left(\mu \mathrm{g} \mathrm{g}^{-1}\right)$ & $26,3 \pm 0,3 ; 28,6 \pm 0,4 ; 24,9 \pm 0,7$ \\
$\mathrm{Na}\left(\mu \mathrm{g} \mathrm{g}^{-1}\right)$ & $101 \pm 5 ; 96 \pm 4 ; 97,1 \pm 0,5$ \\
$\mathrm{Rb}\left(\mu \mathrm{g} \mathrm{g}^{-1}\right)$ & $116 \pm 1 ; 111 \pm 3 ; 102 \pm 1$ \\
$\mathrm{Sb}\left(\mathrm{ng} \mathrm{g}^{-1}\right)$ & $35,6 \pm 2,8 ; 24,6 \pm 2,0$ \\
$\mathrm{Sc}\left(\mathrm{ng} \mathrm{g}^{-1}\right)$ & $0,73 \pm 0,09 ; 0,9 \pm 0,1 ; 0,93 \pm 0,11$ \\
$\mathrm{Se}\left(\mathrm{ng} \mathrm{g}^{-1}\right)$ & $32,3 \pm 13,2$ \\
$\mathrm{Zn}\left(\mu \mathrm{g} \mathrm{g}^{-1}\right)$ & $11,3 \pm 0,1 ; 13,5 \pm 0,1 ; 11,4 \pm 0,1$ \\
\hline
\end{tabular}

* Incerteza calculada considerando erros nas medições das taxas de contagens da amostra e do padrão 
TABELA 14 - Concentrações dos elementos obtidas nas análises dos extratos de C. decandra. (amostra E3)

\begin{tabular}{|c|c|}
\hline Elemento & Resultados individuais \\
\hline As $\left(\right.$ ng g $\left.^{-1}\right)$ & $18,4 \pm 3,7^{*}$ \\
\hline $\mathrm{Br}\left(\mu \mathrm{g} \mathrm{g}^{-1}\right)$ & $9,43 \pm 0,03 ; 8,37 \pm 0,03 ; 8,44 \pm 0,02$ \\
\hline $\mathrm{Ca}\left(\mathrm{mg} \mathrm{g}^{-1}\right)$ & $5,08 \pm 1,3 ; 6,01 \pm 0,04$ \\
\hline $\mathrm{Cl}\left(\mathrm{mg} \mathrm{g}^{-1}\right)$ & $6,0 \pm 0,1 ; 5,4 \pm 0,1 ; 5,5 \pm 0,2 ; 5,2 \pm 0,1$ \\
\hline Co $\left(\right.$ ng g $\left.^{-1}\right)$ & $59,0 \pm 1,8 ; 57,0 \pm 1,5 ; 56,2 \pm 1,7$ \\
\hline $\operatorname{Cr}\left(\right.$ ng g $\left.^{-1}\right)$ & $893 \pm 17 ; 880 \pm 14 ; 930 \pm 18$ \\
\hline Cs (ng g $\left.{ }^{-1}\right)$ & $56,3 \pm 2,7 ; 56,5 \pm 2,3 ; 66,6 \pm 2,6$ \\
\hline $\mathrm{Fe}\left(\mu \mathrm{g} \mathrm{g}^{-1}\right)$ & $20,0 \pm 0,79 ; 12,5 \pm 0,5 ; 10,6 \pm 0,6$ \\
\hline $\mathrm{K}\left(\mathrm{mg} \mathrm{g}^{-1}\right)$ & $10,87 \pm 0,03 ; 9,47 \pm 0,04 ; 8,40 \pm 0,05$ \\
\hline La $\left(\right.$ ng g $\left.^{-1}\right)$ & $1,38 \pm 1,13 ; 10,6 \pm 0,9$ \\
\hline $\operatorname{Mg}\left(\mathrm{mg} \mathrm{g}^{-1}\right)$ & $0,44 \pm 0,23$ \\
\hline $\operatorname{Mn}\left(\mu \mathrm{g} \mathrm{g}^{-1}\right)$ & $10,1 \pm 0,2 ; 11,4 \pm 0,4 ; 11,1 \pm 0,4 ; 9,5 \pm 0,3$ \\
\hline $\mathrm{Na}\left(\mu \mathrm{g}^{-1}\right)$ & $268,0 \pm 0,4 ; 259,0 \pm 0,4 ; 219,5 \pm 0,6$ \\
\hline $\mathrm{Rb}\left(\mu \mathrm{g} \mathrm{g}^{-1}\right)$ & $52,8 \pm 0,4 ; 50,1 \pm 0,4 ; 49,2 \pm 0,5$ \\
\hline Sb (ng g $\left.{ }^{-1}\right)$ & $57 \pm 3 ; 33 \pm 1$ \\
\hline Sc $\left(\right.$ ng g $\left.^{-1}\right)$ & $0,9 \pm 0,1 ; 1,1 \pm 0,1 ; 0,9 \pm 0,1$ \\
\hline $\mathrm{Zn}\left(\mu \mathrm{g} \mathrm{g}^{-1}\right)$ & $28,9 \pm 0,2 ; 23,8 \pm 0,2 ; 23,5 \pm 0,2$ \\
\hline
\end{tabular}

* Incerteza calculada considerando erros nas medições das taxas de contagens da amostra e do padrão 
TABELA 15 - Concentrações dos elementos obtidas nas análises dos extratos de C. sylvestris. (amostra E4)

\begin{tabular}{|c|c|}
\hline Elemento & Resultados individuais \\
\hline As $\left(\operatorname{ng~g}^{-1}\right)$ & $34,9 \pm 6,5^{*}$ \\
\hline $\mathrm{Br}\left(\mu \mathrm{g}^{-1}\right)$ & $16,8 \pm 0,5 ; 15,2 \pm 0,6 ; 15,1 \pm 0,4$ \\
\hline $\mathrm{Ca}\left(\mathrm{mg} \mathrm{g}^{-1}\right)$ & $12,8 \pm 1,7 ; 13,3 \pm 0,6$ \\
\hline $\mathrm{Cl}\left(\mathrm{mg} \mathrm{g}^{-1}\right)$ & $7,43 \pm 0,11 ; 7,05 \pm 0,15 ; 6,75 \pm 0,20 ; 7,46 \pm 0,19$ \\
\hline Co $\left(\right.$ ng g $\left.^{-1}\right)$ & $76,9 \pm 1,9 ; 71,7 \pm 1,8 ; 64,4 \pm 2,1$ \\
\hline $\operatorname{Cr}\left(\mu \mathrm{g} \mathrm{g}^{-1}\right)$ & $1,05 \pm 0,02 ; 1,25 \pm 0,02 ; 1,79 \pm 0,03$ \\
\hline Cs $\left(\right.$ ng g $\left.^{-1}\right)$ & $63,8 \pm 3,2 ; 53,5 \pm 2,3 ; 59,9 \pm 3,0$ \\
\hline Fe $\left(\mu \mathrm{g} \mathrm{g}^{-1}\right)$ & $17,4 \pm 0,7 ; 16,0 \pm 0,6 ; 15,9 \pm 0,7$ \\
\hline $\mathrm{K}(\%)$ & $1,09 \pm 0,01 ; 1,21 \pm 0,1 ; 0,88 \pm 0,01$ \\
\hline La $\left(\right.$ ng g $\left.^{-1}\right)$ & $5,4 \pm 1,7 ; 4,4 \pm 1,9 ; 17,7 \pm 1,3$ \\
\hline $\operatorname{Mg}\left(\mathrm{mg} \mathrm{g}^{-1}\right)$ & $1,15 \pm 0,38$ \\
\hline $\operatorname{Mn}\left(\mu \mathrm{g} \mathrm{g}^{-1}\right)$ & $19,7 \pm 0,2 ; 16,3 \pm 0,2 ; 16,8 \pm 0,5 ; 15,7 \pm 0,4$ \\
\hline $\mathrm{Na}\left(\mu \mathrm{g} \mathrm{g}^{-1}\right)$ & $652 \pm 10 ; 626 \pm 12 ; 623 \pm 22$ \\
\hline $\mathrm{Rb}\left(\mu \mathrm{g} \mathrm{g}^{-1}\right)$ & $62,4 \pm 0,6 ; 57,2 \pm 0,5 ; 53,8 \pm 0,6$ \\
\hline $\mathrm{Sb}\left(\mathrm{ng} \mathrm{g}^{-1}\right)$ & $103 \pm 2 ; 54,7 \pm 1,6$ \\
\hline Sc $\left(\right.$ ng g $\left.^{-1}\right)$ & $1,8 \pm 0,1 ; 1,4 \pm 0,1 ; 1,4 \pm 0,1$ \\
\hline Se $\left(\operatorname{ng~g}^{-1}\right)$ & $41,8 \pm 11,4$ \\
\hline $\mathrm{Zn}\left(\mu \mathrm{g} \mathrm{g}^{-1}\right)$ & $35,5 \pm 0,2 ; 31,4 \pm 0,2 ; 26,1 \pm 0,2$ \\
\hline
\end{tabular}

\footnotetext{
Incerteza calculada considerando erros nas medições das taxas de contagens da amostra e do padrão
} 
APÊNDICE 4. Resultados individuais obtidos nas análises das amostras de solo provenientes dos três pontos de coleta na Mata Atlântica.

TABELA 16 - Concentrações dos elementos obtidas nas análises de solo coletado no Instituto de Química da USP, junto à amostra cultivada de C. sylvestris. (Amostra K1)

\begin{tabular}{|c|c|}
\hline Elemento & Resultados individuais \\
\hline Ca (\%) & $0,73 \pm 0,03^{*} ; 1,04 \pm 0,06 ; 1,32 \pm 0,03$ \\
\hline Ce $\left(\right.$ ng g $\left.^{-1}\right)$ & $186 \pm 1 ; 182 \pm 1 ; 183 \pm 1$ \\
\hline $\mathrm{Eu}\left(\mathrm{ng} \mathrm{g}^{-1}\right)$ & $2,34 \pm 0,07 ; 2,56 \pm 0,08 ; 2,51 \pm 0,09$ \\
\hline Fe (\%) & $4,51 \pm 0,07 ; 5,40 \pm 0,09 ; 4,81 \pm 0,08$ \\
\hline $\mathrm{Hf}\left(\mu \mathrm{g} \mathrm{g}^{-1}\right)$ & $12,8 \pm 0,1 ; 13,2 \pm 0,1 ; 13,4 \pm 0,1$ \\
\hline $\mathrm{La}\left(\mathrm{ng} \mathrm{g}^{-1}\right)$ & $85,3 \pm 0,4 ; 93,4 \pm 0,6 ; 94,4 \pm 0,5$ \\
\hline $\mathrm{Lu}\left(\mathrm{ng} \mathrm{g}^{-1}\right)$ & $318 \pm 3 ; 328 \pm 3 ; 347 \pm 8$ \\
\hline $\mathrm{Nd}\left(\mu \mathrm{g} \mathrm{g}^{-1}\right)$ & $63,8 \pm 3,9 ; 66,4 \pm 3,5 ; 72,2 \pm 4,2$ \\
\hline $\mathrm{Rb}\left(\mu \mathrm{g} \mathrm{g}^{-1}\right)$ & $13,0 \pm 0,8 ; 17,3 \pm 1,3 ; 15,7 \pm 1,1$ \\
\hline Sc $\left(\mu g^{-1}\right)$ & $13,8 \pm 0,1 ; 14,7 \pm 0,1 ; 15,1 \pm 0,2$ \\
\hline $\operatorname{Sm}\left(\mu g^{-1}\right)$ & $10,72 \pm 0,02 ; 11,52 \pm 0,02 ; 12,11 \pm 0,01$ \\
\hline $\mathrm{Tb}\left(\mathrm{ng} \mathrm{g}^{-1}\right)$ & $1,15 \pm 0,05 ; 1,21 \pm 0,05 ; 1,15 \pm 0,05$ \\
\hline $\operatorname{Th}\left(\mu \mathrm{g} \mathrm{g}^{-1}\right)$ & $21,0 \pm 0,2 ; 21,8 \pm 0,1 ; 22,8 \pm 0,2$ \\
\hline $\mathrm{U}\left(\mu \mathrm{g} \mathrm{g}^{-1}\right)$ & $4,36 \pm 0,07 ; 4,18 \pm 0,11 ; 4,01 \pm 0,10$ \\
\hline $\mathrm{Yb}\left(\mu \mathrm{g} \mathrm{g}^{-1}\right)$ & $2,20 \pm 0,02 ; 2,00 \pm 0,02 ; 2,38 \pm 0,04$ \\
\hline $\mathrm{Zn}\left(\mu \mathrm{g} \mathrm{g}^{-1}\right)$ & $42,7 \pm 1,2 ; 47,7 \pm 1,2 ; 43,5 \pm 1,3$ \\
\hline
\end{tabular}

${ }^{*}$ Incerteza calculada considerando erros nas medições das taxas de contagens da amostra e do padrão 
TABELA 17 - Concentrações dos elementos obtidas nas análises de solo coletado na Reserva do Morro Grande , junto à amostra nativa de C. obliqua. (Amostra K2)

\begin{tabular}{cc}
\hline Elemento & \multicolumn{1}{c}{ Resultados individuais } \\
\hline Ca $(\%)$ & $0,47 \pm 0,02^{*} ; 0,45 \pm 0,02$ \\
Ce $\left(\mathrm{ng} \mathrm{g}^{-1}\right)$ & $121,6 \pm 0,9 ; 118,5 \pm 0,8$ \\
Eu $\left(\mathrm{ng} \mathrm{g}^{-1}\right)$ & $376 \pm 12 ; 374 \pm 13$ \\
Fe $(\%)$ & $1,69 \pm 0,03 ; 1,79 \pm 0,03$ \\
Hf $\left(\mu \mathrm{g} \mathrm{g}^{-1}\right)$ & $10,2 \pm 0,1 ; 11,5 \pm 0,1$ \\
La $\left(\mathrm{ng} \mathrm{g}^{-1}\right)$ & $32,3 \pm 0,9 ; 40,6 \pm 0,2$ \\
Lu $\left(\mathrm{ng} \mathrm{g}^{-1}\right)$ & $224 \pm 2 ; 232 \pm 3$ \\
Nd $\left(\mu \mathrm{g} \mathrm{g}^{-1}\right)$ & $24,1 \pm 1,6 ; 23,8 \pm 1,9$ \\
Rb $\left(\mu \mathrm{g} \mathrm{g}^{-1}\right)$ & $16,7 \pm 0,7 ; 19,4 \pm 1,1$ \\
Sc $\left(\mu \mathrm{g} \mathrm{g}^{-1}\right)$ & $3,25 \pm 0,03 ; 3,67 \pm 0,03$ \\
Sm $\left(\mu \mathrm{g} \mathrm{g}^{-1}\right)$ & $3,77 \pm 0,01 ; 3,44 \pm 0,02$ \\
Tb $\left(\mathrm{ng} \mathrm{g}^{-1}\right)$ & $355 \pm 20 ; 315 \pm 20$ \\
Th $\left(\mu \mathrm{g} \mathrm{g}^{-1}\right)$ & $44,9 \pm 0,3 ; 35,8 \pm 0,2$ \\
$\mathrm{U}\left(\mu \mathrm{g} \mathrm{g}^{-1}\right)$ & $4,28 \pm 0,05 ; 4,31 \pm 0,05$ \\
Yb $\left(\mu \mathrm{g} \mathrm{g}^{-1}\right)$ & $1140 \pm 13 ; 1381 \pm 13$ \\
Zn $\left(\mu \mathrm{g} \mathrm{g}^{-1}\right)$ & $32,0 \pm 0,7 ; 33,0 \pm 0,7$ \\
\hline
\end{tabular}

* Incerteza calculada considerando erros nas medições das taxas de contagens da amostra e do padrão 
TABELA 18 - Concentrações dos elementos obtidas nas análises de solo coletado na Reserva do Morro Grande, junto à amostra nativa de C. decandra. (Amostra K3)

\begin{tabular}{cc}
\hline Elemento & Resultados individuais \\
\hline Ca $(\%)$ & $0,75 \pm 0,01^{*} ; 0,69 \pm 0,01 ; 0,81 \pm 0,02$ \\
Ce $\left(\mathrm{ng} \mathrm{g}^{-1}\right)$ & $110 \pm 1 ; 128 \pm 1 ; 123 \pm 1$ \\
Eu $\left(\mathrm{ng} \mathrm{g}^{-1}\right)$ & $410 \pm 14 ; 460 \pm 12 ; 463 \pm 10$ \\
Fe (\%) & $2,19 \pm 0,02 ; 2,15 \pm 0,04 ; 2,28 \pm 0,03 ; 2,18 \pm 0,03$ \\
Hf $\left(\mu \mathrm{g} \mathrm{g}^{-1}\right)$ & $8,53 \pm 0,07 ; 9,90 \pm 0,06 ; 10,66 \pm 0,06$ \\
La $\left(\mathrm{ng} \mathrm{g}^{-1}\right)$ & $42,5 \pm 0,2 ; 36,5 \pm 0,2 ; 43,7 \pm 0,4 ; 41,3 \pm 0,1$ \\
Lu $\left(\mathrm{ng} \mathrm{g}^{-1}\right)$ & $128 \pm 2 ; 139 \pm 2 ; 160 \pm 3$ \\
Nd $\left(\mu \mathrm{g} \mathrm{g}^{-1}\right)$ & $15,8 \pm 1,2 ; 20,5 \pm 1,1 ; 19,0 \pm 0,8$ \\
Rb $\left(\mu \mathrm{g} \mathrm{g}^{-1}\right)$ & $13,7 \pm 0,4 ; 13,3 \pm 1,1 ; 15,2 \pm 0,6 ; 14,5 \pm 0,4$ \\
Sc $\left(\mu \mathrm{g} \mathrm{g}^{-1}\right)$ & $4,41 \pm 0,03 ; 4,21 \pm 0,04 ; 4,66 \pm 0,03 ; 4,53 \pm 0,02$ \\
Sm $\left(\mu \mathrm{g} \mathrm{g}^{-1}\right)$ & $2,559 \pm 0,003 ; 3,149 \pm 0,004 ; 2,894 \pm 0,004$ \\
Tb $\left(\mathrm{ng} \mathrm{g}^{-1}\right)$ & $330 \pm 22 ; 293 \pm 17 ; 316 \pm 15$ \\
Th $\left(\mu \mathrm{g} \mathrm{g}^{-1}\right)$ & $33,8 \pm 0,2 ; 33,3 \pm 0,2 ; 38,4 \pm 0,2$ \\
U $\left(\mu \mathrm{g} \mathrm{g}^{-1}\right)$ & $5,72 \pm 0,05 ; 6,94 \pm 0,06 ; 6,39 \pm 0,05$ \\
Yb $\left(\mu \mathrm{g} \mathrm{g}^{-1}\right)$ & $780 \pm 10 ; 854 \pm 12 ; 897 \pm 30$ \\
Zn $\left(\mu \mathrm{g} \mathrm{g}^{-1}\right)$ & $28,4 \pm 0,5 ; 27,9 \pm 0,7 ; 31,1 \pm 0,6 ; 28,5 \pm 0,5$ \\
\hline
\end{tabular}

* Incerteza calculada considerando erros nas medições das taxas de contagens da amostra e do padrão 
TABELA 19 - Concentrações dos elementos obtidas nas análises de solo coletado na Reserva do Morro Grande, junto à amostra nativa de C. sylvestris. (Amostra K4).

\begin{tabular}{cc}
\hline Elemento & Resultados individuais \\
\hline Ca $(\%)$ & $0,52 \pm 0,02^{*} ; 0,50 \pm 0,01 ; 0,55 \pm 0,01$ \\
Ce $\left(\mathrm{ng} \mathrm{g}^{-1}\right)$ & $118 \pm 1 ; 125 \pm 1 ; 124 \pm 1$ \\
Eu $\left(\mathrm{ng} \mathrm{g}^{-1}\right)$ & $514 \pm 16 ; 543 \pm 13 ; 577 \pm 12$ \\
Fe $(\%)$ & $1,62 \pm 0,03 ; 1,83 \pm 0,02 ; 1,80 \pm 0,04$ \\
Hf $\left(\mu \mathrm{g} \mathrm{g}^{-1}\right)$ & $8,57 \pm 0,07 ; 8,86 \pm 0,06 ; 9,8 \pm 0,1$ \\
La $\left(\mathrm{ng} \mathrm{g}^{-1}\right)$ & $48,6 \pm 0,2 ; 50,2 \pm 0,2 ; 48,0 \pm 0,2$ \\
Lu $\left(\mathrm{ng} \mathrm{g}^{-1}\right)$ & $135 \pm 2 ; 145 \pm 2 ; 149 \pm 3$ \\
Nd $\left(\mu \mathrm{g} \mathrm{g}^{-1}\right)$ & $28,7 \pm 1,7 ; 24,7 \pm 1,2 ; 38,7 \pm 3,8$ \\
Rb $\left(\mu \mathrm{g} \mathrm{g}^{-1}\right)$ & $32,4 \pm 1,7 ; 39,2 \pm 0,8 ; 39,9 \pm 2,2$ \\
Sc $\left(\mu \mathrm{g} \mathrm{g}^{-1}\right)$ & $3,61 \pm 0,03 ; 3,81 \pm 0,03 ; 3,92 \pm 0,02$ \\
Sm $\left(\mu \mathrm{g} \mathrm{g}^{-1}\right)$ & $3,810 \pm 0,004 ; 4,220 \pm 0,004 ; 3,890 \pm 0,005$ \\
Tb $\left(\mathrm{ng} \mathrm{g}^{-1}\right)$ & $385 \pm 21 ; 404 \pm 18 ; 402 \pm 15$ \\
Th $\left(\mu \mathrm{g} \mathrm{g}^{-1}\right)$ & $34,0 \pm 0,2 ; 34,7 \pm 0,2 ; 35,8 \pm 0,1$ \\
U $\left(\mu \mathrm{g} \mathrm{g}^{-1}\right)$ & $6,23 \pm 0,05 ; 5,97 \pm 0,05 ; 6,42 \pm 0,05$ \\
Yb $\left(\mu \mathrm{g} \mathrm{g}^{-1}\right)$ & $916 \pm 11 ; 857 \pm 11 ; 825 \pm 13$ \\
Zn $\left(\mu \mathrm{g} \mathrm{g}^{-1}\right)$ & $37,5 \pm 0,7 ; 39,7 \pm 0,3 ; 40,3 \pm 0,5$ \\
\hline
\end{tabular}

* Incerteza calculada considerando erros nas medições das taxas de contagens da amostra e do padrão 
TABELA 20 - Concentrações dos elementos obtidas nas análises de solo coletado na Reserva do Morro Grande , junto à amostra cultivada de C. sylvestris.. (Amostra K56).

\begin{tabular}{|c|c|}
\hline Elemento & Resultados individuais \\
\hline Ca (\%) & $0,59 \pm 0,02^{*} ; 0,88 \pm 0,02 ; 0,93 \pm 0,01$ \\
\hline $\mathrm{Ce}\left(\mathrm{ng} \mathrm{g}^{-1}\right)$ & $102 \pm 1 ; 105 \pm 1 ; 109 \pm 1$ \\
\hline Eu $\left(\right.$ ng g $\left.^{-1}\right)$ & $423 \pm 12 ; 333 \pm 9 ; 374 \pm 8$ \\
\hline $\mathrm{Fe}(\%)$ & $1,45 \pm 0,02 ; 1,59 \pm 0,02 ; 1,50 \pm 0,01$ \\
\hline $\mathrm{Hf}\left(\mu \mathrm{g} \mathrm{g}^{-1}\right)$ & $12,5 \pm 0,1 ; 11,4 \pm 0,1 ; 13,6 \pm 0,1$ \\
\hline La $\left(\mathrm{ng} \mathrm{g}^{-1}\right)$ & $31,6 \pm 0,2 ; 26,2 \pm 0,3 ; 26,3 \pm 0,1$ \\
\hline Lu (ng g $\left.{ }^{-1}\right)$ & $159 \pm 2 ; 195 \pm 2 ; 234 \pm 1$ \\
\hline $\mathrm{Nd}\left(\mu \mathrm{g}^{-1}\right)$ & $20,7 \pm 1,3 ; 18,0 \pm 1,2 ; 24,3 \pm 2,6$ \\
\hline $\mathrm{Rb}\left(\mu \mathrm{g} \mathrm{g}^{-1}\right)$ & $18,2 \pm 0,8 ; 17,1 \pm 1,1 ; 17,9 \pm 0,4$ \\
\hline Sc $\left(\mu \mathrm{g} \mathrm{g}^{-1}\right)$ & $3,18 \pm 0,02 ; 3,14 \pm 0,02 ; 2,96 \pm 0,01$ \\
\hline $\operatorname{Sm}\left(\mu \mathrm{g} \mathrm{g}^{-1}\right)$ & $2,673 \pm 0,004 ; 2,161 \pm 0,003 ; 2,141 \pm 0,003$ \\
\hline $\mathrm{Tb}\left(\mathrm{ng} \mathrm{g}^{-1}\right)$ & $237 \pm 16 ; 260 \pm 15 ; 326 \pm 12$ \\
\hline Th $\left(\mu \mathrm{g} \mathrm{g}^{-1}\right)$ & $15,8 \pm 0,1 ; 15,4 \pm 0,1 ; 16,5 \pm 0,1$ \\
\hline $\mathrm{U}\left(\mu \mathrm{g}^{-1}\right)$ & $3,60 \pm 0,04 ; 3,05 \pm 0,03 ; 4,19 \pm 0,04$ \\
\hline $\mathrm{Yb}\left(\mu \mathrm{g} \mathrm{g}^{-1}\right)$ & $961 \pm 9 ; 1124 \pm 12 ; 1540 \pm 11$ \\
\hline $\mathrm{Zn}\left(\mu \mathrm{g} \mathrm{g}^{-1}\right)$ & $34,7 \pm 0,6 ; 36,5 \pm 0,6 ; 33,1 \pm 0,5$ \\
\hline
\end{tabular}

* Incerteza calculada considerando erros nas medições das taxas de contagens da amostra e do padrão 
TABELA 21 - Concentrações dos elementos obtidas nas análises de solo coletado na Reserva do Morro Grande, junto à amostra nativa de C. obliqua. (Amostra K7)

\begin{tabular}{|c|c|}
\hline Elemento & Resultados individuais \\
\hline Ca (\%) & $0,47 \pm 0,02^{*} ; 0,56 \pm 0,02$ \\
\hline $\mathrm{Ce}\left(\operatorname{ng~g}^{-1}\right)$ & $153 \pm 2 ; 150 \pm 1$ \\
\hline Eu $\left(\right.$ ng g $\left.^{-1}\right)$ & $331 \pm 12 ; 381 \pm 16$ \\
\hline $\mathrm{Fe}(\%)$ & $1,47 \pm 0,02 ; 1,28 \pm 0,02$ \\
\hline $\mathrm{Hf}\left(\mu \mathrm{g} \mathrm{g}^{-1}\right)$ & $8,92 \pm 0,07 ; 8,85 \pm 0,07$ \\
\hline $\mathrm{La}\left(\mathrm{ng} \mathrm{g}^{-1}\right)$ & $32,8 \pm 0,2 ; 55,2 \pm 0,3$ \\
\hline Lu (ng g $\left.{ }^{-1}\right)$ & $210 \pm 2 ; 271 \pm 3$ \\
\hline $\mathrm{Nd}\left(\mu \mathrm{g} \mathrm{g}^{-1}\right)$ & $19,6 \pm 1,6 ; 20,3 \pm 5,3$ \\
\hline $\mathrm{Rb}\left(\mu \mathrm{g} \mathrm{g}^{-1}\right)$ & $18,4 \pm 1,2 ; 16,7 \pm 0,7$ \\
\hline Sc $\left(\mu \mathrm{g} \mathrm{g}^{-1}\right)$ & $3,48 \pm 0,03 ; 3,25 \pm 0,03$ \\
\hline $\operatorname{Sm}\left(\mu g^{-1}\right)$ & $2,117 \pm 0,003 ; 4,227 \pm 0,005$ \\
\hline $\mathrm{Tb}\left(\mathrm{ng} \mathrm{g}^{-1}\right)$ & $208 \pm 18 ; 453 \pm 23$ \\
\hline Th $\left(\mu \mathrm{g} \mathrm{g}^{-1}\right)$ & $38,2 \pm 0,2 ; 41,1 \pm 0,4$ \\
\hline $\mathrm{U}\left(\mu \mathrm{g} \mathrm{g}^{-1}\right)$ & $3,48 \pm 0,04 ; 4,34 \pm 0,08$ \\
\hline $\mathrm{Yb}\left(\mu \mathrm{g} \mathrm{g}^{-1}\right)$ & $920 \pm 10 ; 1547 \pm 18$ \\
\hline $\mathrm{Zn}\left(\mu \mathrm{g} \mathrm{g}^{-1}\right)$ & $39,4 \pm 0,8 ; 33,8 \pm 0,8$ \\
\hline
\end{tabular}

* Incerteza calculada considerando erros nas medições das taxas de contagens da amostra e do padrão 
TABELA 22 - Resultados individuais obtidos nas determinações de pH das amostras de solo

\begin{tabular}{lcccccc}
\hline & K1 & K2 & K3 & K4 & K56 & K7 \\
\hline $\mathbf{1}^{\text {a determinação }}$ & 4,47 & 3,39 & 3,48 & 3,81 & 3,93 & 3,28 \\
$\mathbf{2}^{\text {a determinação }}$ & 4,50 & 3,37 & 3,48 & 3,89 & 3,96 & 3,30 \\
$\mathbf{3}^{\text {a }}$ determinação & 4,48 & 3,39 & 3,48 & 3,86 & 3,95 & 3,28 \\
\hline
\end{tabular}

K1 - Amostra de solo coletada Instituto de Química da USP, junto à C. sylvestris cultivada. K2 - Amostra de solo coletada na Reserva do Morro Grande, km1, junto à C. obliqua nativa. K3 - Amostra de solo coletada na Reserva do Morro Grande, A42, junto à C. decandra nativa. K4 - Amostra de solo coletada na Reserva do Morro Grande A38, junto à $C$. sylvestris nativa. K56 - Amostra de solo coletada na Reserva do Morro Grande, Cotia, junto à C. sylvestris cultivada. K7 - Amostra de solo coletada na Reserva do Morro Grande, Cotia, junto à C. obliqua nativa. 


\section{REFERÊNCIAS BIBLIOGRÁFICAS}

AJASA, A. M. O.; BELLO, M. O.; IBRAHIM, A. O.; OGUNWANDE, I. A.; OLAWORE, N. O. Heavy trace metals and macronutrient status in herbal plants of Nigeria. Food Chemistry, v. 85, p. 67-71, 2004.

ALFASSI, Z. B. Activation Analysis, Florida: CRC Press, v.1, 1990.

ALLABY, M. Dictionary of Plant Sciences, Oxford: Oxford University Press, 1998.

ALMEIDA, M. M. B.; LOPES, M. F. G.; NOGUEIRA, C. M. D.; MAGALHÃES, C. E. C.; MORAIS, N. M. T. Determinação de nutrientes minerais em plantas medicinais, Ciência e Tecnologia Alimentar, v. 22, p. 94-97, 2002.

BARGAGLI, R.; MONACI, F.; AGNORELLI, C. Oak leaves as accumulators of airborne elements in an area with geochemical and geothermical anomalies, Environmental Pollution, v. 124, p. 321-329, 2003.

BEGOSSI, A.; HANAZAKI, N. ; TAMASHIRO, J. Y. Medicinal plants in the Atlantic Forest (Brazil): knowledge, use and conservation. Human Ecology, v. 30, p. 281-299, 2002.

BEIGUELMAN, B. Curso Prático de Bioestatística. Ribeirão Preto, SP: FUNPEC Editora, 2002.

BERDANIER, C. D. Advanced Nutrition - Micronutrients. New York: CRC Press, 1994.

BODE, P. Instrumental and Organizational Aspects of a Neutron Activation Analysis

Laboratory. Delft University of Technology, 1996, p.148.

BODE, P.; GOEIJ, J.M. Activation Analysis. In: MEYERS, R.A. (Editor). Encyclopedia of Environmental Analysis and Remediation. John Wiley \& Sons, Inc., 1998. p. 68-84. 
BORGES, A. H.; SOARES, A. M.; RODRIGUES, V. M.; ANDRIÃO-ESCARSO, S. H.; DINIZ, H.; HAMAGUCHI, A.; QUINTERO, A.; LIZANO, S.; GUTIÉRREZ, J. M.; GIGLIO, J. R.; HOMSI-BRANDEBURGO, M. I. Effects of aqueous extract of Casearia sylvestris (Flacourtiaceae) on action of snake and bee venoms and on activity of phospholipases A2, Comparative Biochemistry and Physiology Part B, v. 127, p.21-30, 2000.

BORGES, A. H.; SOARES, A. M.; RODRIGUES, V. M.; OLIVEIRA, F.; FRANSHESCHI, A. M.; RUCAVADO, A.; GIGLIO, J. R.; HOMSI-BRANDEBURGO, M. I. Neutralization of proteases from Bothrops snake venoms by the aqueous extract from Casearia sylvestris (Flacourtiaceae), Toxicon, v. 39, p.1863-1869, 2001.

CALDAS, E. D.; MACHADO, L. L. Cadmium, mercury and lead in medicinal herbs in Brazil. Food and Chemistry Toxicology., v. 42, p. 599 - 603, 2004.

CHIZZOLA, R.; MICHITSCH, H.; FRANZ, C. Monitoring of metallic micronutrients and heavy metals in herbs, spices and medicinal plants from Austria. European Food Research Technology., v. 216, p. 404-411, 2003.

CONTE, L. A. Shaman pharmaceuticals' approach to drug development. In: BALICK, M.J.; ELISABESTKY, E.; LAIRD, A.S. (Editors). Medicinal Resources of the Tropical Forest - biodiversity and its importance to human health. New York: Columbia University Press, 1996. p.94-100.

CORRÊA, M. P. Dicionário de Plantas Úteis do Brasil. Rio de Janeiro: Imprensa Nacional, 1978.

CURRIE, L. A. Limits for qualitative detection and quantitative determination. Analytical Chemistry, v. 40, p.586-593, 1968.

CURRIE, L. A. Detection and quantification limits: origins and historical overview. Analytica Chimica Acta, v. 391, p. 127-134, 1999.

DE SOETE, D. ; GIJBELS, R.; HOSTE, J. Neutron Activation Analysis, England: WileyInterscience, 1972.

DE FRANÇA, J. E.. Espécies arbóreas nativas da Mata Atlântica bioacumuladoras de elementos químicos. 2005. Monografia (Exame de Qualificação) - Centro de Energia Nuclear na Agricultura, Piracicaba.

DI STASI, L. C. ; OLIVEIRA, G. P.; CARVALHAES, M. A.; QUEIROZ-JUNIOR, M.; TIEN, O. S.; KAKINAMI, S. H.; REIS, M. S. Medicinal plants popularly used in the Brazilian Tropical Atlantic Forest, Fitoterapia, v. 73, p. 69-91, 2002. 
DIM, I. A., FUNTUA, I. I., OYEWALE, A. O., GRASS, F., UMAR, I. M., GWOZDZ, R., GWARZO, U. S. Determination of some elements in Ageratum conyziodes, a tropical medicinal plant, using instrumental neutron activation analysis. Journal of Radioanalytical and Nuclear Chemistry, v. 261, p. 225-228, 2004.

EN, Z.; VASIDOV, A.; TSIPIN, V.V.; TILLAEV, T.; JUMANIYAZOVA, G.I. Study of element uptake in plants from the soil to assess environmental contamination by toxic elements, Nuclear Instruments \& Methods in Physics Research, Section A, v. 505, p. 462465, 2003.

EPSTEIN, E. Nutrição Mineral das Plantas - Princípios e Perspectivas, São Paulo: EDUSP, 1975.

ESALQ - Escola Superior de Agricultura Luiz de Queiroz. Disponível em: <http://www.esalq.usp.br/trilhas/medicina/am28.htm>. Acesso em: 06/10/2003

ESTEVES, I. ; SOUZA, I. R. ; RODRIGUES, M. ; CARDOSO, L. G. V. ; SANTOS, L. S.; SERTIE, J. A. A. ; PERAZZO, F. F. ; LIMA, L. M. ; SCHNEEDORF, J. M. ; BASTOS, J. K. ; CARVALHO, J. C. T. Gastric antiulcer and anti-inflammatory activieis of the essential oil from Casearia sylvestris SW. Journal of Ethno-pharmacology, v. 101, p.191-196, 2005.

FALCÓ, G.; GÓMEZ-CATALAN, J.; LLOBET, J. M.; DOMINGO, J. L. Contribution of medicinal plants to the daily intake of various toxic elements in Catalonia, Spain. Trace Elements and Electrolytes, v. 20, p. 120-124, 2003.

FARMACOPÉIA BRASILEIRA - Oficializada pelo Governo Federal pelo Decreto 78840 de 25 de novembro de 1976, 3 ed., São Paulo, Organização Andrei Editora S.A., p.946, 1977.

GLADNEY, E. S., BRUNS, C. E. ROELANDTS, I. 1982 compilation of elemental concentrations in eleven United States Geological Survey rock standards, Geostandards Newsletter, v. 7, p. 3-57, 1983.

GOMEZ, M. R.,CERUTTI, S., OLSINA, R. A., SILVA, M. F., MARTÍNEZ, L. D. Metal content monitoring in Hypericum perforatum pharmaceutical derivatives by atomic absorption and emission spectrometry. Journal of Pharmaceutical and Biomedical Analysis, v. 34, p. 569-576, 2003 
GÜLERYÜZ, G.; ARSLAN, H.; KIRMIZI, S.; GÜÇER, S. Investigation of influence of tungsten mine wastes on the elemental composition of some alpine and subalpine plants on Mount Uldag, Bursa, Turkey., Environmental Pollution, v. 120, p. 707-716, 2002.

HARPER, H. A.; RODWELL, V. W.; MAYES, P. A. Manual de Química Fisiológica. São Paulo: Atheneu, 1982.

HOKURA, A. ; MATSUHARA, H. ; FUMIE, K. ; HARAGUCHI, H. Multielement determination of major-to-ultratrace elements in plant reference materials by ICPAES/ICP-MS and evaluation of their enrichment factors. Analytical Sciences, v. 16, p.1161-1168, 2000.

IAEA - INTERNATIONAL ATOMIC ENERGY AGENCY. Practical aspects of operating a neutron activation analysis laboratory. Vienna, 1990. (IAEA - TECDOC 564)

IAEA - INTERNATIONAL ATOMIC ENERGY AGENCY. Reference Sheet. Reference material IAEA-Soil-7, 2000.

INTC - INSTITUTE OF NUCLEAR CHEMISTRY AND TECHNOLOGY. Polish Certified Reference Material for multielement trace analysis. Tea Leaves (INCT-TL-1). Poland, 2002.

ITOKAWA, H.; TOTSUKA, N.; TAKEYA, K.; WATANABE, K.; OBATA, E. Antitumor principles from Casearia sylvestris $S w$. (Flacourtiaceae), estructure elucidation of new cloerodane diterpenes by 2-D NMR spectroscopy, Chemical \& Pharmaceutical Bulletin, v. 36, n. 4, p. 1585-1588, 1988.

ITOKAWA, H.; TOTSUKA, N.; TAKEYA, IITAKA; Y., SCHENKEL, E. P., MOTIDOME, M. New antitumor principles, casearins A-F, for Casearia sylvestris $S w$. (Flacourtiaceae), Chemical \& Pharmaceutical Bulletin, v. 38, n. 12, p. 3384-3388, 1990.

KABATA-PENDIAS, A. ; PENDIAS, H. Trace Elements in Soil and Plants. Florida: CRC Press, 1984.

KAPLAN, L. A.; PESCE, A. J.; KAZMIERCZAK, S. C. Clinical Chemistry - Theory, Analysis, Correlation. 4. ed. London: Mosby, 2003.

KELLNER, R.; MERMET, J. M.; OTTO, M.; WIDMER, H. M. Analytical Chemistry. New York: Wiley-VCH, 1998. 
LEE, J. ; CHON, H. ; KIM, K. Migration and dispersion of trace elements in the rock-soilplant system in areas underlain by black shales and slates of the Okchron Zone, Korea. Journal of Geochemical Exploration, v. 65, p.61-78, 1998.

LEMBERKOVICS, E.; CZINNER, E.; SZENTMIHALYI, K.; BALAZS, A.; SZOKE, E. Comparative evaluation of Helichrysi flos herbal extracts as dietary sources of plant polyphenols, and macro- and microelements, Food Chemistry, v. 78, p. 119-127, 2002.

LORENZI, H. Árvores Brasileiras - Manual de Identificação e Cultivo de Plantas Arbóreas Nativas do Brasil. Nova Odessa, SP: Editora Plantarum, 1992.

LOVKOVA, M. Y.; BUZUK, G. N.; SOKOLOVA, S. M.; KLIMENT’EVA, N. I. Chemical Feature of Medicinal Plants (Review), Applied Biochemistry and Microbiology, v. 37, p. 229-237, 2001.

LOZAK, A.; SOLTYK, K.; OSTAPCZUK, P.; FIJALEK, Z. Determination of selected trace elements in herbs and their infusions, The Science of the Total Environment, v. 289, p.33-40, 2002.

MAISTRO, E. L.; CARVALHO, J. C. T.; MANTOVANI, M. S. Evaluation of the genotoxic potential of the Casearia sylvestris extract on HTC and V79 cells by the comet assay, Toxicology in Vitro, v. 18, p. 337-342, 2004.

MARKERT, B. Instrumental Element and Multi-element Analysis of Plant Samples Methods and Application. New York: John Wiley \& Sons, 1996.

MARTIN JR, D. W.; MAYES, P. A.; RODWELL, V. W.; GRANNER, D. K. Harper's Review of Biochemistry. 20. ed. California: Lange Medical Publications, 1985.

MENEZES, F. G. Avaliação farmacológica e toxicológica de diferentes espécies do gênero Casearia em modelos experimentais de úlcera gástrica. 2004. Tese (doutorado). Instituto de Ciências Biomédicas, Universidade de São Paulo, São Paulo.

MEYERS, R. A. Encyclopedia of Environmental Analysis and Remediation, New York: John Wiley \& Sons, Inc., 1998.

MOITA NETO, J. M.; MOITA, G. C. Uma introdução à análise exploratória de dados multivariados. Química Nova, v.21, n. 4, 1998. 
MOHAMED, A. E. Environmental variations of trace element concentrations in Egyptian cane sugar and soil samples (Edu factories). Food Chemistry, v. 65, p. 503-507, 1998.

MOHANTA, B., CHAKRABORTY, A., SUDARSHAN, M., DUTTA, R. K., BARUAH, M. Elemental profile in some common medicinal plants of Índia. Its correlation with traditional therapeutic usage. Journal of Radioanalytical and Nuclear Chemistry, v. 258, p.175-170, 2003.

MORENO, A. M.; PÉREZ, L,; GONZÁLEZ, J. Relaciones entre contenidos totales de Zn, Pb, Cu y Cd en suelos y plantas, Suelo y Planta, 2, p.757-771, 1992.

MOSADDIK, M. A. ; BANBURY, L. ; FORSTER, P. ; BOOTH, R. ; MARKHAM, J. ; LEACH, D. ; WATERMAN, P. G. Screening of some Australian Flacourtiaceae species for in vitro antioxidant, cytotoxic and antimicrobial activity. Phytomedicine, v. 11, p. 461-466, 2004.

NAIDU, G. R. K.; DENSCHLANG, H. O.; MAUERHOFER, E.; PORTE, N.; BALAJI, T. Determination of macro, micro nutrient and trace element concentrations in Indian medicinal and vegetable leaves using instrumental neutron activation analysis., Applied Radiation and Isotopes, v. 50, p. 947-953, 1999.

NIST - NATIONAL INSTITUTE OF STANDARDS AND TECHNOLOGY. Certificate of Analysis. Standard Reference Material 1515 Apple Leaves, 1995.

NIST - NATIONAL INSTITUTE OF STANDARDS AND TECHNOLOGY. Certificate of Analysis. Standard Reference Material 1573a Tomato Leaves, 1993.

NYE, P. H. Changes of $\mathrm{pH}$ across the rhizosphere induced by roots. Plant and Soil, v. 61, p.7-26, 1981.

OBERLIES, N. H.; BURGESS, J.; NAVARRO, H. A.; PINOS, R. E.; FAIRCHILD, C. R.; PETERSON, R. W.; SOEJARTO, D. D.; FARNSWORTH, N. R.; KINGHORN, A. D.; WANI, M. C.; WALL, M.E. Novel bioactive clerodane diterpenoids from the leaves and twigs of Casearia sylvestris, Journal of Natural Products, v. 65, n. 2, p. 95-99, 2002

OBIAJUNWA, E. I., ABADEJO, A. C., OMOBUWAJO, O. R. Essential and trace element contents of some Nigerian medicinal plants. Journal of Radioanalytical and Nuclear Chemistry, v. 252, p. 473-476, 2002.

OLIVEIRA, T. S.; COSTA, L. M. Heavy metal in soils of a topolithosequence in the Triângulo Mineiro, State of Minas Gerais (Brazil), Revista Brasileira de Ciência do Solo, v. 28, p. 785-796, 2004. 
PHILLIPSON, J. D. 50 years of medicinal plant research - every progress in methodology is a progress in science. Planta Medica, v. 69, p. 491-495, 2003.

PLANTAS BRASILEIRAS, 2002.

Banco de Dados - Plantas medicinais do Brasil, Disponível em:

<http://www.brazilian-plants.com/br/database.cfm> Acesso em: 10/01/2005.

POUTARAUD, A.; GIRARDIN, P. Influence of chemical characteristics of soil on mineral and alkaloid seed contents of Colchicum autumnale. Environmental and Experimental Botany, v. 54, p.101-108, 2005.

RAIJ, B. van ; QUAGGIO, J. A. ; CANTARELLA, H. ; FERREIRA, M. E. ; LOPES, A. S.; BATAGLIA, O. C. Análise Química do Solo para Fins de Fertilidade. Campinas, SP: Fundação Cargill, 1987.

RAJURKAR, N.S.; PARDESH, B. M. Analysis of some herbal plants from India used in the control of diabetes Mellitus by NAA and AAS techniques., Applied Radiation and Isotopes, v. 48, p.1059-1062, 1997.

RAJURKAR, N. S.; DAMAME, M. M. Mineral content of medicinal plants used in the treatment of diseases resulting from urinary tract disorders, Applied Radiation and Isotopes, v. 49, p.773-776, 1998.

RAINTREE-HEALTH (UK) Ltda., Disponível em: http://www.raintree-health.co.uk/cgi-bin/getpage.pl?/plants/guacatonga.html Acesso em: 22/08/2003

RAZIC, S.; ONJIA, A.; POTKINJAK, B. Trace elements analysis of Echinacea purpureaherbal medicine., Journal of Pharmaceutical and Biomedical Analysis, v. 33, p. 845-850, 2003.

REDDY, P. R. K.; REDDY, J. Elemental concentrations in medicinally important leafy materials, Chemosphere, v. 34, p. 2193-2212, 1997.

REIMANN, C.; CARITAT, P. de. Chemical elements in the environment - Factsheets for the geochemist and environmental scientist. Berlim: Springer, 1998.

REIMANN, C.; KOLLER, F.; FRENGSTAD, B.; KASHULINA, G.; NIKAVAARA, H.; ENGLMAIER, P. Comparison of the element composition in several plant species and their substrate from a 1,500,000 $\mathrm{km}^{2}$ area in northern Europe, The Science of the Total Environment, v. 278, p. 87-112, 2001. 
SALVADOR, M. J.; DIAS, D. A.; MOREIRAS, S.; ZUCCHI, O. L. A. D. Analysis of medicinal plants and crude extracts by synchroton radiation total reflection X-ray fluorescence. Journal of Trace and Microprobe Techniques, v. 21, p. 377-388, 2003.

SERFOR-ARMAH, Y.; NYARKO, B.J.B.; AKAHO, E. H. K.; KYERE, A. W. K.; OSAE, S.; OPPONG-BOACHIE, K.; OSAE, E. K. Activation analysis of some essential elements in five medicinal plants used in Ghana., Journal of Radioanalytical and Nuclear Chemistry, v. 250, p.173-176, 2001.

SERFOR-ARMAH, Y.; NYARKO, B. J. B.; AKAHO, E. H. K.; KYERE, A. W. K.; OSAE, S.; OPPONG-BOACHIE, K. Multielemental analysis of some traditional plant medicines used in Ghana, Journal of Trace And Microprobe Techniques, v. 20, p. 419427, 2002.

SERTIE, J. A. A; CARVALHO, J. C. T; PANIZZA, S. Antiulcer activity of the crude extract from the leaves of Casearia sylvestris., Pharmaceutical Biology, v. 38, p.112-119, 2000.

SILVA, J. J. R. F.; WILLIAMS, R. J. P. The Biological Chemistry of the Elements - The inorganic chemistry of life. Oxford: Clarendon Press, 1993.

SINGH, V.; GARG, A.N. Availability of essential trace elements in Ayurvedic Indian medicinal herbs using instrumental neutron activation analysis. Applied Radiation and Isotopes, v. 48, p.97-101, 1997.

SOS MATA ATLANTICA - Fundação SOS Mata Atlântica, 2000.

Atlas dos Municípios da Mata Atlântica

Disponível em: <http://www.sosmatatlantica.org.br/?secao=atlas >

Acesso em: 25/03/2006

SPOSITO, G. The Chemistry of Soils. Oxford: Oxford University Press, 1989, p. 256-258.

TAN, K. H. Environmental Soil Science. New York: Marcel Dekker Inc., 1994, p.176177.

TORRES, R. B.; YAMAMOTO, K. Taxonomia das espécies de Casearia Jacq.

(Flacourtiaceae) do estado de São Paulo. Revista Brasileira de Botânica, v. 9, p.239 - 258, 1986.

VAZ, S. M ; SAIKI, M. ; VASCONCELLOS, M. B. A.; SERTIE, J. A. Análise multielementar de plantas medicinais pelo método de ativação neutrônica. In: REUNIÃO 
ANUAL DA SOCIEDADE BRASILEIRA PARA O PROGRESSO DA CIÊNCIA, 42.,0813 Julho, 1990, Porto Alegre, Resumo... Rio Grande do Sul.

VAZ, S. M. Análise de extratos de plantas medicinais pelo método de ativação com nêutrons. 1995. Dissertação (mestrado). Instituto de Pesquisas Energéticas e Nucleares, São Paulo.

VELOSO, H. P ; RANGEL FILHO, A. L. R.; LIMA, J. C. A. Classificação da vegetação brasileira, adaptada a um sistema universal. Rio de Janeiro: Ministério da Economia, Fazenda e Planejamento, Fundação Instituto Brasileiro de Geografia e Estatística, Departamento de Recursos Naturais e Estudos Ambientais, 1991.

WESOLOWSKI, M.; KONIECZYNSKI, P. Thermoanalytical, chemical and principal component analysis of plant drug., International Journal of Pharmaceutics, v. 27, p. 2937, 2003.

WHO - WORLD HEALTH ORGANIZATION

Traditional Medicine Strategy 2002-2005.

Disponível em: <http://www.who.int/medicines/library/trm/trm_strat_eng.pdf>

Acesso em: 10/12/2004.

WHO - WORLD HEALTH ORGANIZATION

Traditional Medicine, Fact sheet No. 134, Revised May 2003

Disponível em: <www.who.int/mediacentre/factsheets/2003/fs134/en>

Acesso em: 07/08/2003

WYTTENBACH, A.; TOBLER, L.; SCHLEPPI, P.; FURRER, V. Variation of the rare earth element concentrations in the soil, soil extract and in individual plants from the same sites. Journal of Radioanalytical and Nuclear Chemistry, v. 231, p.101-106, 1998.

YAN, X.; WU, S.; WANG, Y.; SHANG, X.; DAI, S. Soil nutrient factors related to salidroside production of Rhodiola sachalinensis distributed in Chang Bai Mountain. Environmental and Experimental Botany, v. 52, p.267-276, 2004.

ZINPRO CORPORATION. Epithelial tissue: body's first line of defense depends upon trace minerals. Trace Mineral Focus, v. 6, p.1-8, 2000. 